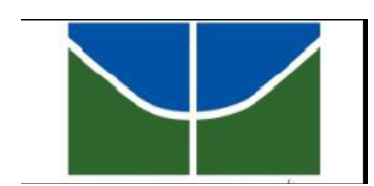

UNIVERSIDADE DE BRASÍLIA

Centro de Excelência em Turismo

Pós-graduação Lato Sensu

Gastronomia e Segurança Alimentar III

\title{
ENGENHARIA DE CARDÁPIO: UM ESTUDO DE CASO EM RESTAURANTE DE FRUTOS DO MAR
}

\author{
ALUNA: JENNIFER LACERDA \\ ORIENTADORA: M.Sc VERÔNICA GINANI \\ CO-ORIENTADOR: M.Sc BRENO SILVA DE ABREU
}

BRASÍLIA-2009 


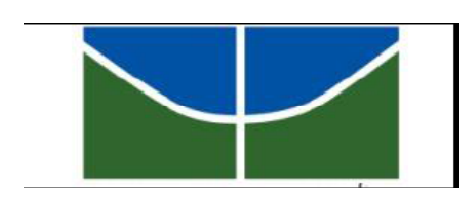

\title{
ENGENHARIA DE CARDÁPIO: UM ESTUDO DE CASO EM RESTAURANTE DE FRUTOS DO MAR
}

\author{
ALUNA: JENNIFER LACERDA \\ ORIENTADORA: M.Sc VERÔNICA GINANI \\ CO-ORIENTADOR: M.Sc BRENO SILVA DE ABREU
}

Monografia apresentada ao Centro de Excelência em Turismo - CET, da Universidade de Brasília - UnB, como requisito parcial à obtenção do grau de Especialista em Gastronomia e Segurança de Alimentos. 


\section{SUMÁRIO}

INTRODUÇÃO

OBJETIVOS 3

REVISÃO DE LITERATURA 4

$\begin{array}{ll}\text { MATERIAL E MÉTODOS } & 15\end{array}$

$\begin{array}{ll}\text { RESULTADOS E DISCUSSÃO } & 17\end{array}$

$\begin{array}{ll}\text { CONCLUSÃO } & 24\end{array}$

REFERÊNCIAS BIBLIOGRÁFICAS $\quad 25$

APÊNDICE 1 Fichas Técnicas de Preparação 28

APENDICE 2 Engenharia de Cardápio aplicada ao mês de fevereiro/09 67

APENDICE 3 Engenharia de Cardápio aplicada ao mês de março/09 68

APENDICE 4 Engenharia de Cardápio aplicada ao mês de abril/09 68

APENDICE 5 Engenharia de Cardápio aplicada ao trimestre $\quad 70$

APENDICE 6: Classificação de pratos do mês de fevereiro/09 71

APENDICE 7: Classificação de pratos do mês de março/09 72

APENDICE 8: Classificação de pratos do mês de abril/09 73

$\begin{array}{ll}\text { ANEXO } 1 \text { Relação diária de vendas do mês de fevereiro } & 74\end{array}$

ANEXO 2 Relação diária de vendas do mês de março 75

ANEXO3 Relação diária de vendas do mês de abril 76 


\section{LISTA DE ILUSTRAÇÕES}

TABELA 1 Evolução de Investimentos em Publicidade

FIGURA 1 Ficha Técnica de Preparação

FIGURA 2 Classificação trimestral de pratos (margem de contribuição e popularidade) 


\section{RESUMO}

A necessidade de fazer as refeições fora de casa tem elevado a oferta de restaurantes, e com tantas opções o cliente busca o que oferece mais qualidade. Nessa qualidade estão envolvidos o alimento propriamente dito, o atendimento, a higiene e o padrão dos pratos. Por traz disso o empresário tem que se preocupar com custos, mão de obra, marketing e o principal: o lucro. Com tantas preocupações o empresário se perde no controle da qualidade que o cliente tanto busca.

Para avaliar a qualidade de um todo, foi utilizada a ferramenta de engenharia de cardápios, modificando as fichas técnicas de preparo e acompanhando durante um determinado período as vendas do restaurante estudado. Constatou-se que o período determinado inicialmente não era o suficiente para uma avaliação precisa. Estendendo tal período pode-se avaliar o impacto da falta do trabalho de marketing, a falta de treinamento de mão de obra, e o principal, a falta de uma pesquisa de mercado anterior à abertura do restaurante em questão.

Medidas foram adotadas para a completa reversão dessas falhas, tornando o empreendimento mais sadio do ponto de vista operacional.

Palavras-chaves: engenharia de cardápios, ficha técnica de preparo gestão de restaurantes, controle de qualidade. 


\begin{abstract}
Changes in personal habits have increase the need of normal individuals to eat out on everyday basis, thus, increasing the restaurant options which not rarely end up being chosen by the quality factor. The quality factor is depicted not only by the food itself, but also by the service, sanitary aspects and quality standards. Under it all, the entrepeneur has to attend issues as keeping costs down, skilled workforce, advertising and last but not least, Profit margins. Such worries often end up affecting the final quality of the service, which is held in high regard by the costumer.

To assess the overall quality, menu engineering based tools were applied, updates on the technical cards and supervision for a determined period of time on the selected restaurant. The initial period has been shown to be insufficient to produce high quality data, thus, the period studied has been extended, being then able to assess the impacts of lack of advertising plan, lack of workmanship training and more importantly, lack of a market research prior to the start of the operations.

Several measures were taken to attain a complete reversion on these issues, making the establishment healthier under the operational aspects.
\end{abstract}

Keywords: restaurants, engineering menu, management, quality control, technical cards. 


\section{INTRODUÇÃO}

Os países desenvolvidos e em desenvolvimento destacam a economia de serviços, como uma das principais atividades. Segundo a última pesquisa do setor, no Brasil, em 2005, o turismo foi responsável pela criação de mais de oito milhões de vagas no mercado de trabalho, sendo a área da alimentação detentora de 37,79\% dessas vagas. A participação do setor de alimentação no tocante a geração de riquezas em 2005, foi de 25 bilhões de reais, sendo o segundo setor com maior capacidade de agregação de valor, suplantado somente pelo transporte rodoviário (BERGAMINI, 2005). Nos Estados Unidos, de cada dez empregos, oito estão no setor de serviços (TINOCO et al., 2008). Devido a esse crescimento, e consequente competitividade no setor, as empresas estão cada vez mais preocupadas com a qualidade.

Dentro do setor de serviços, encontram-se os estabelecimentos que fornecem refeições. Observa-se que a necessidade de realizar refeições fora de casa resulta na crescente oferta de restaurantes, assim como no aumento do orçamento destinado ao consumo de refeições fora do lar. Atualmente, no Brasil, 25\% do orçamento per capita são gastos para este fim e as expectativas para 2012 é de que atinja 30\% (PORTAL FATOR BRASIL, 2009).

Outro aspecto que justifica o elevado número de restaurantes é a ascensão da atividade turística. O Programa Nacional de Turismo (PNT) classifica o desenvolvimento da gastronomia como forte diferencial competitivo no mercado turístico brasileiro. A previsão do PNT é que sejam criados 1,7 milhões de empregos, no setor do turismo (JUNIOR, 2007).

Dentro do turismo não se pode deixar de observar o grande fluxo de pessoas que freqüentam os shoppings centers como forma de lazer. Nesses centros as pessoas fazem compras, divertem-se em cinemas e fazem suas refeições nas praças de alimentação, quer como forma de lazer, quer por necessidade do dia-a-dia por estar próximo do ambiente de trabalho ou de sua residência. Os shoppings centers se tornaram presentes no cotidiano dos brasileiros a partir dos anos 80 (COLLAÇO, 2004) e vêm crescendo na oferta de restaurantes.

O crescimento do setor de alimentação há de desencadear uma pressão significativa do mercado, no sentido de elevar o padrão mínimo de qualidade esperado pelos usuários dos serviços de alimentação (PORTAL FATOR BRASIL, 2009). No 
entanto, são poucos estabelecimentos que enxergam a necessidade de apresentar um serviço de qualidade (SPENA, 2008).

São muitos os requisitos para se obter o sucesso de um empreendimento no setor da alimentação. O empresário deve conhecer de finanças, recursos humanos, legislação, marketing e controle de qualidade (MARICATO, 2001). Neste último se encaixam um serviço de excelência e um cardápio bem elaborado, com um acompanhamento constante. Para o planejamento do cardápio é preciso considerar a padronização, qualidade de produtos, o mínimo de desperdício, as necessidades fisiológicas e culturais dos clientes e uma boa visão das novas tendências.

Algumas ferramentas são utilizadas para viabilizar o sucesso das ações próqualidade dentro do planejamento do cardápio. Dentre elas, a ficha técnica de preparo (FTP) demonstra eficácia principalmente no que se refere à padronização e tudo que se relaciona. A partir da FTP é possível controlar gastos com a matéria-prima e coordenar toda a produção (AKUTSU et al., 2005). Contudo, os serviços de um restaurante não se limitam ao produto em si, ou seja, ao prato de refeição servida. Vários aspectos, como atendimento, apresentação, ambiente, entre outros, contribuem para o sucesso ou insucesso do local. A venda dos pratos servidos, portanto, deve ser analisada considerando todos esses aspectos, para assegurar a estratégia a ser adotada pela gerência.

Prevendo todos esses fatores, Jeolás e Silva (2000) propuseram a utilização da Engenharia de Cardápio como modelo para análise de cardápios servidos em restaurantes. $\mathrm{O}$ instrumento é baseado em premissas básicas de gestão de negócios em Alimentos e Bebidas, a partir da Matriz de Boston (BCG). O objetivo é otimizar os ganhos nos serviços de alimentação.

O uso das ferramentas citadas pode ser um diferencial para estabelecimentos do ramo. Para tanto, estudos que demonstrem as vantagens da utilização destes recursos devem ser estimulados.

Sendo assim, esta pesquisa é de grande importância devido à necessidade de conscientização sobre a importância do uso de ferramentas de gestão (FTP e Engenharia de Cardápios) por parte dos envolvidos com a produção de refeições no local estabelecido. A demonstração de dados que revelam vantagens operacionais e financeiras para o empreendimento, possivelmente auxiliará no andamento das atividades executadas e no sucesso do negócio. 


\subsection{OBJETIVOS}

\subsubsection{Objetivo geral}

Analisar o cardápio de um restaurante especializado em frutos do mar por meio da técnica da engenharia de cardápios.

\subsubsection{Objetivos específicos}

1. Analisar e refazer as fichas técnicas de preparação (FTP) dos pratos sob o aspecto do fator de correção (FC) determinado pelo restaurante;

2. Determinar o custo das preparações;

3. Avaliar a venda das preparações servidas no período de $1^{\circ}$ de abril a 30 de abril de 2009;

4. Aplicar a engenharia de cardápios;

5. Verificar o uso adequado das FTP's através de visitas;

6. Aplicar e sugerir ações corretivas para a melhoria do desempenho do cardápio existente. 


\section{REVISÃO DE LITERATURA}

\subsection{RESTAURANTES: TIPOLOGIA E QUALIDADE}

Por volta do século XVIII, a palavra restaurante significava alimento que restaura. Até o fim do mesmo século, não eram encontrados lugares para se comer além de tabernas e aubergues que eram lugares por onde os viajantes se alojavam durante uma viagem e comiam para repor suas energias (LAROUSSE GASTRONOMIQUE, 2004; MARICATO, 2001). Foi em 1765, que em Paris, um homem chamado Boulanger começou a oferecer refeições quentes a seus clientes. Mas o primeiro verdadeiro restaurante foi o La Grande Taverne de Londres, fundado na Rua de Richelieu, por Antoine Beauvilliers, em 1782 (KONEMANN, 2001).

No Brasil, os restaurantes estão associados à indústria hoteleira. Esse crescimento ocorreu no período de 1930 a 1951, com a abertura de Hotéis Cassino. Com a proibição dos Cassinos por parte do governo, esse setor se estagnou e só se desenvolveu novamente a partir de 1964 (REBELATO, 1997).

A grande ascensão do setor é determinada também pela grande diversidade de produtos que podem ser ofertados pelos restaurantes. Como "estabelecimento comercial onde se prepara e se servem refeições" (HOLANDA pag. 1498, 1986) os restaurantes se dedicam a especialidades distintas, buscando atender a uma clientela cada vez mais exigente. Para tanto, todo restaurante possui um conceito, um ambiente e um tipo de comida direcionada a um público-alvo específico (FONSECA, 1999).

\subsubsection{TIPOLOGIA}

Devido à grande demanda por refeições fora do ambiente doméstico e o crescente aumento de restaurantes, a especialização do setor se tornou necessária. Para atender a diversidade dos clientes, os restaurantes buscam por uma identidade. Sendo assim, criou-se uma tipologia própria para a classificação dos restaurantes, conforme descrição a seguir, descrita por Fonseca (2000) e Lippel (2002): 


\section{1.2.1 Restaurante a la carte:}

Tipo de restaurante que personaliza o atendimento, à medida que o cliente escolhe seu prato mediante apresentação do cardápio, onde estão listadas todas as opções de pratos preparados no estabelecimento. O garçom anota o pedido, e realiza todo o serviço necessário para que o cliente fique satisfeito e realize sua refeição, até o fechamento da conta.

Os restaurantes a la carte podem apresentar conceitos diferentes, apresentando uma gastronomia da mais requintada a mais simples.

\subsubsection{Restaurante de especialidade}

Restaurantes que buscam a especialização em relação a cozinha ofertada são classificados de acordo com os diferentes parâmetros. São eles:

- Restaurante internacional: servem pratos da cozinha internacional, apresentando carta de vinhos diversificada. O ambiente é mais requintado, e atendem clientes de diversas procedências;

- Restaurante gastronômico: são sofisticados, apresentam pratos requintados, muitas vezes apresentados sob forma de menu degustação, onde o indivíduo experimenta uma seqüência de pratos, normalmente harmonizados com vinhos sugeridos por um sommelier, profisssional responsável pela elaboração da carta de vinhos, compras e estoque desses itens. Esse tipo de restaurante possui um chef de cozinha que muitas vezes recebe o cliente e sugere algum prato. Por praxe, a reserva nesse tipo de restaurante é aconselhável, pois normalmente possuem uma baixa rotatividade e o tempo de refeição é longo. Na Europa esse tipo de restaurante está fora dos centros urbanos para aproveitar elementos regionais de arquitetura para compor sua ambientação, como castelos, monastérios entre outras estruturas marcantes. Diferentemente, no Brasil é possível encontrar essa classe de empreendimentos imersos nos grandes centros urbanos;

- Fusion food: a cozinha de fusão é a mescla entre elementos de varias culturas. Essa mescla pode ser feita de formas diversas, como tipo de cocção, apresentação dos itens, com o objetivo de se obter um resultado diferente e único. Essas combinações são feitas normalmente com pratos da cozinha oriental e ocidental, e apresentam-se como uma forte tendência no dias de hoje. 
- Restaurantes típicos: também podem estar em auto-serviço e serviço direto. Podem apresentar pratos típicos de uns pais, a citar: italiana, alemã, francesa, entre outras, bem como a Cozinha regional, que pode se apresentar de forma ampla, como na cozinha baiana ou nordestina, ou estrita, como no caso do churrasco Gaúcho;

- Casual dinning: tem características de coffee shop mesclado com fusion food e grill. As preparações são rápidas leves e utilizam itens de varias culturas;

- Casas de sucos e vitaminas: oferecem sucos e vitaminas e tiveram uma grande expansão devido a valorização dos produtos naturais;

- Vegetariano: especializados em servir alimentos vegetais não derivados da carne vermelha;

2.1.2.3 Brasseries: são restaurantes e casa de bebidas ao mesmo tempo. Teve inicio na Alemanha, expandindo para França e Suíça. Normalmente possuem dois salões: um para serviço de bebidas e outro para serviços de refeições que normalmente sevem pratos variados e típicos.

2.1.2.4 Choperias: é uma adaptação das brasseries européias ao Brasil. Além dos chopes são servidos petiscos como batata frita, frango à passarinho, etc. Possuem uma rotatividade baixa pelo fato de serem freqüentadas por grupos de amigos que freqüentam esse tipo de restaurante para encontros descontraídos.

2.1.2.5 Casas noturnas: lugares para diversão variada como musica, danças, espetáculos, tendo se tornado cada vez mais multifuncionais devido a variedade de seus freqüentadores, ocasionando ambientes direcionados para uma finalidade especifica, restaurantes, bares, trazendo ao cliente várias opções de lazer no mesmo lugar.

2.1.2.6 Coffee shop: possuem cardápios de preparação simples, estão localizados normalmente em hotéis e aeroportos e funcionam $24 \mathrm{~h}$. Servem salgados, cafés, sucos, lanches, sopas, sobremesas, etc.

2.1.2.7 Lanchonetes: restaurante especializado em lanches, pratos rápidos e bebidas. Por ter um serviço mais informal, oferece preço mais acessível mesmo tendo um ambiente mais sofisticado e possui alta rotatividade.

2.1.2.8 Catering: preparação de alimentação em meios de transporte, com exceção de navios. Seguem padrões rígidos de higiene no processo de manipulação, acompanhados por nutricionistas e chefes de cozinha. Há também muito cuidado com a apresentação e 
variedade. Por confeccionarem alimentação em grande volume os cuidados com embalagem, reaquecimento e armazenamento devem ser intensos.

2.1.2.9 Rotisserie: restaurantes que vendem pratos "para viagem", como massas, carnes assadas ou grelhadas.

2.1.2.10 Doçarias: casas que vendem doces, chocolates, tortas, bolos, salgados, sorvetes e pães.

2.1.2.11 Sorveterias: casas onde são vendidos sorvetes que podem ser artesanais ou não.

2.1.2.12 Drugstore: Conceitualmente definida com drogarias que vendem, além de medicamentos, também alimentos rápidos. Em virtude do dispositivo legal 5.991/73, tais estabelecimentos encontram-se impedidos de comercializar alimentos em território nacional, restringindo-se tão somente a dietoterápicos. Em tempo, esta medida está em consulta pública (CP 69), para flexibilização e inclusão de alimentos na lista de artigos de comercialização permitida.

2.1.13 Restaurante de auto-serviço: oferecem um atendimento rápido, de baixo custo, onde o próprio cliente se serve do alimento que desejar. Estão crescendo cada vez mais devido ao crescimento de pessoas que trabalham fora e dispõem de pouco tempo para se alimentar, não podendo realizar em casa suas refeições. Os restaurantes de auto-serviço podem variar em relação ao ambiente, cardápio, variedades apresentadas e preço.

2.1.2.14 Restaurante self-service: possui cardápio extenso e preparações tradicionais que atendem um publico diversificado, dentre ele crianças e idosos. Geralmente possui decoração e utensílios simples, mas há um crescimento de restaurante com esse tipo de serviço com preparações e ambientes mais sofisticados. Estão localizados geralmente em centros comerciais. O cardápio deve ser diversificado para que não se torne exaustivo, ganhando a fidelidade do cliente. O cliente se serve do que deseja, passa por uma balança onde sua refeição é pesada, pagando somente por aquilo que consome. Isso acaba tornando esse tipo de refeição mais acessível financeiramente. Alguns deles funcionam sem garçons, onde o próprio cliente se serve da bebida. A mesa de refeição é pequena, cabendo somente a bandeja com o prato e bebida, pois o espaço necessário para esse tipo de restaurante precisa ser bem aproveitado.

2.1.2.15 Restaurante de coletividade: Esse tipo de restaurante é comumente situado em prédios ou complexos industriais ou comerciais que oferecem alimentação para os 
empregados da empresa. Deve oferecer um cardápio variado e balanceado para que as necessidades nutricionais sejam atendidas, já que são clientes diários.

2.1.2.16 Buffets: realizam serviços de banquetes, coquetéis na própria sede ou em locais externos. Podem ser requintadas ou mais simples. Nesse tipo de serviço, o cliente também se serve. Atuam normalmente em ocasiões especiais como casamentos, formaturas, etc.

2.1.2.17 Casa de chá: restaurante especializado em servir chás, cafés, bolos, tortas, doces, bebidas, salgados. Funciona, normalmente no final da tarde.

\subsubsection{Restaurantes de serviço direto}

São restaurantes que oferecem sempre os mesmo pratos e o serviço também, é sempre o mesmo. Fazem parte dessa categoria os rodízios, no qual consiste o serviço de vários tipos de alimento de um mesmo grupo, como carnes, pizzas, massas, etc. Se faz alimentos. O preço é cobrado por pessoa. Dentro dessa categoria estão as churrascarias, onde são servidos vários tipos de carne feitos na brasa, guarnições e acompanhamentos e sobremesas as pizzarias.

Ao se criar um restaurante é de grande importância a definição do conceito a ser adotado e seguido para melhor adequação de utensílios, equipamentos, mão de obra, decoração, local de funcionamento, marketing a ser trabalhado, cardápio dentre outros.

\subsubsection{RESTAURANTES EM SHOPPING CENTERS}

A diversidade de restaurantes encontrou um local importante para sua clientela que são os shopping centers, ou centro de compras. Eles são definidos como um grupo de negócios de varejo planejado, desenvolvido, possuído e administrado como uma unidade (KOTLER \& ARMSTRONG, 1994).

Os shopping centers entraram no cotidiano dos brasileiros em meados dos anos 80 trazendo o que futuramente seria um fator distintivo para esse tipo de centro comercial: as praças de alimentação. Essas praças estão situadas numa área ampla destinada apenas para as pessoas se alimentarem. Os restaurantes são encontram lado a lado, cada qual com sua especialidade. Há um grande salão com mesas e cadeiras bem próximas umas das outras que são de uso comum de todos os restaurantes. As pessoas chegam, fazem seu pedido, esperam alguns minutos, recebem seu prato, procuram lugar pra sentar, comem, levantam-se e vão embora (COLLAÇO, 2004). 
As praças de alimentação, inicialmente ofertavam restaurantes de serviços rápidos, ou fast- food. Esse tipo de serviço apresenta preparo e serviços rápidos o que demanda pouca mão de obra, consequentemente reduzindo os preços dos pratos se comparado a restaurantes tradicionais (COLLAÇO, 2004). Porém, nos dias atuais, podem-se encontrar restaurantes de serviço direto com suas próprias mesas e cadeiras em seu próprio salão, casas de chá, casas noturnas, enfim, não se pode mais resumir suas praças de alimentação à restaurantes fast-food.

\subsubsection{QUALIDADE PERCEBIDA}

Presume-se que indivíduos motivados inicialmente apenas por uma necessidade fisiológica buscam refeições fora do ambiente doméstico em virtude da praticidade. No entanto, sabe-se que o elevado número de opções existentes nos grandes centros urbanos, torna a escolha cada vez mais difícil e o mercado mais competitivo. Dessa forma, o ponto de honra de qualquer restaurante é agradar e satisfazer às necessidades dos clientes sejam essas imediatas ou ainda por anseio em experimentar um novo prato.

É importante notar que na ultima década, a economia no Brasil sofreu mudanças que fizeram com que o setor da alimentação, para garantir sua permanência num mercado cada vez mais competitivo, passasse a se destacar dos seus concorrentes não só pelos produtos, mas também pela qualidade do serviço por ele oferecido. "Qualidade é aquilo que satisfaz o cliente" e para controlar essa qualidade é preciso que se mantenham os produtos e os serviços nos níveis de tolerância aceitáveis pelo consumidor (AKUTSU et al., 2005).

Segundo Tinoco et al. (2008) a qualidade percebida pelos clientes é definida como a avaliação que o cliente faz durante ou após um determinado serviço. Esta avaliação é feita através de uma comparação com outro serviço prestado e o que o cliente esperava deste serviço.

O cliente satisfeito retorna e indica o estabelecimento a outros. A satisfação não se resume somente a saciar a fome. Se o cliente não sentir atenção, carinho e eficiência, não retornará. Segundo pesquisas, $70 \%$ dos clientes são perdidos por má qualidade dos serviços, mesmo que só 4\% destes reclamem (MARICATO, 2001).

A preocupação com a satisfação do cliente permite a percepção de falhas e correções, assim como, possivelmente modifica eventuais impressões negativas sobre o estabelecimento. Ou seja, clientes que não têm suas expectativas atendidas em um 
restaurante, pode se convencer que vale a pena retornar ao local, caso tenha sido dada a devida importância ao fato pelos envolvidos com o serviço (COUTINHO et al., 2005).

Alguns itens devem ser destacados na busca da qualidade. A padronização, assim como o preço e os serviços de um restaurante são aspectos observados normalmente pelos clientes, que comparam esse aspecto com a concorrência. O controle destes aspectos assegura um planejamento de cardápio satisfatório e restaurantes que tiverem medidas de controle eficientes destes pontos, provavelmente poderão atender com sucesso às expectativas de seus clientes (AKUTSU et al., 2005; ZANELLA, 2007).

Esse cenário ideal dificilmente é atingido sem esforço, visto que existe uma tendência do empresário na visualização do lucro, prescindindo algumas vezes da qualidade na indústria de serviços e ainda negligenciando as necessidades do cliente, pois sua atenção está voltada à orientação financeira em curto prazo, o que contribui para arruinar o setor de serviços (FITZSIMMONS, 2000).

\subsection{PLANEJAMENTO DE CARDÁPIO E MARKETING}

\subsubsection{PLANEJAMENTO DE CARDÁPIO}

O cardápio é o instrumento de informação, venda e publicidade de um restaurante. Através dele o cliente escolhe os alimentos e bebidas que irão consumir (BARRETO, 2002).

Devido à sua complexidade se faz necessário um minucioso estudo e uma ampla pesquisa de mercado para o planejamento de um cardápio. Devem ser destacados os seguintes aspectos: perfil dos clientes atuais e potenciais, dia e horário de funcionamento, condições climáticas da região, sistema de atendimento ao cliente, técnicas de produção, processos de estocagem, disponibilidade de produtos, volume e quantidade de produtos a serem produzidos, custos dos materiais, apresentação dos pratos, tipo de corte dos alimentos, hábitos dos clientes, hábitos regionais, entre outros (ZANELLA, 2007).

Para Maricato (2001), o cardápio é tão importante, que deve ser precedido, até mesmo, à montagem da cozinha. Assim podem ser definidos os espaços, equipamentos necessários para o preparo dos pratos escolhidos e a disposição desses equipamentos. O cardápio dá a identidade ao restaurante e define qual o tipo de decoração a ser usada. 
Mesmo seguindo todos os passos importantes, os resultados dependerão da aceitação dos clientes e isso requer muita paciência e tempo para assimilar a estrutura do cardápio. Uma auto-análise do restaurante deve ser feita não só no inicio das operações, mas também no decorrer do funcionamento. Deve ser verificado nessa análise se os produtos e serviços, efetivamente apresentam qualidade, se há muito desperdício e o que deve ser feito para evitá-lo, se os preços estão em nível adequado, etc. (ZANELLA, 2007).

\subsubsection{MARKETING}

Outro aspecto de grande importância depois da criação do cardápio é o trabalho de marketing contínuo do restaurante. O trabalho de marketing vai influenciar diretamente na capacidade de captação de clientes e na fidelização dos mesmos.

Para Kotler (1998), marketing pode ser definido como a tarefa de criar, promover e fornecer bens e serviços a clientes. Zanella (2007) diz que marketing é o conjunto de ações que pode ser usado para atrair e conquistar clientes e enfrentar os concorrentes, o que torna esse instrumento imprescindível para o sucesso de um empreendimento. Os dois conceitos supracitados foram adotados neste estudo.

O marketing pode ser feito de diferentes maneiras. De forma direta quando se utiliza internet, correio, telefone, fax para se comunicar com o cliente.

Por meio da promoção de vendas, ferramenta de incentivos em curto prazo para encorajar a compra de um produto. Deve-se tomar essa medida em ocasiões com baixa movimentação do estabelecimento, para atrair mais pessoas.

E ainda através da propaganda, ferramenta paga que apresenta e promove mercadorias (KOTLER, 1998).

Segundo Barma (2001), o cardápio deve passar imagem positiva e atrativa do restaurante. As informações como preços e acesso devem ser claras e precisas para que não passem ambigüidade para o cliente. A comunicação dentro do plano de marketing deve determinar:

- Objetivo: conhecimento, fidelização e imagem

- Alvo: clientes atuais, potenciais e formadores de opinião

- Tema da comunicação: uma única mensagem

- Área geográfica: regional, nacional ou internacional 
- Retorno: controle para medir o impacto qualitativo e quantitativo

Logo que estes pontos sejam definidos ficará mais fácil de avaliar o conteúdo da mensagem captada pelo consumidor, a mídia a ser utilizada e o período mais apropriado para o lançamento de alguma campanha de marketing. Na Tabela 1, pode-se acompanhar a evolução dos investimentos gastos em publicidade no mundo no período de 1996 a 2001(em milhões de dólares americanos).

Tabela 1: Evolução de investimentos gastos em publicidade no mundo no período de 1996 a 2001

\begin{tabular}{|c|c|c|c|}
\hline Tipo de mídia & $\mathbf{1 9 9 6}$ & $\mathbf{2 0 0 1}$ & Evolução \\
\hline Promoção & 259103 & 375947 & $+45,10 \%$ \\
Cartas & 32776 & 80267 & $+145,00 \%$ \\
Telemarketing & 11556 & 17413 & $+50,70 \%$ \\
Revistas & 8592 & 15197 & $+77,80 \%$ \\
Radio & 18292 & 18685 & $+2,15 \%$ \\
Televisão & 32265 & 44713 & $+38,50 \%$ \\
Internet & 1920 & 7525 & $+292,00 \%$ \\
\hline Total & 364504 & 559727 & $+65,12$ \\
\hline
\end{tabular}

Fonte: Barma, 2004

Através dos dados apresentados fica muito claro que o setor terciário vem investindo em publicidade o que é de grande importância para o sucesso do negocio.

\subsection{FICHA TÉCNICA DE PREPARO (FTP): FERRAMENTA PARA A PADRONIZAÇÃO}

Akutsu et al.. (2005) identifica que diante desse cenário a padronização é uma peça fundamental para que haja um controle da qualidade. A padronização no processo de produção de uma refeição ajuda o trabalho de quem comanda uma cozinha facilitando o treinamento e o trabalho diário de uma equipe, além de eliminar a interferência por dúvidas nas preparações.

Para Fonseca (2000), a ficha técnica de preparação é um dos documentos mais importantes de um restaurante. Registra todo o processo de elaboração de um prato, as matérias primas utilizadas e suas quantidades, assim como seus custos. Serve também para padronizar a montagem dos pratos através de fotos, manter um histórico das 
preparações do restaurante, permitir a comparação de informações de consumo e facilitar nas compras.

Outro aspecto de relevante importância, segundo Akutsu et al. (2005), é que cada ficha técnica possui a composição centesimal da preparação. O fato que garante ao cliente que cada prato, além de ter o mesmo aspecto sensorial e físico, poderá compor um cardápio balanceado nutricionalmente, satisfazendo assim às necessidades do cliente e o tornando fiel ao restaurante.

\subsection{ENGENHARIA DE CARDÁPIOS}

Ao se planejar um cardápio são necessários alguns cuidados como, conhecimentos culinários, conhecimentos de serviços de restaurante, análise da clientela e análise de venda. Esta última é de suma importância, pois reflete as preferências dos clientes em relação ao que o cardápio oferece e indica os pratos que dão mais lucro, os que devem ser trabalhados e os que deverão sair do cardápio (BARRETO, 2002).

Com o objetivo de otimizar os ganhos da empresa, utiliza-se da Engenharia de Cardápios. $\mathrm{O}$ instrumento é baseado em premissas básicas de gestão de negócios em Alimentos e Bebidas, a partir da Matriz de Boston (BCG).

A matriz é um modelo para análise de portfólio de produtos ou de unidades de negócio baseado no conceito de ciclo de vida do produto. A matriz tem duas dimensões: crescimento do mercado e participação relativa de mercado (que é a participação da empresa em relação à participação de seu maior concorrente). Quanto maior a participação de mercado de um produto ou quanto mais rápido o mercado de um produto cresce, melhor para a empresa.

De acordo com Bruce Henderson, criador da Matriz BCG, uma empresa para ter sucesso precisa ter um portfólio dos seus produtos com taxas de crescimento e participação no mercado diferentes. Pois produtos com alto crescimento precisam de injeções de dinheiro para crescer enquanto os de baixo crescimento devem gerar excesso de caixa. Os dois são necessários simultaneamente (COLLETTI, 2009).

Com o uso dessa ferramenta, o que se busca é que os pratos vendidos em um restaurante comercial apresentem uma margem de contribuição maior. Para isso se faz necessário o controle de custos, estratégias de marketing para o aumento das vendas, entre outros aspectos que envolvem o universo desse tipo de empreendimento. 
Zanella (2007) define margem de contribuição como o lucro bruto, isto é, a relação do custo do produto e o preço. Popularidade segundo Holanda (1986) é a estima geral, ou ainda manifesto de muitas pessoas ou do povo em geral (MICAHELIS, 2009). De acordo com estes critérios os itens são classificados em champagne, uva, pimenta e abacaxi e são propostas ações corretivas para cada um dos grupos.

\section{Champanhe}

Os itens classificados como Champanhe apresentam a popularidade e a margem de contribuição alta, alcançando dessa forma o lucro, que é o objetivo maior de uma empresa (KOTLER, 1998). Em princípio se encontram em uma situação ideal. Contudo necessitam de cuidados constantes para que permaneçam dentro desta classificação. Há de se manter a qualidade e o preço para que continuem a vender bem e apresentem a margem de contribuição desejada pelo estabelecimento.

\section{Uva}

Os itens classificados como UVA possuem uma alta popularidade, porém uma baixa margem de contribuição. Neste caso os pratos precisam ser revisados buscando o aumento dessa margem de contribuição (VAZ, 2006; ZANELLA, 2007):

\section{Pimenta}

Os itens classificados como PIMENTA possuem uma baixa popularidade, mas uma alta margem de contribuição, portanto é necessário trabalhar o marketing desses itens para que se tornem mais populares.

\footnotetext{
Abacaxi

E finalmente, os itens classificados com Abacaxi. Estes possuem margem de contribuição e popularidade baixas.
} 


\section{MATERIAL E MÉTODOS}

A pesquisa realizada é um estudo de caso. Utilizou-se a técnica de engenharia de cardápios descrita por Jeolás (2000) em um restaurante especializado em frutos do mar no período de $1^{\mathrm{o}}$ a 30 de abril de 2009, baseado no cardápio vigente do local durante a pesquisa.

Inicialmente, foram analisadas todas as FTP's, identificando-se os custos com a matéria-prima, assim como os relatórios de vendas do período supracitado. Com base nos relatórios foi aplicada a técnica de engenharia de cardápios, para análise da margem de contribuição e popularidade dos itens do cardápio. Posteriormente as preparações ofertadas foram classificadas de acordo com o método e foram sugeridas ações corretivas pertinentes.

Para a análise dos resultados utilizaram-se as planilhas propostas por Jeolás (2000), que são autoavaliativas.

A análise ocorreu em duas etapas, conforme descrição a seguir.

\section{Primeira Etapa}

Referente à coleta e registro dos dados, foi subdivida nas seguintes atividades:

1. Coleta dos dados (revisão das FTP's, Apêndice 1) e obtenção da planilha de vendas do período, (Anexo 1, 2 e 3)

2. Identificação e classificação dos itens do cardápio, somando o total de itens constantes na planilha no final da coluna.

3. Registrar os números de couverts vendidos no período.

4. Calcular a proporção do mix de vendas.

5. Registrar o custo individual de cada item ou prato.

6. Calcular a margem de contribuição de cada item ou prato.

7. Calcular o custo total do cardápio.

8. Calcular a receita total do cardápio. 
A FTP utilizada nesse estudo está descrita na Figura 1.

\begin{tabular}{|c|c|c|c|c|c|c|}
\hline \multirow{3}{*}{\begin{tabular}{|l|} 
Tipo de produto \\
item \\
NGRED ENTES \\
\end{tabular}} & \multirow[b]{3}{*}{ UND ADE DE MED DA } & \multirow{2}{*}{\multicolumn{5}{|c|}{ FICHA TÉCNIC A DE PREP ARO }} \\
\hline & & & & & & \\
\hline & & PESO BRUTO & PESO LIQUDO & FATOR DE CORREÇÃOO & CUSTO UNI & \begin{tabular}{|l|} 
CUSTO TOTAL \\
\end{tabular} \\
\hline & & & & & & \\
\hline & & & & & & \\
\hline & & & & & & \\
\hline & & & & & & \\
\hline & & & & & & \\
\hline & & & & & & \\
\hline & & & & & & \\
\hline & & & & & & \\
\hline & & & & & & \\
\hline & & & & & & \\
\hline & & & & & & \\
\hline TEMPO MÉD D DE PREP ARO & CUSTO DOS NGREL & DENTES & & & & \\
\hline & & & & & & \\
\hline & & Ganho líquido & & & & \\
\hline & & eço inal de ven & & & & \\
\hline MODO DE PREP ARO : & & & & & & \\
\hline Rendimento $(\mathrm{kg})$ & 0 & & porção (ôes) & & & \\
\hline Porção(RS/kg) & & & & & & \\
\hline
\end{tabular}

Figura 1: Ficha Técnica de Preparação (FTP)

\section{LEGENDA DA FIGURA 1:}

1. Ingredientes são insumos utilizados na preparação, com seus devidos cortes.

2. Unidade de medida: se os insumos estão sendo medidos em quilo, litro, porção, xícara, etc.

3. Peso líquido: quando o alimento está pronto para ser consumido.

4. Peso bruto: quanto o alimento pesa in natura, isto é, sem que tenha sido descascado, sofrido cocção, etc.

5. Fator de correção: é a diferença entre o peso bruto do alimento e o peso líquido.

6. Modo de preparo: descreve passo a passo como fazer o prato

7. Custo unitário: custo de cada item na sua unidade de medida

8. Custo total: custo do insumo pela quantidade utilizada no prato.

9. Foi considerado que os insumos já tinham em seu valor o imposto sobre circulação de mercadorias e serviços (ICMS) 


\section{Segunda Etapa}

Relacionada ao cálculo das médias gerais e análise dos dados, foi realizada de acordo com a descrição abaixo (Apêndices 2 a 9):

1. Estabelecer potencial de custo dos itens ou pratos.

2. Calcular a margem de contribuição total.

3. Determinar a margem de contribuição media do cardápio.

4. Determinar o Índice Geral de Popularidade.

5. Classificar cada item pela Margem de Contribuição.

6. Classificar cada item pelo percentual do mix de vendas.

7. Classificação total dos itens ou pratos.

8. Determinar e registrar ações sobre os itens ou pratos.

A determinação do período necessário para a caracterização das margens de contribuição e popularidade dos pratos foi avaliada através de amostragens mensais e trimestrais, devidamente confrontadas para a visualização de eventuais flutuações nos índices de avaliação no processo de engenharia de cardápios.

\subsection{Descrição do estabelecimento}

O restaurante em estudo integra a lista de restaurantes comerciais de Brasília, situado no Taguatinga Shopping, na praça de alimentação. Trata-se de um restaurante $a$ la carte, de especialidade em frutos do mar. É o único restaurante a servir um cardápio especializado em frutos do mar. Tem como concorrente a rede Giraffas, Spoleto, Mac Donalds, etc., porém é o único que trabalha com frutos do mar. Possui uma clientela diversificada: funcionários do shopping, estudantes, pessoas que trabalham em hospitais e concessionárias da vizinhança, além de famílias de Taguatinga e Águas claras.

Taguatinga é uma cidade-satélite ou região administrativa do estado do Distrito Federal. Devido a seu crescimento nos últimos anos, tornou-se o pólo de diversões das cidades satélites mais próximas (WIKIPIDIA, 2009). Como funciona há apenas um ano e meio, demonstra contínuo interesse na melhoria de suas ações de gestão para aumento da produtividade e conseqüente lucratividade. Para atingir esta meta, a profissionalização de todos os colaboradores, a partir do entendimento do emprego de modelos de controle e análise dos produtos servidos, é de extrema relevância. 


\section{RESULTADOS E DISCUSSÃO}

Segundo Jeolás (2000), os itens no cardápio apresentam classificação quanto à margem de contribuição e popularidade, descritas resumidamente na Figura 2.

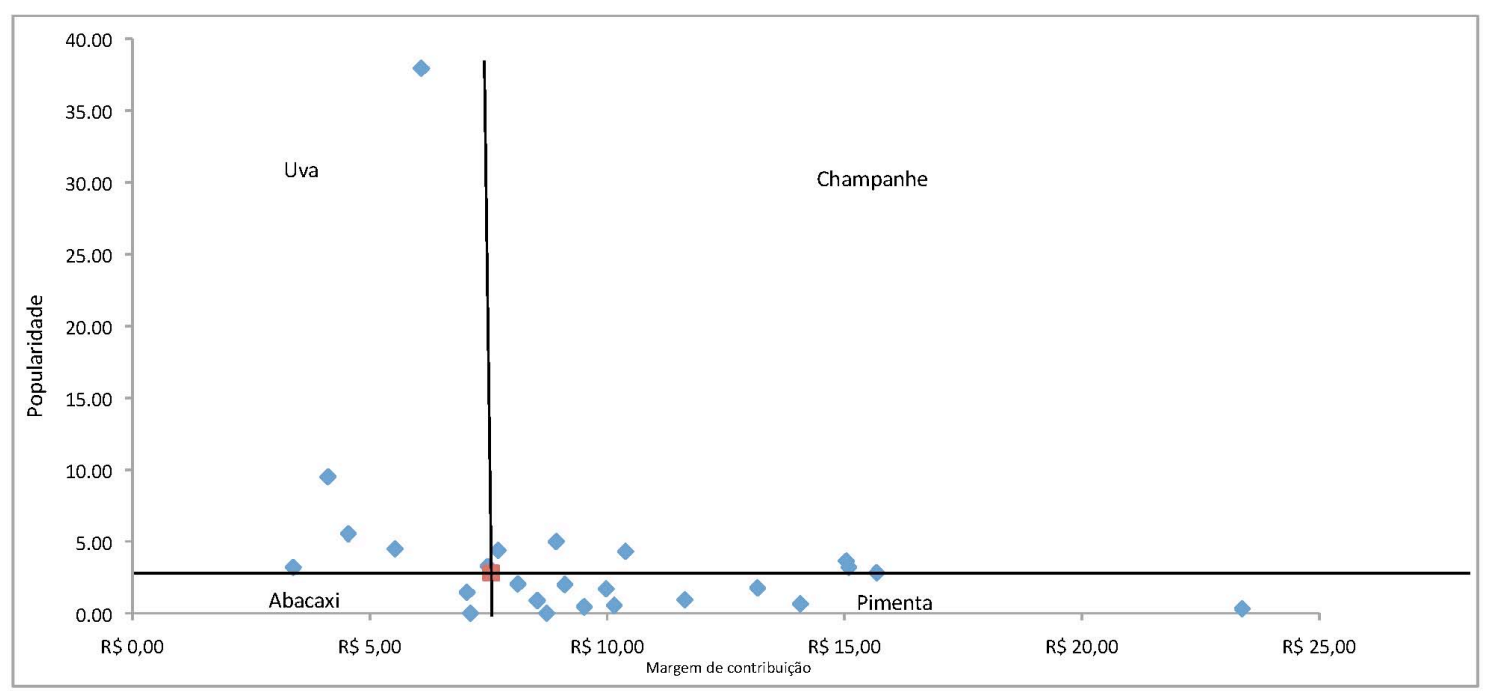

Figura 2: Classificação Trimestral de pratos (margem de contribuição e popularidade)

Ao analisar os dados apresentado na Figura 2, notou-se uma tendência de itens classificados como CHAMPANHE a se tornarem PIMENTA e itens classificados como UVA muito próxima a classificação denominada ABACAXI. A partir daí sentiu-se a necessidade de buscar dados a mais para um analise mais precisa.

Da mesma forma que foi empregada a engenharia de cardápios para o mês de abril e seu respectivo gráfico, foi feito para os meses de fevereiro e março do mesmo ano. Em seguida a mesma técnica foi empregada para os três meses a fim de se fazer uma comparação entre esses três meses e notou-se que a adoção de períodos pequenos pode gerar ruídos e em função do reduzido número amostral envolvido.

A adoção de dados referentes ao período trimestral mostrou-se uma alternativa viável para a análise mais precisa das informações, dando efetivamente mais segurança na determinação de abordagens críticas na engenharia de cardápios.

Uma característica da técnica de engenharia de cardápio é a apresentação de uma distribuição não homogênea dos dados dentro das classificações CHAMPANHE, UVA, PIMENTA e ABACAXI, normalmente apresentando essencialmente um item longe da zona limítrofe de transição entre as zonas de classificação. Tal observação parece se 
justificar pelo padrão de consumo centralizado de alguns pratos considerados "padrão", deixando os outros itens de segundo plano.

Esse mesmo evento leva a transição na classificação de itens entre alguns meses, como observado no mês de fevereiro, caracterizado pela elevação da movimentação familiar em virtude do período de recesso escolar, onde o prato denominado "Pescada empanada" desce de CHAMPANHE para UVA, exatamente no momento em que ocorre a elevação da classificação da "Caldeirada" de PIMENTA para CHAMPANHE. Essa influência cruzada com características sazonais parece demonstrar uma tendência de competição forte entre os pratos, ao invés de um processo de suplementação entre eles.

Obviamente, tal fenômeno é esperado, visto que invariavelmente ocorre a determinação de um prato intitulado "carro-chefe", ostentando uma demanda elevada em relação aos outros pratos, contudo, é sábio adotar ferramentas para fins de elevar o interesse nos pratos secundários, mostrando a versatilidade da cozinha do empreendimento. Porem, por se tratar de um cardápio exclusivamente de frutos do mar, onde temos praticamente os mesmos itens em todas as preparações, mudando a forma de cocção e os molhos, pode agrava-se o fenômeno de competição.

Neste ponto, sugere-se a determinação de um estudo de público-alvo para melhor posicionamento do mercado, bem como na determinação da campanha de marketing tão necessária aos itens classificados como PIMENTA, que tem a popularidade baixa mas uma margem de contribuição desejada pelo restaurante.

O item classificado como ABACAXI durante os três meses causou uma certa estranheza e junto ao proprietário e funcionários descobriu-se que pelo fato do item ter pouca saída, os funcionários não deixavam o pré-preparo desse prato feito. Então quando o cliente solicitava a salada de penne, não havia penne cozido pra vender o prato o que levava o consumidor a comprar outro item. Isso influencia negativamente a visão do cliente em relação á empresa.

O preço de alguns pratos devido ao uso incorreto das FTP apresentava o custo de ingredientes falso, como o Bobó de camarão que é prato mais popular e vendido. Pratos que normalmente são populares em outros restaurantes desse tipo, como o Camarão ao catupiry, terá seu preço diminuído para ter uma melhor saída. A dúvida é se com seu preço reduzido ele passará a ser vendido pelo consumidor que gosta desse tipo de prato, mas nunca comprou por dificuldade financeira ou se haverá uma migração do 
consumidor de outro item. Isso só poderá ser verificado depois de analisar as vendas futuras feitas depois das modificações.

Os consumidores, em sua maioria, não compravam pratos que possuíam nomes técnicos da gastronomia. Por se tratar de uma cidade satélite como Taguatinga, há uma mistura de classes muito grande. Moradores de Taguatinga com alto poder aquisitivo mas pouco conhecimento cultural, moradores de baixo poder aquisitivo além do efetivo pessoal de serviço do Shopping que apresenta um perfil econômico na alimentação diária durante o intervalo de trabalho. Esse tipo de cliente consome pratos mais populares e de nomenclatura mais conhecida como Bobó de camarão, merluza empanada, moqueca de frutos do mar. Já moradores de Águas Claras, possuem médio poder aquisitivo e conhecimento razoável de pratos mais sofisticados como Risoto, Caldeirada, Paella, Talharim, Bacalhau.

Através do estudo, foram detectados vários erros e problemas. As FTP por exemplo, estavam feitas sem conter o FC dos insumos o que representa as modificações que ocorrem com o alimento durante a etapa do pré-preparo, ou seja, eventuais perdas desde a aquisição até o preparo (VAZ 2003). Portanto, calculava-se o preço em cima do peso liquido.

As compras estavam sendo feitas sem nenhum tipo de programação. Não havia dias determinados para insumos perecíveis e não perecíveis. Os cozinheiros verificavam o que iria faltar e faziam uma lista diária de compras. Com isso os insumos, muitas vezes eram comprados em supermercados de luxo, ao invés de atacadistas.

Verificou-se o uso incorreto da quantidade de insumos. No Strogonoff, por exemplo, não estava sendo usada a medida indicada na FTP para o creme de leite, que é um ingrediente caro e se não usado na quantidade indicada altera o valor final do prato.

Ao analisar os currículos dos cozinheiros e através de entrevistas, verificou-se que o restaurante não possuía mão de obra não qualificada, isto é, nunca tinham feito curso algum e nem sequer trabalhado em outros restaurantes. Outro aspecto que torna difícil manter a qualidade é o fato da mão de obra ser praticamente artesanal e em quase toda sua totalidade não qualificada. O baixo nível cultural dos funcionários desse restaurante também atrapalha, pois gera uma dificuldade de entendimento de certas responsabilidades e normas de higiene e isso tudo compromete a estabilidade da qualidade. 
Notou-se, através de visitas diárias, que muitos insumos perecíveis eram comprados em demasia, sem verificação de estoque e eram descartados diariamente. Alguns molhos guarnições que eram feitos diariamente, estavam sendo feito numa quantidade além da que se vendia.

Foi detectado desperdício no uso de itens que elevam os custos fixo, gastos decorrentes do processo de produção que não podem ser associados diretamente ao um produto ou serviço específico (VAZ 2006). Como o acendimento de duas chamas de fogão quando uma só era suficiente. As luzes de estoque estavam sempre acesas. Funcionários usavam o telefone da empresa para assuntos particulares.

No cardápio impresso, havia muitos erros como foto que não correspondia ao que estava escrito, ausência de itens em alguns pratos. Isso causa confusão e certamente o cliente prefere escolher algo que seja mais simples e claro, já que a escrita deverá ser de fácil legibilidade (ZANELA/CÂNDIDO, 2002). Além disso, a nomenclatura dos pratos não era conhecida pelo publico de Taguatinga;

A empresa não investia em propaganda. E as promoções de venda em forma de folhetos eram feitas para os pratos que não tinham a margem de contribuição desejada (classificados como uva que não precisavam desse tipo de marketing). E essa era a único tipo de promoção realizada.

Havia falta de comunicação entre atendimento e cozinha. Muitas vezes um item que estava em falta era vendido, causando insatisfação do cliente que muitas vezes já tinha pagado por esse item. Foi verificada também através do acompanhamento do atendimento ao cliente, a falta de preparo dos atendentes. Muitas vezes eles não sabiam sequer explicar o que havia num determinado prato.

Ainda no atendimento uma falha muito grave foi detectada. O profissional que lida diretamente com o publico não desempenhava bem essa função. $O$ atendimento era feito com mau humor, descaso, "cara fechada", impaciência, preguiça, falta de postura física (debruçados no balcão), etc.

Não havia gerente capacitado, por não se querer se gastar com um salário compatível com tal cargo. Nenhum tipo de monitoramento de cozinha e atendimento era realizado.

Após analise dos erros e problemas detectados foram tomadas algumas ações para corrigir tais problemas. 
As fichas foram refeitas (Apêndice 1) e o preço de custo real dos pratos que foram usadas neste estudo está à disposição do restaurante para que sejam tomadas as devidas providencias.

Com o objetivo de minimizar custos através de boa administração das compras buscando fornecedores que vendam com melhores preços, foi implantada uma agenda semanal de compras, dividindo-se itens perecíveis e não perecíveis e seus respectivos locais de compra. A questão fundamental para uma política de compra e estoque é estabelecer data, quantidade de itens a serem comprados e onde comprá-los (ZANELA, 2002).

Além disso, foi solicitado que a fiscalização no momento do recebimento de ingredientes fosse feita com rigidez e que essa seja uma tarefa de responsabilidade de uma determinada pessoa, não aceitando insumos de má qualidade. O recebimento de mercadorias é tão importante quanto às compras, pois nele é verificado a qualidade, quantidade e preço dos insumos (FONSECA, 2000).

Foi orientado que a aquisição de insumos perecíveis fosse feita diariamente e a programação dessas compras deverá ser feita com base em estimativa de consumo, bem como o estabelecimento de inspeção permanente nos estoques para verificar as condições e quantidade de insumos. Tal prática tem como objetivo minimizar desperdícios de insumos reduzindo os níveis de estoque. Foi realizada a redução da quantidade diária, deixando sob refrigeração e utilizando somente a quantidade para a porção vendida. O que restava era aproveitado no próximo turno ou no dia seguinte, desde que a qualidade esteja íntegra, de acordo com os padrões vigentes de vigilância sanitária.

Foi implantado o porcionamento de todos os insumos. Tudo passou a ser pesado e embalado para o momento do uso ou utilizado com o auxilio de medidores. A utilização dos insumos deve corresponder ao que é indicado nas FTP, documento mais importante de um restaurante, pois registra todo o processo de elaboração de um prato, as matérias primas utilizadas e suas quantidades (FONSECA, 2000).

Para que seja verificado o uso corretos das FTP, um acompanhamento semanal dos funcionários por um consultor em gastronomia foi sugerido. Além disso, o consultor poderá ensinar técnicas de gastronomia e higiene e novos pratos. Um treinamento mensal sobre regras de higiene e manipulação de alimentos com uma nutricionista também será adotado. Foi passado ao proprietário que um investimento por 
parte da empresa em cursos rápidos de gastronomia para que seus funcionários aprendam e se motivem trará retorno positivo futuramente.

Redução de custos fixos, economizando gás, água, energia, e telefone. Luzes de estoque só serão acesas quando o mesmo for acessado. O telefone foi bloqueado para fazer ligações. O descongelamento passou a ser feito sob refrigeração de um dia para o outro.

Revisar como os pratos estão descritos no cardápio (ZANELLA 2007). Foi solicitado ao proprietário do restaurante que refaça a impressão do cardápio e modifique a nomenclatura de alguns itens. Como essa analise foi a primeira a ser feita do cardápio, haverá uma simplificação dos nomes. Por exemplo, crostinis para torradas.

Foi sugerido ao proprietário o investimento em propaganda tipo outdoors e rádio, uso de folhetos promocionais, acrescentando aos pratos classificados como pimenta uma bebida (refrigerante, chope ou vinho) sem ônus para o cliente.

Implantou-se um self-service de salada com três itens de baixo custo como alface, cenoura ralada, beterraba ralada, etc. Além de se sugerir ao proprietário a distribuição aos clientes de um cartão fidelidade, onde a cada nove refeições compradas, a décima, seria cortesia do estabelecimento. Isso levaria a um aumento de consumo por clientes que fazem suas refeições todos os dias no shopping.

Foi sugerida ao proprietário a contratação de um gerente qualificado para desempenhar essa função. Ainda, definiu-se a ocorrência de uma conferencia diária e por turno dos itens em falta na cozinha por parte dos atendentes.

Alguns atendentes serão dispensados de seus postos de trabalho, com sua reocupação por profissionais submetidos a um treinamento com um consultor de gastronomia pra que aprendam os pratos, além de degustarem os mesmos, pois assim não só saberão dizer os insumos que compõem os pratos, mas poderão explicar o sabor, textura, etc. $\mathrm{O}$ treinamento também abrangerá abordagem ao cliente, como se portar no local de trabalho.

Acompanhamento semanal do atendimento por parte do consultor em gastronomia e monitoramento constante pelo proprietário. 


\section{CONCLUSÃO}

Através desse estudo pode-se verificar que a aplicação da engenharia de cardápio é realmente uma ferramenta satisfatória para análise geral da saúde de um cardápio, porém deve ser feita de forma clara e bem definida, por períodos mais longos e precisos. A sazonalidade, dias de semana $\mathrm{x}$ fim de semana, pode trazer alterações nos resultados, já que o perfil do cliente também sofre alterações.

Uma mão de obra não qualificada e sem treinamentos influencia diretamente no insucesso de uma empresa de alimentação. Pois requisitos como o uso correto das FTP e regras de higiene sanitárias podem gerar desperdícios desnecessários para a empresa, afetando tanto a reprodutibilidade de um prato, quanto a qualidade do alimento e do serviço prestado.

A pesquisa de mercado também denotou-se como componente imprescindível para a elaboração de cardápio, para que se possa saber o que o cliente quer e quanto quer pagar, além de buscar a melhor linguagem para esse tipo de comunicação e o tipo de marketing a ser utilizado.

Esse estudo torna-se um claro exemplo do impacto da não adoção das ferramentas de gestão de estabelecimentos gastronômicos, tanto do ponto de vista técnico como administrativo. Ainda que o estabelecimento aqui estudado mostrava-se superavitário, a análise profunda demonstrou uma enorme margem para melhora nos serviços, que, sem sombra de dúvida, tornarão o empreendimento mais lucrativo. 


\section{REFERÊNCIAS BIBLIOGRÁFICAS}

1. AKUTSU, Rita de Cássia; BOTELHO, Raquel; CAMARGO, Érika; SÁVIO, Karin; ARAÚJO, Wilma. Adequação das boas práticas de fabricação em serviços de alimentação. Rev. Nutr., Campinas, 18(3):419-427, maio/jun., 2005.

2. AKUTSU, Rita de Cássia; BOTELHO, Raquel; CAMARGO, Érika; SÁVIO, Karin/ARAÚJO, Wilma. A ficha técnica de preparação como instrumento de qualidade na produção de refeições. Rev. Nutr., Campinas, 18(2):277-279, mar./abr., 2005.

3. BARMA, Jean -Louis, Marketing du tourismeet de l'hôtellerie, Études de cas commentées Corrigés, Troisième édition, Éditions d'Organisation, 2001.

4. BARRETO,Ronaldo Lopes Pontes. Passaporte para o sabor. São Paulo, Editora Senac, p.21,31,2002.

5. COLLAÇO, Janine. Estudos Históricos, Rio de Janeiro, $n^{0} 33$, janeiro-junho de 2004, p. 116-135.

6. COUTINHO, Edilma Pinto; MOREIRA, Ricardo Targino; SOUZA Dayane Muniz. Aplicação do ciclo de serviços na análise da gestão da qualidade de um restaurante universitário. XXV Encontro Nac. de Eng. de Produção. Porto Alegre, RS, Brasil, 29 out a 01 de nov de 2005.

7. FITZSIMMONS, James A.; FITZSIMMONS, Mona J. Administração de serviços: operações, estratégia e tecnologia de informação. 2 ed. Porto Alegre: Bookman, 2000.

8. FONSECA, Marcelo Traldi.Tecnologias gerenciais de restaurantes. São Paulo: Editora Senac ,2000 p 11,71.

9. HOLANDA, Aurélio Buarque de. Novo Dicionário Aurélio. 2 ed. Editora Nova Fronteira, 1986.

10. BERGAMINI, Ricardo. Economia do Turismo - uma perspectiva macroeconômica 2000-2005. IBGE, Instituto Brasileiro de Geografia e Estatística, 2005.

11. JEOLÁS Roberto/ SANTOS Elias.O negocio em alimentos e bebidas. Editora Ponto Crítico, 2000.

12. JUNIOR, Paulo Solmucci. Plano Nacional de Turismo. A inserção na mesa do turismo brasileiro,06/09/2007. Disponível em: http://www.abrasel.com.br/index.php/atualidade/item/2121. Acesso em: 13 jul 2009. 
13. KONEMANN, Especialidades Francesas, Portugal, 2001.

14. KOTLER, Philip. Administração de Marketing: análise, planejamento, implementação e controle. 5.ed. São Paulo: Atlas, 1998.

15. KOTLER, Philip ; ARMSTRONG, Gary. Principles of Marketing. New Jersey : Prentice-Hall, 1994. 692 p.

16. LAROUSEE, Gastronomique, França, 2004.

17. LIPPEL, Isabela Laginski. GESTÃO DE CUSTOS EM RESTAURANTES UTILIZAÇÃO DO MÉTODO ABC. Dissertação de Mestrado,FLORIANÓPOLIS,2002.

18. MARICATO, Percival. Como montar e administrar bares e restaurantes, 3 Ed, São Paulo, Editora SENAC,p. 34,95,2001.

19. MICHAELIS, disponível em: http://michaelis.uol.com.br/moderno/portugues/index.php?lingua=portuguesportugues\&palavra=popularidade/1998-2009 Editora Melhoramentos Ltda, UOL. Acessado em 04/04/ 2009.

20. PACHECO, Aristides de Oliveira. Manual do Maître D'Hôtel. São Paulo: Editora Senac São Paulo, 1995.

21. Portal Fator Brasil. Gastos com refeições fora do lar devem chegar a 30\% em $2012, \quad \mathbf{1 8 / 0 6 / 2 0 0 9}$. Disponível em : http://www.abrasel.com.br/index.php/atualidade/item/5522/, acessado em : 13/07/09.

22. REBELATO, Marcelo Giroto. Uma análise sobre a estratégia competitiva e operacional dos restaurantes self-service. Revista Gestão \& Produção:Volume 04, no 03, p. 321-334, dezembro/1997.

23. SPENA, Rossana. Atendimento: serviço bem prestado é obrigação,Hotellnews, Ed.344, maio/junho, 2008. Disponível em: http://www.revistahotelnews.com.br/2006/ssHome/index.php?id=6\&subId=123 7\&edicao $=344 \&$ meio $=. . /$ ssEdicoesAnteriores/meioEdicao.php\&y $=2008$. Acessado em: 28/05/2009.

24. TINOCO, Maria Auxiliadora/ RIBEIRO, Jose Luis Duarte. Estudo qualitativo dos principais atributos que determinam a percepção de qualidade e de preço dos consumidores de restaurantes a la carte.Gest. Prod., são Carlos, v.15, n.1, p.73-87, jan-abr.2008.

25. VAZ, Célia Silvério. Alimentação de Coletividade, Brasília, p.178, 2003.

26. VAZ, Célia Silvério. Restaurantes- controlando custos e aumentando lucro, Brasília, p. 177,2006. 
27. ZANELLA, Luiz Carlos; CANDIDO, Índio. Restaurante, técnicas e processos de administração e operação, Caxias do Sul, EDUCS, 2002.

28. ZANELLA, Luiz Carlos. Instalação e Administração de restaurantes, São Paulo, Editora Metha, p 25, 26,27, 69, 163, 2007.

29. WIKIPIDEA, Matriz BCG, acessado em 02/03/2008. http://pt.wikipedia.org/wiki/Matriz_BCG

30. WIKIPIDEA, disponível em http://pt.wikipedia.org/wiki/ Taguatinga, Distrito Federal, acessado em14/08/2009.

31. COLLETTI, José Carlos. Disponível em http://www.administradores.com.br/artigos/matriz_bcg/13017. Acessado em: 12/08/2009. 
APÊNDICE I

Fichas Técnicas de Preparação

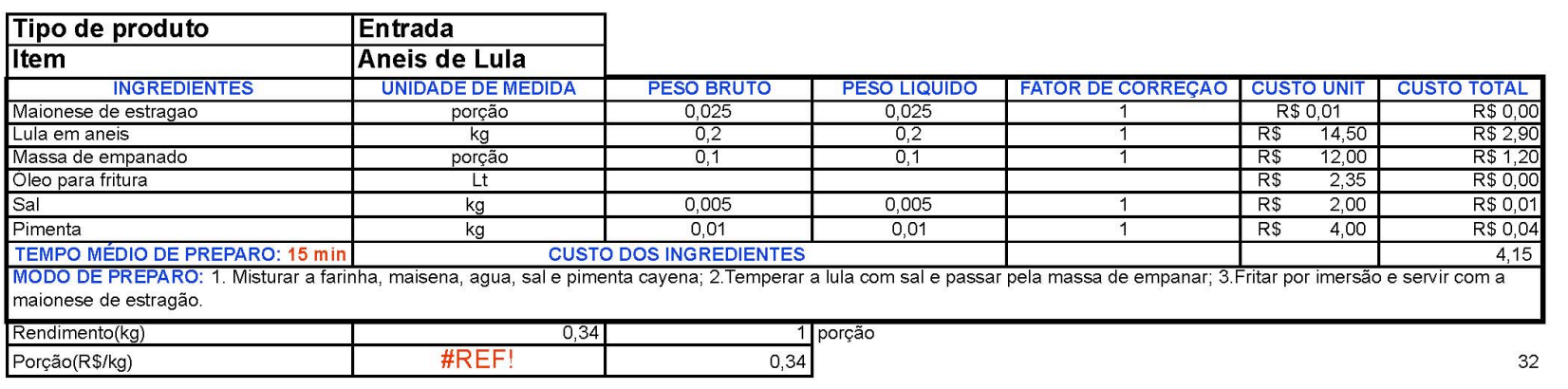




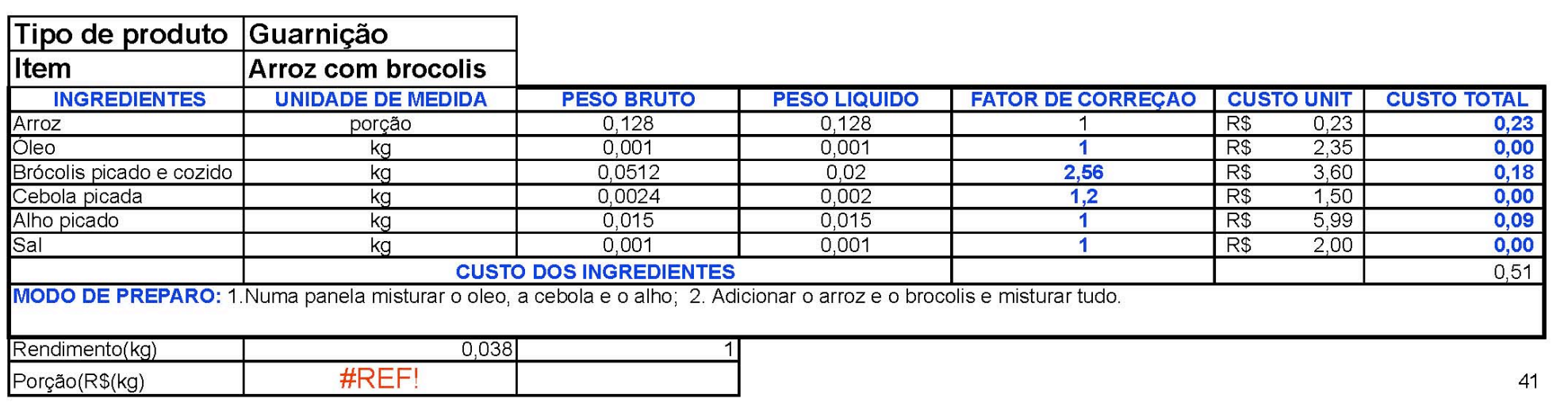




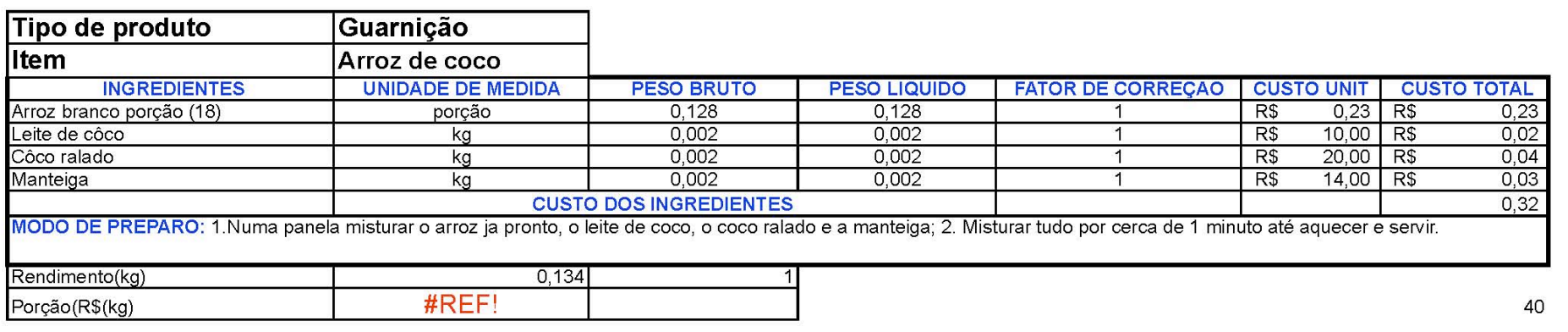


Tipo de produto

Guarnição

INGREDIENTES

Batata frita

\begin{tabular}{|l|l|}
\hline INGREDIENTES & UNIDADE DE MEDIDA \\
\hline
\end{tabular}

$\frac{\text { PESO BRUT }}{0,1}$

\begin{tabular}{|c|c|c|cr|r|}
\hline RUTO & PESO LIQUIDO & FATOR DE CORREÇAO & \multicolumn{1}{|c|}{ CUSTO UNIT } & \multicolumn{2}{l|}{ CUSTO TOTAL } \\
\hline 0,1 & 0,1 & 1 & $\mathrm{R} \$$ & 3,00 & 0,30 \\
\hline 0,001 & 0,001 & 1 & $\mathrm{R} \$$ & 2,00 & 0,00 \\
\hline- & & & & - & 0,50 \\
\hline
\end{tabular}

Óleo para fritura

TEMPO MEDIO DE PREPARO: 1 CUSTO DOS INGREDIENTES

MODO DE PREPARO: Aquecer o óleo 200 graus na fritadeira elétrica e fritar a batata até ficar dourada e crocante

Rendimento(kg) 0,11 


\begin{tabular}{|c|c|c|c|c|c|c|}
\hline Tipo de produto & Guarnição & & & & & \\
\hline Item & Batata sauté & & & & & \\
\hline INGREDIENTES & UNIDADE DE MEDIDA & PESO BRUTO & PESO LIQUIDO & FATOR DE CORREÇAO & CUSTO UNIT & CUSTO TOTAL \\
\hline Batata em cubos & $\mathrm{kg}$ & 0.12 & 0,1 & 1,2 & $\begin{array}{|ll|}\text { RS } & 1,16 \\
\end{array}$ & 0,14 \\
\hline Margarina & $\mathrm{kg}$ & 0,01 & 0,01 & 1 & 10,00 & 0,10 \\
\hline Sal & $\mathrm{kg}$ & 0,002 & 0,002 & 1 & 2,00 & 0,00 \\
\hline Salsa picadinha & $\mathrm{kg}$ & 0,00125 & 0,001 & 1,25 & 3,00 & 0,00 \\
\hline TEMPO MIEDIO DE PREPA & CUSTO DOS INGREDIE & \begin{tabular}{|l|} 
NTES \\
\end{tabular} & & & & 0,25 \\
\hline & PERCENTUAL DE IMPOSTOS S & OBRE VENDAS & & & & \\
\hline & CUSTO TOTAL POR PO & RCQÁO & & & & \\
\hline & & Ganho líquido & & & & \\
\hline & & eço final de vend & & & & \\
\hline IODO DE PREPARO: 1.0 & ozinhar a batata; 2.Refogar com m & largarina acrescel & & & & \\
\hline$\frac{\text { Rendimento(kg) }}{\text { Porção(R\$/kg) }}$ & \begin{tabular}{r|}
0.113 \\
0
\end{tabular} & \begin{tabular}{|l|}
1 porção \\
0,113
\end{tabular} & & & & 44 \\
\hline
\end{tabular}




\begin{tabular}{|c|c|c|c|c|c|c|}
\hline Tipo de produto & Guarnição & & & & & \\
\hline Item & Hortaliças refogadas & & & & & \\
\hline INGREDIENTES & UNIDADE DE MEDIDA & PESO BRUTO & PESO LIQUIDO & FATOR DE CORREÇAO & CUSTO UNIT & CUSTO TOTAL \\
\hline Vagem & $\mathrm{kg}$ & 0,0375 & 0,03 & 1,25 & $\begin{array}{|ll|}R \$ & 2,90 \\
\end{array}$ & 0,10875 \\
\hline Cenoura & $\mathrm{kg}$ & 0,0345 & 0,03 & 1,15 & 1,30 & 0,04485 \\
\hline Couve-flor & $\mathrm{kg}$ & 0,066 & 0,03 & 2,2 & 8,00 & 0,528 \\
\hline Batata & $\mathrm{kg}$ & 0,036 & 0,03 & 1,2 & 1,16 & 0,04176 \\
\hline Margarina & $\mathrm{kg}$ & 0,015 & 0,015 & 1 & 14,00 & 0,21 \\
\hline salsa & $\mathrm{kg}$ & 0,00125 & 0,001 & 1,25 & 18,00 & 0,0225 \\
\hline sal & $\mathrm{kg}$ & 0,002 & 0,002 & 1 & 2,00 & 0,004 \\
\hline pimenta & \begin{tabular}{l|}
$\mathrm{kg}$ \\
\end{tabular} & 0,001 & 0,001 & 1 & 4,00 & 0,004 \\
\hline TEMPO MEDIO DE PREPAR & CUSTO DOS INGREDIE & NTES & & & & 0,96 \\
\hline $\begin{array}{l}\text { MODO DE PREPARO: 1.Coz } \\
\text { até que fique al dente; } 4 . \text { Cozir } \\
\text { e salsa picada. }\end{array}$ & $\begin{array}{l}\text { inhar a vagem em agua fervente } c \\
\text { hhar a batata até que fique al dente }\end{array}$ & $\begin{array}{l}\text { om sal por } 3 \mathrm{mi} \\
; 5 \text {.Aqueçer um }\end{array}$ & os; 2. Cozinhe & ouve flor em agua ferv & $\begin{array}{l}\text { por } 5 \text { minutos; } 3 \\
\text { legumes e tempe }\end{array}$ & $\begin{array}{l}\text { Cozinhar a cenoura } \\
\text { erar com sal, pimenta }\end{array}$ \\
\hline Rendimento(Gr) & 0,139 & & brção & & & \\
\hline Porção(R\$/Gr) & \#REF! & & & & & 45 \\
\hline
\end{tabular}




\begin{tabular}{|c|c|c|c|c|c|c|}
\hline Tipo de produto & Guarnição & & & & & \\
\hline Item & Purê de batatas & & & & & \\
\hline INGREDIENTES & UNIDADE DE MEDIDA & PESO BRUTO & PESO LIQUIDO & FATOR DE CORREÇAO & CUSTO UNIT & CUSTO TOTAL \\
\hline Batata cozida e amassada & $\mathrm{kg}$ & 1,2 & 1 & 1,2 & $\begin{array}{ll}\mathrm{R} \$ & 1,80 \\
\end{array}$ & 2,16 \\
\hline margarina & $\mathrm{kg}$ & 0,2 & 0,2 & 1 & 10,00 & 2 \\
\hline sal & $\mathrm{kg}$ & 0,05 & 0,05 & 1 & 2,00 & 0,1 \\
\hline creme de leite & $\mathrm{kg}$ & 0,1 & 0,1 & 1 & 10,00 & 1 \\
\hline \begin{tabular}{|l|l|} 
leite & \\
\end{tabular} & It & 0,25 & 0,25 & 1 & 1,98 & 0,495 \\
\hline TEMPO MEDIO DE PREPARO: 10 & CUSTO DOS INGR & DIENTES & & & & 5,755 \\
\hline MODO DE PREPARO: 1 1. Misturar $t$ & todos os ingredientes numa & panela e levar ao & $7 \mathrm{me}$ & minutos. & & \\
\hline \begin{tabular}{|l|} 
Rendimento $(\mathrm{kg})$ \\
Porção(R\$/kg)
\end{tabular} & \#REF! & \begin{tabular}{r|}
10 \\
0,16 \\
\end{tabular} & porção & & & 46 \\
\hline
\end{tabular}




\begin{tabular}{|c|c|c|c|c|c|c|}
\hline Tipo de produto & Principal & & & & & \\
\hline Item & Camarão ao Curry & & & & & \\
\hline INGREDIENTES & UNIDADE DE MIEDIDA & PESO BRUTO & PESO LIQUIDO & FATOR DE CORREÇAO & CUSTO UNIT & \begin{tabular}{|l|} 
CUSTO TOTAL \\
\end{tabular} \\
\hline Camarão & $\mathrm{kg}$ & 0,492 & 0,12 & 4,1 & $\mathrm{R} \$ \quad 16,50$ & 8.118 \\
\hline Creme de leite & $\mathrm{kg}$ & 0,05 & 0,05 & 1 & 12,00 & 0,6 \\
\hline Sal & $\mathrm{kg}$ & 0,002 & 0,002 & 1 & 2,00 & 0,004 \\
\hline pimenta & $\mathrm{kg}$ & 0,002 & 0,002 & 1 & 4,00 & 0,008 \\
\hline Oleo de soja & $\mathrm{kg}$ & 0,025 & 0,025 & 1 & 2,35 & 0,05875 \\
\hline Curry & $\mathrm{kg}$ & 0,002 & 0,002 & 1 & 30,00 & 0,06 \\
\hline Molho Bechamel (26) & $\mathrm{kg}$ & 0,1 & 0.1 & 1 & 11,15 & 1,115 \\
\hline Arroz de coco porção(19) & porção & 0 & 0,2 & & 1,30 & 0,7 \\
\hline Hortaliças refogadas (23) & \begin{tabular}{l|l} 
porção & 1 \\
\end{tabular} & 0 & 0 & 0 & 2,00 & \\
\hline TEMPO MEDIO DE PREPA & \begin{tabular}{|l|} 
CUSTO DOS INGREDIEI \\
\end{tabular} & VTES S & & & & 12,66 \\
\hline \multicolumn{7}{|c|}{$\begin{array}{l}\text { MODO DE PREPARO: 1.Aquecer uma frigideira e adicionar o curry e deixar por alguns segundos; 2.Acrescentar o oleo e em seguida os camaroes temperados com } \\
\text { sal e pimenta; 3.Adicionar o creme de leite e o molho bechamel. }\end{array}$} \\
\hline Rendimento $(\mathrm{kg})$ & 0,501 & & \multirow{2}{*}{\multicolumn{4}{|c|}{ 1]porção }} \\
\hline Porção(R\$/kg) & \#REF! & & & & & \\
\hline
\end{tabular}




\begin{tabular}{|c|c|c|c|c|c|c|}
\hline Tipo de produto & Principal & & & & & \\
\hline Item & Camarão ao catupiry & & & & & \\
\hline INGREDIENTES & UNIDADE DE MEDIDA & PESO BRUTO & PESO LIQUIDO & FATOR DE CORREÇAO & CUSTO UNIT & CUSTO TOTAL \\
\hline Camarăo & $\mathrm{kg}$ & 0,492 & 0,12 & 4,1 & $\begin{array}{|ll|}\mathrm{R} \$ & 16,50 \\
\end{array}$ & 8,118 \\
\hline Cebola picada & $\mathrm{kg}$ & 0.03 & 0,025 & 1,2 & 1,50 & 0,045 \\
\hline Oleo & $\mathrm{kg}$ & 0,025 & 0,025 & 1 & 18,00 & 0,45 \\
\hline Queijo catupiry & $\mathrm{kg}$ & 0,06 & 0,06 & 1 & 19,40 & 1,164 \\
\hline Molho Bechamel (26) & $\mathrm{kg}$ & 0.08 & 0,08 & 1 & 11,15 & 0,892 \\
\hline Batata frita (01) & Porção & 0 & & 1 & $\begin{array}{ll}\mathrm{R} \$ & 0,96 \\
\end{array}$ & 0,96 \\
\hline Arroz com brocoli porção (20 & \begin{tabular}{|l|l} 
porção \\
\end{tabular} & 0 & & 1 & 1,13 & 1,13 \\
\hline TEMPO MEDIO DE PREPA月 & CUSTO DOS INGREDI & ENTES & & & & 12.76 \\
\hline \multicolumn{7}{|c|}{$\begin{array}{l}\text { MODO DE PREPARO: 1. Numa frigideira quente juntar os camarões temperados com sal e pimenta, acrescentar a cebola picada e continuar refogando até } \\
\text { ficarem na concistência adequada e com a cor avermelhada; } 2 . E m \text { seguida acrescentar o molho bechamel e o queijo catupiry. }\end{array}$} \\
\hline Rendimento $(\mathrm{kg})$ & 0,31 & & \multirow{2}{*}{\multicolumn{4}{|c|}{1 porção }} \\
\hline Porção(RS/kg) & \#REF! & & & & & \\
\hline
\end{tabular}




\begin{tabular}{|c|c|c|c|c|c|c|}
\hline Tipo de produto & Principal & & & & & \\
\hline Item & gratinado de bacalhau & & & & & \\
\hline INGREDIENTES & UNIDADE DE MEDIDA & PESO BRUTO & PESO LIQUIDO & |FATOR DE CORREÇAO & CUSTO UNIT & CUSTO TOTAL \\
\hline Bacalhau desfiado e desalgado & $\mathrm{kg}$ & 0,252 & $\begin{array}{l}0,1 \\
\end{array}$ & 2,52 & $\begin{array}{|ll|}\mathrm{R} \$ & 19,50 \\
\end{array}$ & 4,914 \\
\hline $\begin{array}{l}\text { Azeitonas pretas } \\
\end{array}$ & $\mathrm{kg}$ & 0,0066 & 0,005 & 1,32 & 8,25 & 0,05445 \\
\hline Salsa picada & $\mathrm{kg}$ & 0,0025 & 0,002 & 1,25 & 3,00 & 0,0075 \\
\hline Cebola picada & $\mathrm{kg}$ & 0,006 & 0,005 & 1,2 & 1,50 & 0,009 \\
\hline \begin{tabular}{|l|l} 
Alho picado \\
\end{tabular} & $\mathrm{kg}$ & 0.002 & 0,002 & 1 & 5,99 & 0,01198 \\
\hline Pimentão verde & $\mathrm{kg}$ & 0,0157 & 0,01 & 1,57 & 2,78 & 0,043646 \\
\hline Pimentão vermelho & $\mathrm{kg}$ & 0,0157 & 0,01 & 1,57 & 7,50 & 0,11775 \\
\hline Pimentão amarelo & $\mathrm{kg}$ & 0,0157 & 0,01 & 1,57 & 9,90 & 0,15543 \\
\hline Sal & $\mathrm{kg}$ & 0,002 & 0,002 & 1 & 2,00 & 0,004 \\
\hline Pimenta & $\mathrm{kg}$ & 0,1 & 0,1 & 1 & 4,00 & 0,4 \\
\hline Molho bechamel & $\mathrm{kg}$ & 0,01 & 0,01 & 1 & 11,15 & 0,1115 \\
\hline Queijo parmesão & $\mathrm{kg}$ & 0,06 & 0,06 & 1 & 16,00 & 0,96 \\
\hline Porçăo de batata sauté (22) & Porção & 0 & 1 & & 0,79 & 0,79 \\
\hline Porção de farofa de banana(21) & Porção & 0 & 1 & & 1,75 & 1,75 \\
\hline TEMPO MEDIO DE PREPARO: $10 \mathrm{~m}$ & CUSTO DOS INGR & ENTES & & & & 9,33 \\
\hline $\begin{array}{l}\text { MODO DE PREPARO: } 1 \text {. Refogar a c } \\
\text { ramequim e polvilhar com queijo; } 4 \text {. Gr }\end{array}$ & $\begin{array}{l}\text { ebola e o alho no azeite de ol } \\
\text { ratinar. }\end{array}$ & 2.Acresentar 0 & & & nar o becham & , passar para um \\
\hline$\frac{\text { Rendimento(Kg) }}{\text { Porcão(R\$/Kq) }}$ & & & & & & 50 \\
\hline
\end{tabular}




\begin{tabular}{|c|c|c|c|c|c|c|}
\hline Tipo de produto & Principal & & & & & \\
\hline Item & caldeirada & & & & & \\
\hline INGREDIENTES & UNIDADE DE MEDIDA & PESO BRUTO & PESO LIQUIDO & FATOR DE CORREÇAO & CUSTO UNIT & CUSTO TOTAL \\
\hline Polvo & $\mathrm{kg}$ & 0,02 & 0,02 & 1 & RS 17,00 & 0,34 \\
\hline Lula & $\mathrm{kg}$ & 0.02 & 0,02 & 1 & 15,50 & 0,31 \\
\hline Mexilhão & $\mathrm{kg}$ & 0,02 & 0,02 & 1 & 14,50 & 0,29 \\
\hline Camarão & $\mathrm{kg}$ & 0,082 & 0,02 & 4,1 & 16,50 & 1,353 \\
\hline Lagosta & $\mathrm{kg}$ & 0,0556 & 0,02 & 2,78 & 45,00 & 2,502 \\
\hline Oleo & litro & 0,02 & 0,02 & 1 & 2,35 & 0,047 \\
\hline Tomate & $\mathrm{kg}$ & 0,03 & 0,02 & 1,5 & 2,00 & 0,06 \\
\hline Cebola & $\mathrm{kg}$ & 0,024 & 0,02 & 1,2 & 1,50 & 0,036 \\
\hline Pimentão verde & $\mathrm{kg}$ & 0,0314 & 0,02 & 1,57 & 278 & 0,087292 \\
\hline Coentro & $\mathrm{kg}$ & 0,025 & 0,02 & 1,25 & 3,00 & 0,075 \\
\hline Salsa & $\mathrm{kg}$ & 0,0025 & 0,002 & 1,25 & 3,00 & 0,0075 \\
\hline Cebolinha & $\mathrm{kg}$ & 0,0025 & 0,002 & 1,25 & 3,00 & 0,0075 \\
\hline Sal & $\mathrm{kg}$ & 0,002 & 0,002 & 1 & 2,00 & 0,004 \\
\hline pimenta & $\mathrm{kg}$ & 0,001 & 0,001 & 1 & 4,00 & 0,004 \\
\hline Extrato de tomate & $\mathrm{kg}$ & 0,2 & 0,2 & 1 & 5,99 & 1,198 \\
\hline Alho & $\mathrm{kg}$ & 0,01 & 0,01 & 1 & 8,50 & 0,085 \\
\hline Porção de arroz branco 18) & $\mathrm{kg}$ & & 0,1 & & 1,75 & 1,75 \\
\hline Porçäo de farofa de banana (21) & $\mathrm{kg}$ & & 0,01 & & & 0,23 \\
\hline TEMPO MEDIO DE PREPARO: $10 \mathrm{~min}$ & CUSTODOS INGR & EDIENTES & & & & 8,39 \\
\hline \multicolumn{7}{|c|}{$\begin{array}{l}\text { MODO DE PREPARO: 1.Refogar a cebola, o alho, os pimentões e os frutos do mar em azeite de oliva, acrescentar o extrato de tomate, os tomates e água; } \\
\text { 2. Cozinhar por cerca de } 10 \text { minutos para incorporar os sabores. }\end{array}$} \\
\hline Rendimento(Kg) & 0,417 & & \multirow{2}{*}{\multicolumn{4}{|c|}{ porção }} \\
\hline Porção(R\$/Kg) & \#REF! & & & & & \\
\hline
\end{tabular}




\begin{tabular}{|c|c|c|c|c|c|c|}
\hline Tipo de produto & Principal & & & & & \\
\hline Item & Merluza empanada & & & & & \\
\hline INGREDIENTES & UNIDADE DE MEDIDA & PESO BRUTO & PESO LIQUIDO & JFATOR DE CORRECCAO & CUSTO UNIT & \begin{tabular}{|l|} 
CUSTO TOTAL \\
\end{tabular} \\
\hline File de merluza & $\mathrm{kg}$ & 0,2988 & 0,18 & 1,66 & $\begin{array}{|lr|}\text { RS } & 8,50 \\
\end{array}$ & 2,5398 \\
\hline Massa para empanados & $\mathrm{kg}$ & 0,1 & 0,1 & 1 & 12,00 & 1,2 \\
\hline Arroz branco (18) & porção & 1 & 1 & 1 & & 0,23 \\
\hline Hortaliças refogadas (23) & porção & 1 & 1 & 1 & & \\
\hline Maionese de estragão & $\mathrm{kg}$ & 0.025 & 0,025 & 1 & 10,00 & 0,25 \\
\hline sal & litro & 0,02 & 0,02 & 1 & 2,00 & 0,04 \\
\hline pimenta & \begin{tabular}{l|l}
$\mathrm{kg}$ & \\
\end{tabular} & 0,01 & 0,01 & 1 & 4,00 & 0,04 \\
\hline TEMPO MEDIO DE PREPARO: 1 & CUSTO DOS INGRED & \begin{tabular}{|l|l|} 
IENTES \\
\end{tabular} & & & & 6,30 \\
\hline \multirow{2}{*}{\multicolumn{7}{|c|}{ MODO DE PREPARO: 1. Temperar o peixe com sal e pimenta e passar pela massa de empanar; 2.Fritar por imersão. }} \\
\hline \begin{tabular}{|l|l} 
Rendimento(kg) \\
Porcão(R\$/kg)
\end{tabular} & 0,28 & & \multirow{2}{*}{\multicolumn{4}{|c|}{1 porção }} \\
\hline Porção(R\$/kg) & \#REF! & & & & & \\
\hline
\end{tabular}




\begin{tabular}{|c|c|c|c|c|c|c|}
\hline \multirow{2}{*}{$\begin{array}{l}\text { Tipo de produto } \\
\text { Item }\end{array}$} & \multicolumn{6}{|l|}{ Principal } \\
\hline & \multicolumn{6}{|c|}{ Spaghetti com frutos do mar } \\
\hline INGREDIENTES & UNIDADE DE MEDIDA & PESO BRUTO & PESO LIQUIDO & FATOR DE CORRECCAO & CUSTO UNIT & CUSTO TOTAL \\
\hline Sapghetti cozido & $\mathrm{kg}$ & 0,2 & \begin{tabular}{|c|}
0,2 \\
\end{tabular} & 1 & \begin{tabular}{|ll} 
RS & 9,00 \\
\end{tabular} & 1,8 \\
\hline Camarăo sem casca & $\mathrm{kg}$ & 0,205 & 0,05 & 4.1 & 16,50 & 3,3825 \\
\hline Mexilão sem casca & $\mathrm{kg}$ & 0,05 & 0,05 & 1 & 14,50 & 0,725 \\
\hline Lula em aneis & $\mathrm{kg}$ & 0,05 & 0,05 & 1 & 15,50 & 0,775 \\
\hline Tomate picado sem pele e sem sementes & $\mathrm{kg}$ & 0,075 & 0,05 & 1,5 & 2,00 & 0.15 \\
\hline Alho amassado & $\mathrm{kg}$ & 0,005 & 0,005 & 1 & 5,99 & 0,02995 \\
\hline Cebola picada & $\mathrm{kg}$ & 0,036 & 0,03 & 1,2 & 1,50 & 0,054 \\
\hline Salsa picada & $\mathrm{kg}$ & 0,00125 & 0,001 & 1,25 & 3,00 & 0,00375 \\
\hline Vinho Branco & It & 0,03 & 0,03 & 1 & 6,00 & 0,18 \\
\hline Sal & $\mathrm{kg}$ & 0,002 & 0,002 & 1 & 2,00 & 0,004 \\
\hline Pimenta & $\mathrm{kg}$ & 0,001 & 0,001 & 1 & 4,00 & 0,004 \\
\hline Extrato de tomate & $\mathrm{kg}$ & 0,02 & 0,02 & 1 & 5,00 & 0,1 \\
\hline oleo & It & 0,02 & 0,02 & 1 & 2,35 & 0,047 \\
\hline TEMPO MÉDIO DE PREPARO: $10 \mathrm{~min}$ & CUSTO DOS INGRE & DIENTES & & & & 7,26 \\
\hline $\begin{array}{l}\text { MODO DE PREPARO: 1. Aquecer uma pa } \\
\text { temperados com sal e pimenta; } 4 \text {.Adiciona }\end{array}$ & $\begin{array}{l}\text { la e colocar o azeite; } 2 . J \\
\text { vinho e deixar reduzir; } 5\end{array}$ & $\begin{array}{l}\text { Untar o alho, a c } \\
\text { Juntar o spaghe }\end{array}$ & $\begin{array}{l}\text { bola e o extrato } \\
\text { ti, os tomates pic }\end{array}$ & $\begin{array}{l}\text { nate; } 3 \text {. Refogar por algun } \\
\text { e a salsa. }\end{array}$ & minutos e Jun & ir os frutos do mar \\
\hline Rendimento(kg) & 0,509 & & & & & \\
\hline Porção(R\$/kg) & \#REF! & 0,509 & & & & 53 \\
\hline
\end{tabular}




\begin{tabular}{|c|c|c|c|c|c|c|}
\hline Tipo de produto & Guarnição & & & & & \\
\hline Item & farofa de banana & & & & & \\
\hline $\begin{array}{l}\text { INGREDIENTES } \\
\end{array}$ & UNIDADE DE MEDIDA & PESO BRUTO & PESOLIQUIDO & FATOR DE CORRECCAO & CUSTOUNIT & CUSTO TOTAL \\
\hline Banana da terra cortada em cubos & $\mathrm{kg}$ & 0,48 & 0,4 & 1,2 & RS $\quad 3,90$ & 1,872 \\
\hline Cebola picada & $\mathrm{kg}$ & 0,048 & 0,04 & 1,2 & 1,50 & 0,072 \\
\hline Alho picado & $\mathrm{kg}$ & 0,01 & 0.01 & $\frac{1}{1}$ & 8.50 & 0,085 \\
\hline Farinha de mandioca & $\mathrm{kg}$ & 0,25 & 0.25 & 1 & 2,00 & 0,5 \\
\hline Sal & $\mathrm{kg}$ & 0,02 & 0.02 & 1 & 2,00 & 0.04 \\
\hline Pimenta & $\mathrm{kg}$ & 0,002 & 0,002 & 1 & RS 4,00 & 0,008 \\
\hline Margarina & $\mathrm{kg}$ & 0.1 & 0,1 & 1 & $\mathrm{R} \$ 14,00$ & $\frac{3,4}{1,4}$ \\
\hline $\begin{array}{l}\text { MODO DE PREPARO: 1. Refogar } \\
\text { mandioca e continuar a mexer por }\end{array}$ & $\begin{array}{l}\text { cebola e o alho nna ma } \\
\text { ais } 5 \text { minutos; } 4 \text {.Adiciol }\end{array}$ & $\begin{array}{l}\text { 2.Acrescental } \\
\text { pimenta. }\end{array}$ & s de banana da & a e refogar por mais um te & ipo; 3.Acrescent & ra farinha de \\
\hline Rendimento(kg) & 0,822 & & rçőes & & & \\
\hline Porção(R\$/kg) & \#REF! & & & & & 42 \\
\hline
\end{tabular}




\begin{tabular}{|c|c|c|c|c|c|c|}
\hline \multirow{2}{*}{$\begin{array}{l}\text { Tipo de produto } \\
\text { Item }\end{array}$} & Principal & & & & & \\
\hline & \multicolumn{6}{|l|}{ Fetuccine com camarão } \\
\hline \begin{tabular}{|l} 
INGREDIENTES \\
\end{tabular} & UNIIDADE DE MEDIDA & PESO BRUTO & PESO LIQUIDO & FATOR DE CORREÇAO & CUSTO UNIT & CUSTO TOTAL \\
\hline Fettucine cozido & $\mathrm{kg}$ & 0,23 & 0,23 & 1 & $\begin{array}{|ll|}\text { RS } & 5,00 \\
\end{array}$ & $\begin{array}{r}1,15 \\
\end{array}$ \\
\hline Camarão & $\mathrm{kg}$ & 0,492 & 0,12 & 4,1 & 16,50 & 8,118 \\
\hline Tomate sem pele e sem semente & $\mathrm{kg}$ & 0,075 & 0,05 & 1,5 & 2,00 & 0,15 \\
\hline Alho amassado & $\mathrm{kg}$ & 0,01 & 0,01 & 1 & 5,90 & 0,059 \\
\hline Cebola picada & $\mathrm{kg}$ & 0,048 & 0,04 & 1,2 & 1,50 & 0,072 \\
\hline Oleo & $\mathrm{kg}$ & 0,025 & 0,025 & 1 & 2,35 & 0,05875 \\
\hline Sal & $\mathrm{kg}$ & 0,002 & 0,002 & 1 & 2,00 & 0,004 \\
\hline Pimenta & $\mathrm{kg}$ & 0,001 & 0,001 & 1 & 4,00 & 0,004 \\
\hline Caldo de camarão & $\mathrm{kg}$ & 0 & & 1 & RS & \\
\hline Salsa picada grosseiramente & $\mathrm{kg}$ & 0,00125 & 0,001 & 1,25 & 3,00 & 0,00375 \\
\hline Manjericão fresco & $\mathrm{kg}$ & 0,0025 & 0,002 & 1,25 & 4,00 & 0.01 \\
\hline Extrato de tomate & $\mathrm{kg}$ & 0,02 & 0,02 & 1 & 5,00 & 0,1 \\
\hline \multirow{2}{*}{\multicolumn{7}{|c|}{$\begin{array}{l}\text { MODO DE PREPARO: 1. Aquecer uma panela e colocar o azeite; } 2 \text {. Juntar o camarão temperado com sal e pimenta, em seguida } 0 \text { alho, a cebola e o extrato de tomate; } \\
\text { 3.Refogar por alguns minutos e juntar os tomates; } 4 \text {. Deixar cozinhar até os tomates se desmancharem; } 5 \text {. Adicione o fettucine e aquecer, por ultimo juntar as folhas de } \\
\text { manjericão. }\end{array}$}} \\
\hline & & & & & & \\
\hline Rendimento(kg) & 0,501 & & & & & \\
\hline Porção(RS/kg) & \#REF! & 0,381 & & & & \\
\hline
\end{tabular}




\begin{tabular}{|c|c|c|c|c|c|c|}
\hline \multirow{2}{*}{$\begin{array}{l}\text { Tipo de produto } \\
\text { Item }\end{array}$} & \multicolumn{6}{|l|}{ Principal } \\
\hline & \multicolumn{6}{|c|}{ Risoto de frutos do mar } \\
\hline INGREDIENTES & UNIDADE DE MEDIDA & PESO BRUTO & PESO LIQUIDO & FATOR DE CORREÇAO & CUSTO UNIT & CUSTO TOTAL \\
\hline Fundo para risoto & $\mathrm{kg}$ & 0 & & & & \\
\hline Cebola picada & $\mathrm{kg}$ & 0,072 & 0.06 & 1,2 & 1,50 & 0,015 \\
\hline Alho amassado & $\mathrm{kg}$ & 0,01 & 0,01 & 1 & 5,99 & 0,4792 \\
\hline Arroz arboreo & $\mathrm{kg}$ & 0,08 & 0,08 & 1 & 7,00 & 0,861 \\
\hline Camarão sem casca & $\mathrm{kg}$ & 0,123 & 0,03 & 4,1 & 16,50 & 0.495 \\
\hline Lula em aneis & $\mathrm{kg}$ & 0,03 & 0,03 & 1 & 15,50 & 0,465 \\
\hline Polvo & $\mathrm{kg}$ & 0,03 & 0,03 & 1 & 14,50 & 0,435 \\
\hline Mexilhão sem casca & $\mathrm{kg}$ & 0,03 & 0,03 & 1 & 14,50 & 0,2175 \\
\hline margarina & $\mathrm{kg}$ & 0,015 & 0,015 & 1 & 10,00 & 0,02 \\
\hline Sal & & 0,002 & 0,002 & 1 & 2,00 & 0,05 \\
\hline Oleo & $\mathrm{kg}$ & 0,025 & 0,025 & 1 & 2,35 & 0,0705 \\
\hline Vinho branco & $\mathrm{kg}$ & 0,03 & 0,03 & 1 & 10,00 & 0,75 \\
\hline Tomate picado sem pele e sem sementes & $\mathrm{kg}$ & 0,075 & 0,05 & 1,5 & 2,00 & 0,002 \\
\hline pimenta & $\mathrm{kg}$ & 0,001 & 0,001 & 1 & 4,00 & \\
\hline TEMPO MEDIO DE PREPARO: $10 \mathrm{~min}$ & CUSTO DOS INGF & EDIENTES & & & & $\begin{array}{r}3,86 \\
\end{array}$ \\
\hline \multicolumn{7}{|c|}{$\begin{array}{l}\text { MODO DE PREPARO: 1. Numa panela aquecer o oleo, juntar o alho e a cebola; 2.Refogar até que fiquem transparentes; } 3 \text {.Juntar o arroz e mexer, adiconar o vinho branco } \\
\text { e deixe secar; 4.Adiconar o fundo até cobrir o arroz e continuar mexendo, à medida que o fundo for secando, adicionar mais fundo sem parar de mexer; } 5 \text {.Em outra panela } \\
\text { aquecer o azeite e refogar os frutos do mar temperados com sal e pimenta e junte ao arroz; } 6 \text {. Finalizar com a manteiga e os tomates. }\end{array}$} \\
\hline Rendimento $(\mathrm{kg})$ & 0,393 & & oorção & & & \\
\hline Porção(R\$/kg) & \#REF! & & & & & \\
\hline
\end{tabular}




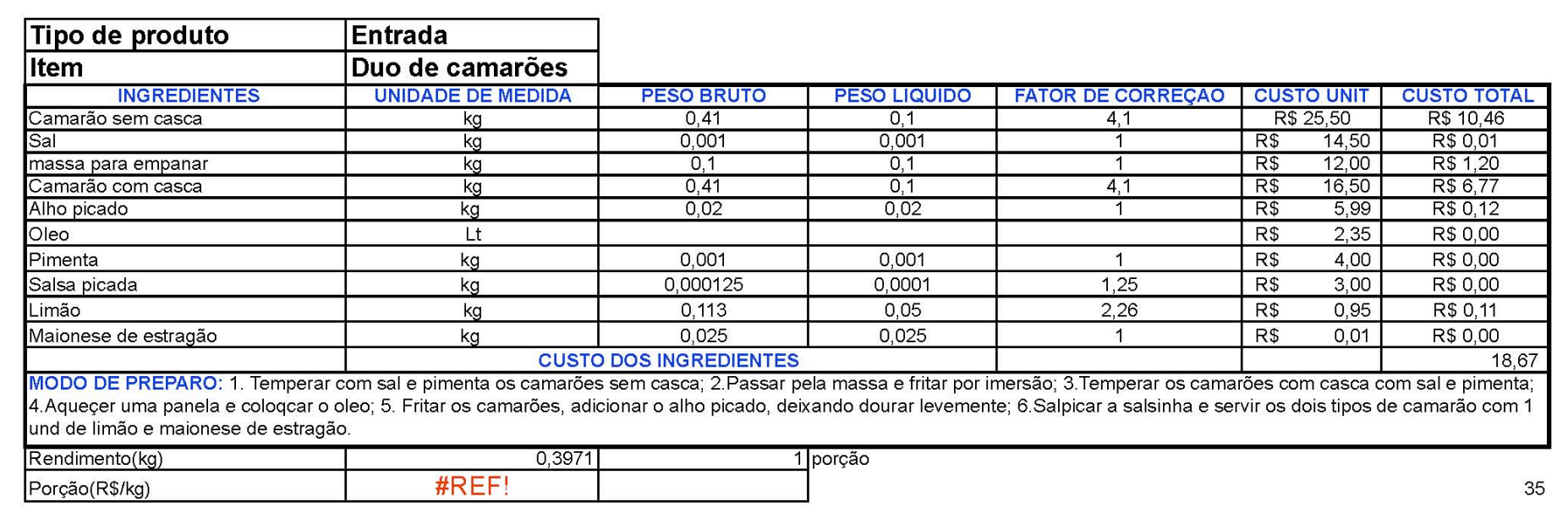




\begin{tabular}{|c|c|c|c|c|c|c|}
\hline Tipo de produto & Principal & & & & & \\
\hline Item & Talharim bacalhau & & & & & \\
\hline INGREDIENTES & UNIDADE DE MEDIDA & PESO BRUTO & PESO LIQUIDO & FATOR DE CORRECAO & CUSTO UNIT & CUSTO TOTAL \\
\hline Talharin cozido & $\mathrm{kg}$ & 0,23 & 0,23 & 1 & RS 8,00 & 1,84 \\
\hline Cebola & $\mathrm{kg}$ & 0,012 & 0,01 & 1,2 & 1,50 & 0,018 \\
\hline Alho picado & $\mathrm{kg}$ & 0,002 & 0,002 & 1 & 5,99 & 0,01198 \\
\hline Bacalhau desfiado e dessalgado & $\mathrm{kg}$ & 0,378 & 0,15 & 2,52 & 19,50 & 7,371 \\
\hline Azeitonas pretas & $\mathrm{kg}$ & 0,0264 & 0,02 & 1,32 & 8,25 & 0,2178 \\
\hline Molho bechamel porção (26) & porção & 0,1 & 01 & 1 & 11,15 & 1,115 \\
\hline Oleo & $\mathrm{kg}$ & $\begin{array}{l}0,025 \\
\end{array}$ & 0,025 & 1 & RS & 0,05975 \\
\hline TEMPO MEDIO DE PREPARO: $10 \mathrm{mi}$ & CUSTO DOS INGREL & IENTES S & & & & 10,63 \\
\hline MODO DE PREPARO: 1. Refogar o ba & & & & & & \\
\hline$\frac{\text { Rendimento(kg) }}{\text { Porção(R\$/kg) }}$ & \#REF! & $\begin{array}{r}1 \\
0,537\end{array}$ & & & & 56 \\
\hline
\end{tabular}




\begin{tabular}{|c|c|c|c|c|c|c|}
\hline Tipo de produto & Principal & & & & & \\
\hline Item & \multicolumn{6}{|c|}{ Strogonoff de camarão } \\
\hline INGREDIENTES & UNIDADE DE MEDIDA & PESO BRUTO & PESO LIQUIDO & |FATOR DE CORREÇAO & CUSTO UNIT & \begin{tabular}{|l|} 
CUSTO TOTAL \\
\end{tabular} \\
\hline Camarão & $\begin{array}{c}\mathrm{kg} \\
\end{array}$ & 0,492 & \begin{tabular}{|c|}
0,12 \\
\end{tabular} & 4,1 & \begin{tabular}{|ll}
$R \$ \quad 16,50$ \\
\end{tabular} & $8,11 \varepsilon$ \\
\hline Catchup & $\mathrm{kg}$ & 0,03 & 0,03 & 1 & 6,00 & $0,1 \varepsilon$ \\
\hline Mostarda & $\mathrm{kg}$ & 0,015 & 0,015 & 1 & 6,00 & 0,09 \\
\hline Creme de leite de caixinha & $\mathrm{kg}$ & 0,1 & 0,1 & 1 & 10,00 & \\
\hline Cebola picada & $\mathrm{kg}$ & 0,012 & 0,01 & 1,2 & 1,50 & 0,018 \\
\hline Alho picado & $\mathrm{kg}$ & 0,05 & 0,05 & 1 & 5,99 & 0,2995 \\
\hline Sal & $\mathrm{kg}$ & 0,002 & 0,002 & 1 & 2,00 & 0,002 \\
\hline $\begin{array}{l}\text { Conhaque } \\
\end{array}$ & $\mathrm{kg}$ & 0,02 & 0,02 & 1 & 4.50 & 0,09 \\
\hline Champignon & $\mathrm{kg}$ & 0,02 & 0,02 & 1 & 8,00 & 0,16 \\
\hline TEMPO MEDIO DE PREPARO & CUSTO DOS INGRE & EDIENTES & & & & 9,96 \\
\hline \multicolumn{7}{|c|}{$\begin{array}{l}\text { MODO DE PREPARO: 1. Numa panela aquecida, refogar os camarões, em seguida o alho a cebola, acrescentar o conhaque e flambar; } 2 \text {. Acrescentar o } \\
\text { catchup, a mostarda o creme de leite e os champignons. }\end{array}$} \\
\hline \begin{tabular}{|l|} 
Rendimento(kg) \\
Porcão(R\$/kg)
\end{tabular} & 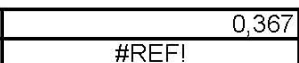 & & porção & & & 5 \\
\hline
\end{tabular}




\begin{tabular}{|c|c|c|c|c|c|c|}
\hline Tipo de produto & Principal & & & & & \\
\hline Item & Bobó de camarão & & & & & \\
\hline INGREDIENTES & UNIDADE DE MEDIDA & PESO BRUTO & PESO LIQUIDO & FATOR DE CORREÇAO & CUSTO UNIT & CUSTO TOTAL \\
\hline Molho do bobó de camarăo (porçăo) & $\mathrm{kg}$ & \begin{tabular}{l|}
0,15 \\
\end{tabular} & \begin{tabular}{|c|}
0,15 \\
\end{tabular} & 1 & \begin{tabular}{|l|l|} 
RS & 6,00 \\
\end{tabular} & $\begin{array}{r}0,9 \\
\end{array}$ \\
\hline Camarão & $\mathrm{kg}$ & 0,492 & 0,12 & 4,1 & 16,50 & 8,118 \\
\hline Leite de côco & litro & 0,03 & 0,03 & 1 & 10,00 & 0,3 \\
\hline Sal & litro & 0,002 & 0,002 & 1 & 2,00 & 0,004 \\
\hline Porção de arroz branco & 0,12 & 0 & & & & 0,23 \\
\hline Porção da fritas & - & 0 & & & & 0,96 \\
\hline TEMMPO MEDIO DE PREPARO: $10 \mathrm{~min}$ & CUSTO DOS INGRE & DIENTES & & & & 10,51 \\
\hline & RCENTUAL DE IMPOSTO & S SOBRE VENU & & & & \\
\hline Rendimento $(\mathrm{kg})$ & 0,302 & & orção & & & \\
\hline Porção(R\$/kg) & & & & & & 58 \\
\hline
\end{tabular}




\begin{tabular}{|c|c|c|c|c|c|c|}
\hline \multicolumn{2}{|c|}{ Tipo de produ|Principal } & & & & & \\
\hline Item & \multicolumn{6}{|c|}{ Hamburguer de frutos do mar } \\
\hline INGREDIENTES & \begin{tabular}{|l|l|} 
UNIDADE DE MEDIDA & \\
\end{tabular} & PESO BRUTO| & PESO LIQUIDO & |FATOR DE CORRECGAO & CUSTO UNIT & CUSTO TOTAL \\
\hline File de peixe & $\mathrm{kg}$ & \begin{tabular}{|l|}
1,66 \\
\end{tabular} & 1 & 1,66 & $\begin{array}{|ll|}\mathrm{R} \$ & 7.90 \\
\end{array}$ & 13,114 \\
\hline Camarão & $\mathrm{kg}$ & 1,23 & 0,3 & 4,1 & 16,50 & 20,295 \\
\hline Mexilhão & $\mathrm{kg}$ & 0,3 & 0,3 & 1 & 14,50 & 4,35 \\
\hline Cebola & und & 0,12 & 0,1 & 1,2 & 2,00 & 0,24 \\
\hline Alho & und & 0,005 & 0,005 & 1 & 5,99 & 0,02995 \\
\hline Sal & $\mathrm{kg}$ & 0,01 & 0.01 & 1 & 2,00 & 0,02 \\
\hline Pimenta & $\mathrm{kg}$ & 0,005 & 0,005 & 1 & 4,00 & 0,02 \\
\hline Farinha de rosca & $\mathrm{kg}$ & 0,01 & 0,01 & 1 & 3,90 & 0,039 \\
\hline Ovo & unidade & 0,24 & 0,24 & 1 & 1,50 & 0,36 \\
\hline Cheiro verde & \begin{tabular}{l|l}
$\mathrm{kg}$ & \\
\end{tabular} & 0,00625 & 0,005 & 1,25 & 3,00 & 0,01875 \\
\hline TEMPO MEDIO DE H & CUSTO DOS INGREDIE & \begin{tabular}{|l|l|} 
NTTES \\
\end{tabular} & & & & 38,49 \\
\hline \multicolumn{7}{|c|}{$\begin{array}{l}\text { MODO DE PREPARO: 1. Passar os frutos do mar num processador, temperar com sal e pimenta, adicionar o ovo e o cheiro verde; } 2 \text {.Usar a farinha de } \\
\text { rosca para dar o ponto do hamburguer; } 3 \text {. Espalhar a massa em uma assadeira e levarv à geladeira por cerca de } 12 \text { horas; } 4 \text {. Cortar os discos com ajuda de } \\
\text { um aro. }\end{array}$} \\
\hline$\frac{\text { Rendimento }(\mathrm{kg})}{\text { Porcão }(\mathrm{R} \$(\mathrm{~kg})}$ & \#REFI & \begin{tabular}{c|c|c|}
16 \\
012
\end{tabular} & porção & & & \\
\hline
\end{tabular}




\begin{tabular}{|c|c|c|c|c|c|c|}
\hline Tipo de produto & Principal & & & & & \\
\hline Item & Hamburguer de frutos & do mar & & & & \\
\hline INGREDIENTES & UNIDADE DE MEDIDA & PESO BRUTC & PEESO LIQUIDO & FATOR DE CORRECGAC & OCUSTO UNIT & CUSTO TOTAL \\
\hline Maionese de estragăo & & & & 1 & & $0,2^{2}$ \\
\hline Tomate fresco & $\mathrm{kg}$ & 0,03 & 0.02 & 15 & 2,00 & 0,06 \\
\hline Alface americana & $\mathrm{kg}$ & 0,046 & 0.04 & 1,15 & 4,00 & 0,184 \\
\hline Hamburguer de frutos do mar & porçãa & & & & 3.56 & 3,56 \\
\hline Porção de fritas & porção & 1 & 1 & 1 & 3,80 & 0,96 \\
\hline Päo de hamburguer & und & 1 & 1 & 1 & 0,7 & 0,7 \\
\hline TEMPO MEDIO DE PREPARO: & HSTO DOS INGREDIENTES & & & & & 5,714 \\
\hline MODO DE PREPARO: 1. Mont & ar o hamburguer com a alface & 8,0 tomate em & elas, o ham & uer e a maionese & gão. & \\
\hline
\end{tabular}




\begin{tabular}{|c|c|c|c|c|c|c|}
\hline \multicolumn{2}{|c|}{ Tipo de produ|Principal } & & & & & \\
\hline Item & \multicolumn{6}{|c|}{ Hamburguer de frutos do mar } \\
\hline INGREDIENTES & \begin{tabular}{|l|l|} 
UNIDADE DE MEDIDA & \\
\end{tabular} & PESO BRUTO| & PESO LIQUIDO & |FATOR DE CORRECGAO & CUSTO UNIT & CUSTO TOTAL \\
\hline File de peixe & $\mathrm{kg}$ & \begin{tabular}{|l|}
1,66 \\
\end{tabular} & 1 & 1,66 & $\begin{array}{|ll|}\mathrm{R} \$ & 7.90 \\
\end{array}$ & 13,114 \\
\hline Camarão & $\mathrm{kg}$ & 1,23 & 0,3 & 4,1 & 16,50 & 20,295 \\
\hline Mexilhão & $\mathrm{kg}$ & 0,3 & 0,3 & 1 & 14,50 & 4,35 \\
\hline Cebola & und & 0,12 & 0,1 & 1,2 & 2,00 & 0,24 \\
\hline Alho & und & 0,005 & 0,005 & 1 & 5,99 & 0,02995 \\
\hline Sal & $\mathrm{kg}$ & 0,01 & 0.01 & 1 & 2,00 & 0,02 \\
\hline Pimenta & $\mathrm{kg}$ & 0,005 & 0,005 & 1 & 4,00 & 0,02 \\
\hline Farinha de rosca & $\mathrm{kg}$ & 0,01 & 0,01 & 1 & 3,90 & 0,039 \\
\hline Ovo & unidade & 0,24 & 0,24 & 1 & 1,50 & 0,36 \\
\hline Cheiro verde & \begin{tabular}{l|l}
$\mathrm{kg}$ & \\
\end{tabular} & 0,00625 & 0,005 & 1,25 & 3,00 & 0,01875 \\
\hline TEMPO MEDIO DE H & CUSTO DOS INGREDIE & \begin{tabular}{|l|l|} 
NTTES \\
\end{tabular} & & & & 38,49 \\
\hline \multicolumn{7}{|c|}{$\begin{array}{l}\text { MODO DE PREPARO: 1. Passar os frutos do mar num processador, temperar com sal e pimenta, adicionar o ovo e o cheiro verde; } 2 \text {.Usar a farinha de } \\
\text { rosca para dar o ponto do hamburguer; } 3 \text {. Espalhar a massa em uma assadeira e levarv à geladeira por cerca de } 12 \text { horas; } 4 \text {. Cortar os discos com ajuda de } \\
\text { um aro. }\end{array}$} \\
\hline$\frac{\text { Rendimento }(\mathrm{kg})}{\text { Porcão }(\mathrm{R} \$(\mathrm{~kg})}$ & \#REFI & \begin{tabular}{c|c|c|}
16 \\
012
\end{tabular} & porção & & & \\
\hline
\end{tabular}




\begin{tabular}{|c|c|c|c|c|c|c|}
\hline Tipo de produto & Principal & & & & & \\
\hline Item & Moqueca & & & & & \\
\hline INGREDIENTES & UNIDADE DE MEDIDA & PESO BRUTO & PESO LIQUIDO & |FATOR DE CORRECAO & CUSTO UNIT & CUSTO TOTAL \\
\hline Lula & $\mathrm{kg}$ & 0,02 & 0,02 & 1 & \begin{tabular}{|ll}
$\mathrm{R} \$$ & 14,50 \\
\end{tabular} & 0,29 \\
\hline Camarão & $\mathrm{kg}$ & 0,082 & 0,02 & 4,1 & 16,50 & 1,353 \\
\hline Merluza cortada em tiras & $\mathrm{kg}$ & 0,1992 & 0.12 & 1,66 & 8,50 & 1,6932 \\
\hline Oleo & litro & 0,02 & 0,02 & 1 & 2,35 & 0,047 \\
\hline Tomate & $\mathrm{kg}$ & 0,03 & 0,02 & 1,5 & 2,00 & 0,06 \\
\hline Cebola & $\mathrm{kg}$ & 0,024 & 0,02 & 1,2 & 1,50 & 0,036 \\
\hline Pimentão verde & $\mathrm{kg}$ & 0,0314 & 0,02 & 1,57 & 2,78 & 0,087292 \\
\hline Coentro & $\mathrm{kg}$ & 0,0025 & 0,002 & 1,25 & 3,00 & 0,0075 \\
\hline Salsa & $\mathrm{kg}$ & 0,0025 & 0,002 & 1,25 & 3,00 & 0,0075 \\
\hline Cebolinha & $\mathrm{kg}$ & 0,0025 & 0,002 & 1,25 & 3,00 & 0,0075 \\
\hline Sal & $\mathrm{kg}$ & 0,002 & 0,002 & 1 & 2,00 & 0,004 \\
\hline Pimenta & $\mathrm{kg}$ & 0.001 & 0,001 & 1 & 4,00 & 0,004 \\
\hline Leite de coco & $\frac{\text { litro }}{\text { lito }}$ & 0,02 & 0,02 & 1 & 9,60 & 0,192 \\
\hline Azeite de dende & litro & 0,02 & 0,02 & 1 & 5,00 & 0,1 \\
\hline Extrato de tomate & $\mathrm{kg}$ & 0,02 & 0,02 & 1 & 5,00 & 0,1 \\
\hline Alho & $\mathrm{kg}$ & 0,01 & 0,01 & 1 & 5,99 & 0,0599 \\
\hline Porção de arroz branco & porção & 0 & 1 & & & 0,23 \\
\hline Porção de farofa de banana & porcăo & 0 & 1 & & & 1,75 \\
\hline TEMPO MEDIO DE PREPARO: & CUSTO DOS INGR & DIENTES & & & & 6,03 \\
\hline $\begin{array}{l}\text { MODO DE PREPARO: 1. Numa } \\
\text { sal e pimenta; } 3 \text {. Em seguida, acr } \\
\text { cerca de } 5 \text { minutos para incorpora }\end{array}$ & $\begin{array}{l}\text { panela aqucida, acrescent } \\
\text { escentar os pimentões, o e } \\
\text { ar os sabores. }\end{array}$ & $\begin{array}{l}\text { ir o azeite e ref } \\
\text { xtrato de tomat }\end{array}$ & $\begin{array}{l}\text { i a cebola e o all } \\
\text { s tomates, o der }\end{array}$ & $\begin{array}{l}\text { רo; } 2 \text {. Juntar agua e adicio } \\
\text { רde e o leite de coco; } 4 \text {. Ac }\end{array}$ & $\begin{array}{l}\text { Os frutos do me } \\
\text { centar as ervas }\end{array}$ & $\begin{array}{l}\text { i temperados com } \\
\text { e cozinhar por }\end{array}$ \\
\hline Rendimento(kg) & 0,319 & & $\sqrt{\text { porção }}$ & & & \\
\hline Porção(R\$/kg) & \#REF! & & & & & 61 \\
\hline
\end{tabular}




\begin{tabular}{|c|c|c|c|c|c|c|}
\hline Tipo de produto & Principal & & & & & \\
\hline Item & Hamburguer de frutos & do mar & & & & \\
\hline INGREDIENTES & UNIDADE DE MEDIDA & PESO BRUTC & PEESO LIQUIDO & FATOR DE CORRECGAC & OCUSTO UNIT & CUSTO TOTAL \\
\hline Maionese de estragăo & & & & 1 & & $0,2^{2}$ \\
\hline Tomate fresco & $\mathrm{kg}$ & 0,03 & 0.02 & 15 & 2,00 & 0,06 \\
\hline Alface americana & $\mathrm{kg}$ & 0,046 & 0.04 & 1,15 & 4,00 & 0,184 \\
\hline Hamburguer de frutos do mar & porçãa & & & & 3.56 & 3,56 \\
\hline Porção de fritas & porção & 1 & 1 & 1 & 3,80 & 0,96 \\
\hline Päo de hamburguer & und & 1 & 1 & 1 & 0,7 & 0,7 \\
\hline TEMPO MEDIO DE PREPARO: & HSTO DOS INGREDIENTES & & & & & 5,714 \\
\hline MODO DE PREPARO: 1. Mont & ar o hamburguer com a alface & 8,0 tomate em & elas, o ham & uer e a maionese & gão. & \\
\hline
\end{tabular}




\begin{tabular}{|c|c|c|c|c|c|c|}
\hline Tipo de produto & Principal & & & & & \\
\hline Item & \multicolumn{6}{|c|}{ Merluza com espinafre } \\
\hline INGREDIENTES & UNIDADE DE MEDIDA & PESO BRUTO & PESO LIQUIDO & JFATOR DE CORRECAO & CUSTO UNIT & \begin{tabular}{|l} 
CUSTO TOTAL \\
\end{tabular} \\
\hline File de merluza & $\mathrm{kg}$ & 0,2988 & 0,18 & 1,66 & \begin{tabular}{|lr}
$\mathrm{RS}$ & 8,50 \\
\end{tabular} & $\begin{array}{r}2,5398 \\
\end{array}$ \\
\hline Molho bechamel & porçao & 0,1 & 0,1 & 1 & 11,15 & 1,115 \\
\hline Espinafre & $\mathrm{kg}$ & 0,0895 & 0,05 & 1,79 & 5,00 & 0,4475 \\
\hline oleo & $\mathrm{kg}$ & 0,02 & 0,02 & 1 & 2,35 & 0,047 \\
\hline pimenta & $\mathrm{kg}$ & 0,001 & 0,001 & 1 & 4,00 & 0,004 \\
\hline Arroz branco & porçao & 0 & 1 & & & 0,23 \\
\hline Batata frita & porçao & 0 & 1 & & & 0,96 \\
\hline sal & $\mathrm{kg}$ & 0 & 0,002 & & 2,00 & \\
\hline TEMPO MEDIO DE PREPA & \multicolumn{2}{|c|}{ CUSTO DOS INGREDIENTES } & & & & 5,34 \\
\hline \multicolumn{7}{|c|}{$\begin{array}{l}\text { MODO DE PREPARO: 1. Temperar o peixe com sal e pimenta e numa frigideira aquecida com oleo, saltear o peixe; } 2 \text {.Refogar o espinafre em um pouco } \\
\text { de oleo, juntar o molho bechamel e bater no liquidificador. }\end{array}$} \\
\hline Rendimento $(\mathrm{kg})$ & \multirow{2}{*}{\multicolumn{2}{|c|}{0,351}} & \multirow{2}{*}{\multicolumn{4}{|c|}{1 porção }} \\
\hline Porção(R\$/kg) & & & & & & \\
\hline
\end{tabular}




\begin{tabular}{|c|c|c|c|c|c|c|}
\hline Tipo de produto & Principal & & & & & \\
\hline Item & Camarão na abobora & & & & & \\
\hline INGREDIENTES & UNIDADE DE MEDIDA & PESO BRUTO & PESO LIQUIDO & FATOR DE CORRE & CUSTO UNIT & CUSTO TOTAL \\
\hline Camarão & $\begin{array}{c}\mathrm{kg} \\
\end{array}$ & 0,984 & \begin{tabular}{|c|}
0,24 \\
\end{tabular} & 4,1 & $\begin{array}{|ll|}\text { RS } & 16,50 \\
\end{array}$ & 16,236 \\
\hline Sal & $\mathrm{kg}$ & 0,002 & 0,002 & 1 & 2,00 & 0,004 \\
\hline Pimenta & $\mathrm{kg}$ & 0,001 & 0,001 & 1 & 4,00 & 0,004 \\
\hline Abobora pequena & $\mathrm{kg}$ & 0,3 & 0,3 & 1 & 2,00 & 0,6 \\
\hline Abobora cozida e amassada & $\mathrm{kg}$ & 0,1064 & 0,08 & 1,33 & 1,00 & 0,1064 \\
\hline Cebola picada & $\mathrm{kg}$ & 0,0012 & 0,001 & 1,2 & 1,50 & 0,0018 \\
\hline Alho amassado & $\mathrm{kg}$ & 0,01 & 0,01 & 1 & 5,99 & 0,0599 \\
\hline Leite & $\mathrm{kg}$ & 0,05 & 0,05 & 1 & 1,98 & 0,099 \\
\hline Queijo catupiry & $\mathrm{kg}$ & 0,06 & 0,06 & 1 & 19,40 & 1,164 \\
\hline Arroz de coco & porção & 0 & 1 & & 0,80 & 0,7 \\
\hline Batata frita porção (1) & \begin{tabular}{|l|l} 
porção & \\
\end{tabular} & 0 & 1 & & 0,48 & 0,96 \\
\hline TEMPO MEDIO DE PREPARO: 10 & \begin{tabular}{|l|} 
CUSTO DOS INGREDI \\
\end{tabular} & ENTES & & & & $\begin{array}{r}19,94 \\
\end{array}$ \\
\hline \multicolumn{7}{|c|}{$\begin{array}{l}\text { MODO DE PREPARO: 1. Cozinhar no forno as mini aboboras cobertas com papel aluminio até ficarem macias; 2. Tirar a polpa e sementes; 3.Para o molho: bater a } \\
\text { abobora cozida com leite e catupiry; } 3 \text {. Numa frigideira puxar os camarões temperados com sal e pimenta, acrescentar alho e cebola; } 4 \text {. Tirar } 3 \text { unidades para } \\
\text { decoração; } 5 \text {.Adicionar o creme de abobora e ajustar o sal; Servir dentro da abobora. }\end{array}$} \\
\hline Rendimento $(\mathrm{kg})$ & 0,744 & & jporção & & & \\
\hline
\end{tabular}




\begin{tabular}{|c|c|c|c|c|c|c|}
\hline Tipo de produto & Principal & & & & & \\
\hline Item & Camarão na abobora & & & & & \\
\hline INGREDIENTES & UNIDADE DE MEDIDA & PESO BRUTO & |PESO LIQUIDO & |FATOR DE CORRECCAO & CUSTO UNIT & CUSTO TOTAL \\
\hline Arroz cozido & $\mathrm{kg}$ & 0,205 & 0,05 & 4,1 & $\begin{array}{|ll|}\mathrm{R} \$ & 3,00 \\
\end{array}$ & 0,615 \\
\hline Azeite de oliva composto & It & 0,03 & 0,03 & 1 & 4,90 & 0,147 \\
\hline Açafrão & $\mathrm{kg}$ & 0,002 & 0,002 & 1 & 20,00 & 0,04 \\
\hline Lula & $\mathrm{kg}$ & 0,05 & 0,05 & 1 & 15,50 & 0,775 \\
\hline Polvo & $\mathrm{kg}$ & 0.05 & 0,05 & 1 & 14,50 & 0,725 \\
\hline Mexilhão & $\mathrm{kg}$ & 0,05 & 0,05 & 1 & 14,50 & 0,725 \\
\hline Camarão & $\mathrm{kg}$ & 0,205 & 0,05 & 4,1 & 16,50 & 3,3825 \\
\hline Cebola & $\mathrm{kg}$ & 0,036 & 0,03 & 1,2 & 1,50 & 0,054 \\
\hline Alho & $\mathrm{kg}$ & 0,005 & 0,005 & 1 & 8,50 & 0,0425 \\
\hline Pimentão verde & $\mathrm{kg}$ & 0,03925 & 0,025 & 1,57 & 2,00 & 0,0785 \\
\hline Pimentão vermelho & $\mathrm{kg}$ & 0,03925 & 0,025 & 1,57 & $\begin{array}{|ll|}\mathrm{R} \$ & 6,90 \\
\end{array}$ & 0,270825 \\
\hline Camarão ou lagostin para decorar & $\mathrm{kg}$ & 0,1 & 0,1 & 1 & $R \$ 25,00$ & 2,5 \\
\hline Ervilha verde & $\mathrm{kg}$ & 003 & 0,03 & 1 & $\mathrm{RS} \quad 15,00$ & 0.45 \\
\hline TEMPO MEDIO DE PREPARO: $10 \mathrm{~min}$ & CUSTO DOS INGRE & IENTES & & & & 9,81 \\
\hline $\begin{array}{l}\text { MODO DE PREPARO: } 1 \text {. Refogar a ceb } \\
\text { a lula tem um tempo de cocção rápido); } \\
\text { o prato. }\end{array}$ & $\begin{array}{l}\text { ola e alho no azeite, acresce } \\
\text { 2. Adicionar o arroz, e os dem }\end{array}$ & $\begin{array}{l}\text { ntar a mistura de } \\
\text { ais ingredeitnes }\end{array}$ & $\begin{array}{l}\text { açafrão e os frut } \\
\text { e colocar o fundo }\end{array}$ & o mar (lembrando que o & $\begin{array}{l}\text { olvo já estará pre } \\
\text { stin no fundo de }\end{array}$ & $\begin{array}{l}\text { viamente pronto e } \\
\text { camarão e decorar }\end{array}$ \\
\hline Rendimento(kg) & 0,497 & & porção & & & \\
\hline Porção( $(\mathrm{R} / \mathrm{kg})$ & & & & & & 65 \\
\hline
\end{tabular}




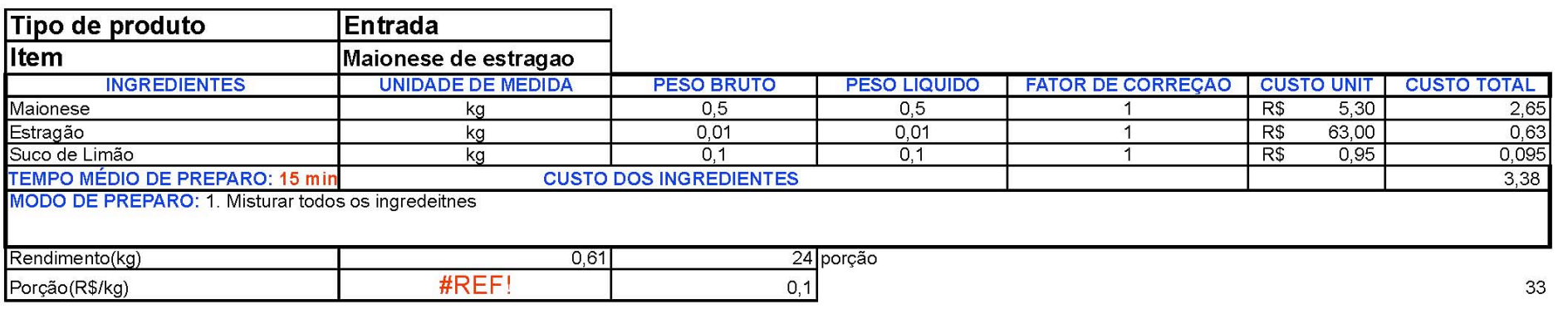




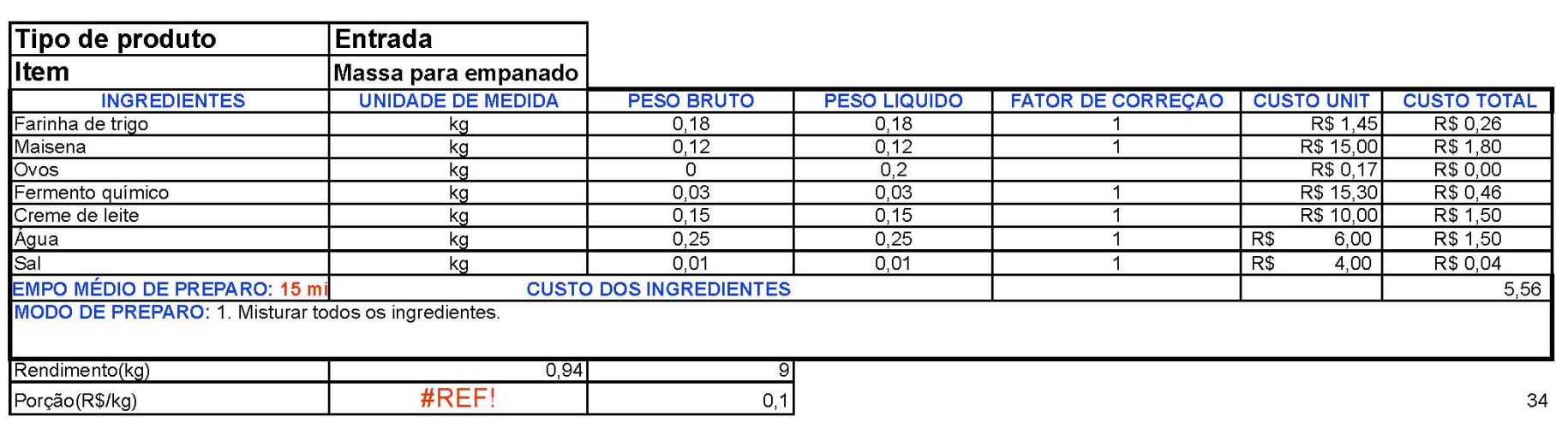




\begin{tabular}{|c|c|c|c|c|c|c|}
\hline Tipo de produto & Principal & & & & & \\
\hline Item & Molho bechamel & & & & & \\
\hline INGREDIENTES & UNIDADE DE MEDIDA & PESO BRUTO & PESO LIQUIDO & FATOR DE CORREÇAO & CUSTO UNIT & CUSTO TOTAL \\
\hline Farinha de trigo & $\mathrm{kg}$ & 0,06 & 0,06 & 1 & $\begin{array}{|ll|}R \$ & 2,00 \\
\end{array}$ & 0,12 \\
\hline Margarina & $\mathrm{kg}$ & 0,06 & 0,06 & 1 & 14,00 & 0,84 \\
\hline Leite & $\mathrm{Lt}$ & 1 & 1 & 1 & 1,98 & 1,98 \\
\hline Louro & folha & 1 & 1 & 1 & 4,00 & \\
\hline Cebola & $\mathrm{kg}$ & 0 & 0,04 & & 1,50 & \\
\hline Sal & $\mathrm{kg}$ & 0,01 & 0,01 & 1 & 2,00 & 0,02 \\
\hline Pimenta & $\mathrm{kg}$ & 0,002 & 0,002 & 1 & 4 & 0,008 \\
\hline TEMPO MEDIO DE PREPAR & CUSTO DOS INGREDIENTES S & EM IMPOSTOS & & & & 6,97 \\
\hline $\begin{array}{l}\text { MODO DE PREPARO: } 1 . E m \\
\text { mexer por alguns minutos; } 3 . J\end{array}$ & $\begin{array}{l}\text { uma panela aquecer o leite com a } \\
\text { untar o leite ao roux, aos poucos, } s\end{array}$ & $\begin{array}{l}\text { cebola e o louro } \\
\text { sem parar de me }\end{array}$ & $\begin{array}{l}\text { 2. Numa outra } \mathrm{pe} \\
\text { exer; } 4 \text { Colocar sa }\end{array}$ & ta colocar a margarina e & $\begin{array}{l}\text { ixar derreter, ac } \\
\text { a de } 10 \text { minutos }\end{array}$ & $\begin{array}{l}\text { dicione a farinha e } \\
\text { s. }\end{array}$ \\
\hline Rendimento(kg) & 2,172 & & porção & & & \\
\hline Porção(R\$/kg) & \#REF! & 0,1 & & & & 48 \\
\hline
\end{tabular}




\begin{tabular}{|c|c|c|c|c|c|c|}
\hline Tipo de produto & Molho & & & & & \\
\hline Item & Molho para bobó & & & & & \\
\hline INGREDIENTES & UNIDADE DE MEDIDA & PESO BRUTO & PESO LIQUIDO & FATOR DE CORREÇAO & CUSTO UNIT & CUSTO TOTAL \\
\hline Mandioca limpa & $\mathrm{kg}$ & 1 & 1 & 1 & $\begin{array}{ll}\mathrm{R} \$ & 0,75 \\
\end{array}$ & 0,75 \\
\hline Agua & litro & 3 & 3 & 1 & RS & \\
\hline Cebola picada & $\mathrm{kg}$ & 0,115 & 0,1 & 1,15 & 1,50 & 0,17 \\
\hline Alho picado & $\mathrm{kg}$ & 0,05 & 0,05 & 1 & 5,99 & 0,30 \\
\hline Pimentão vermelho em cubos & $\mathrm{kg}$ & 0,25 & 0,1 & 2,5 & 9,90 & 2,48 \\
\hline Pimentão amarelo em cubos & $\mathrm{kg}$ & 0,25 & 0,1 & 2,5 & 7,50 & 1,88 \\
\hline Pimentão verde verde em cubos & $\mathrm{kg}$ & 0,5 & 0,2 & 2,5 & 2,78 & 1,39 \\
\hline Azeite de dendê & litro & 0,125 & 0,05 & 2,5 & 3,00 & 0,38 \\
\hline Coentro picado & $\mathrm{kg}$ & 0,055 & 0,05 & 1,1 & 3,00 & 0,17 \\
\hline Cebolinha picada & $\mathrm{kg}$ & 0,055 & 0,05 & 1,1 & 3,00 & 0,17 \\
\hline Tomates em cubos & $\mathrm{kg}$ & 0,3 & 0,2 & 1,5 & 2,00 & 0,60 \\
\hline Sal & $\mathrm{kg}$ & 0,05 & 0,05 & 1 & 2,00 & 0,10 \\
\hline Pimenta do reino & $\mathrm{kg}$ & 0,05 & 0,05 & 1 & 4,00 & 0,20 \\
\hline Extrato de tomate & $\mathrm{kg}$ & 0,2 & 0,2 & 1 & 5,00 & 1,00 \\
\hline Folha de louro & & 0,004 & 0,004 & 1 & 4,00 & 0,02 \\
\hline TEMPO MEDIO DE PREPARO: $15 \mathrm{~min}$ & CUSTO DOS II & KEDIENTES & & & & 9,58 \\
\hline
\end{tabular}
coco e acrescentar o sal

\begin{tabular}{|c|c|}
\hline Rendimento $(\mathrm{Kg})$ & 5,204 \\
\hline Porçăo(RS/Kg) & \#REF! \\
\hline
\end{tabular}




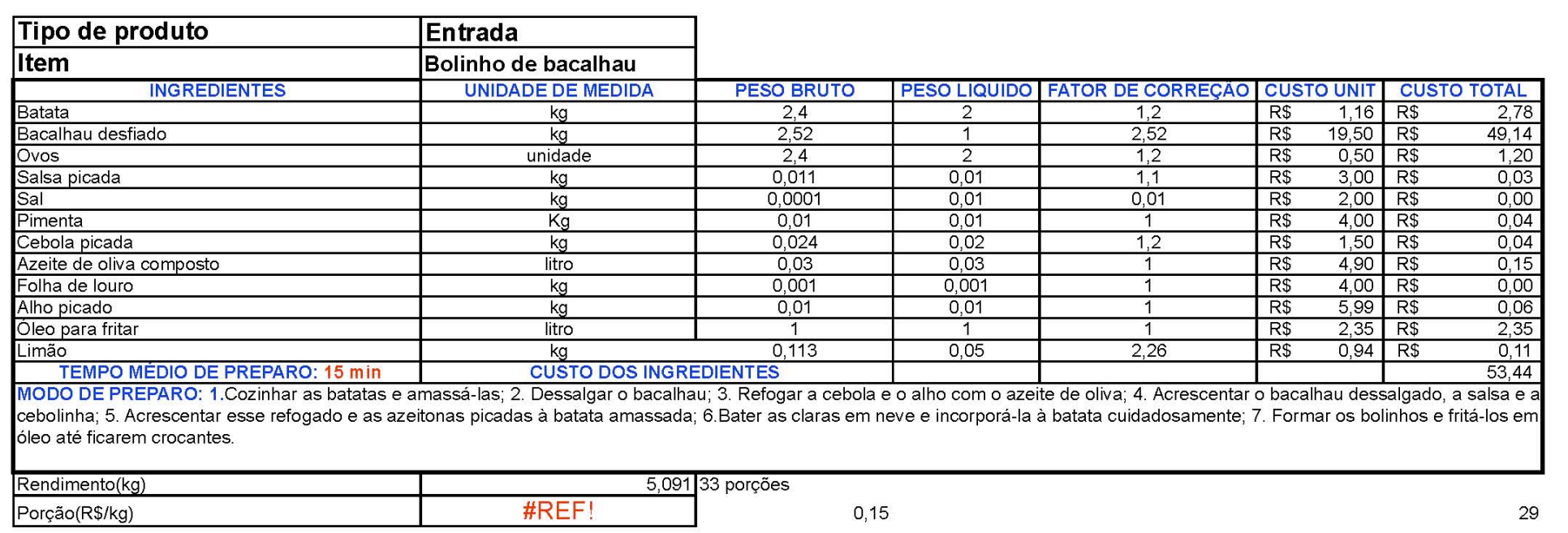




\begin{tabular}{|c|c|c|c|c|c|c|}
\hline Tipo de produto & Entrada & & & & & \\
\hline Item & Casquinha de siri & & & & & \\
\hline INGREDIENTES & UNIDADE DE MEDIDA & PESO BRUTO & PESO LIQUIDO & FATOR DE CORREÇAO & CUSTOUNIT & CUSTO TOTAL \\
\hline Carne de siri & $\mathrm{kg}$ & 0,8 & 0,8 & 1 & \begin{tabular}{|ll} 
RS & 14,00 \\
\end{tabular} & $\begin{array}{ll}\mathrm{R} \$ & 11,20 \\
\end{array}$ \\
\hline Salsa picada & $\frac{\mathrm{gg}}{\mathrm{kg}}$ & 0,0375 & 0,03 & 1,25 & 3,00 & 0,11 \\
\hline Coentro picado & $\frac{\mathrm{gg}}{\mathrm{kg}}$ & 0,0375 & 0,03 & $\frac{1,25}{1,25}$ & 3,00 & 0,11 \\
\hline Cebolinha picada & $\mathrm{kg}$ & 0,0375 & 0,03 & 1,25 & 3,00 & 0,11 \\
\hline Tomate picado & $\mathrm{kg}$ & 0,6 & 0,4 & 1,5 & 2,00 & 1,20 \\
\hline Cebola picada & $\mathrm{kg}$ & 0,12 & 0,1 & 1,2 & 1,50 & 0,18 \\
\hline Azeite de dende & litro & 0,1 & 0,1 & 1 & 3,00 & 0,30 \\
\hline Oleo & litro & 0,025 & 0,025 & 1 & 2,35 & 0,06 \\
\hline Alho amassado & $\mathrm{kg}$ & 0,04 & 0,04 & 1 & 5,99 & 0,24 \\
\hline Pimentão verde & $\mathrm{kg}$ & 0,157 & 0,1 & 1,57 & 2,78 & 0,44 \\
\hline Leite de coco & litro & 0,2 & 0,2 & 1 & 10,00 & 2,00 \\
\hline Sal & $\mathrm{Kg}$ & 0,05 & 0,05 & 1 & 2,00 & 0,10 \\
\hline Pimenta & $\mathrm{kg}$ & 0,02 & 0,02 & 1 & 4,00 & 0,08 \\
\hline Queijo parmesão & $\mathrm{kg}$ & 0,08 & 0,08 & 1 & 14,00 & 1,12 \\
\hline Farinha de rosca & $\mathrm{kg}$ & 0,15 & 0,15 & 1 & 4,00 & 0,60 \\
\hline Limão & $\frac{\mathrm{g}}{\mathrm{kg}}$ & 0,0226 & 0,01 & 2,26 & 1,94 & 0,04 \\
\hline TEMPO MEDIO DE PREPARO: $15 \mathrm{~min}$ & & CUSTODOSIN & REDIENTES & & & 17,90 \\
\hline $\begin{array}{l}\text { MODO DE PREPARO: } 1 \text {. Numa panela, } \\
\text { tomates, um pouco de água e o leite de } c \\
\text { com a farinha de rosca; } 8 \text {. Colocar nas for }\end{array}$ & cçer o oleo e juntar o alho & $\begin{array}{l}\text { esmanchar; } 6 \text { 6.Ju } \\
\text { solvilhar parmes }\end{array}$ & $\begin{array}{l}\text { o sal, a pime } \\
\text { lado; } 8 \text {. Gratin }\end{array}$ & ar a carne de siri e refog & $\begin{array}{l}\text { mais alguns minutos } \\
\text { o; 7. Deixar o caldo re } \\
\text { quarto de de limão. }\end{array}$ & $\begin{array}{l}\text { 4. Adicionar os } \\
\text { luzir; 8. Engrosse }\end{array}$ \\
\hline Rendimento $(\mathrm{kg})$ & 2,165 & 21 porções & & & & \\
\hline Porção(R\$/kg) & \#REF! & 0,1 & & & & 30 \\
\hline
\end{tabular}




\section{FICHA TÉCNICA DE PRODUÇÃO}

\begin{tabular}{|c|c|c|c|c|c|c|}
\hline Tipo de produto & Entrada & & & & & \\
\hline Item & Escondidinho & & & & & \\
\hline INGREDIENTES & UNIDADE DE MEDIDA & PESO BRUTO & PESO LIQUIDO & FATOR DE CORREÇAO & CUSTO UNIT & CUSTO TOTAL \\
\hline Mandioca & $\mathrm{kg}$ & 2 & 2 & 1 & $\begin{array}{ll}\mathrm{R} \$ & 0,75 \\
\end{array}$ & $\begin{array}{ll}\mathrm{R} \$ & 1,50 \\
\end{array}$ \\
\hline Creme de leite & $\mathrm{kg}$ & 0,1 & 0,1 & 1 & 10,00 & 1,00 \\
\hline margarina & $\mathrm{kg}$ & 0,08 & 0,08 & 1 & 8,00 & 0,64 \\
\hline Camarão & $\mathrm{kg}$ & 1,23 & 0,3 & 4,1 & 16,50 & 20,30 \\
\hline Lula & $\mathrm{kg}$ & 0,3 & 0,3 & 1 & 15,50 & 4,65 \\
\hline Mexilhão & $\mathrm{kg}$ & 0,3 & 0,3 & 1 & 14,50 & 4,35 \\
\hline Polvo & $\mathrm{kg}$ & 0,3 & 0,3 & 1 & 14,50 & 4,35 \\
\hline Cebola picada & $\mathrm{kg}$ & 0,24 & 0,2 & 1,2 & 1,50 & 0,36 \\
\hline Alho picado & $\mathrm{kg}$ & 0,08 & 0,08 & 1 & 5,99 & 0,48 \\
\hline $\begin{array}{l}\text { Coentro } \\
\end{array}$ & $\mathrm{kg}$ & 0,0625 & 0,05 & 1,25 & 3,00 & 0,19 \\
\hline Cebolinha & $\mathrm{kg}$ & 0,0625 & 0,05 & 1,25 & 3,00 & 0,19 \\
\hline Extrato de tomate & $\mathrm{kg}$ & 0,1 & 0,1 & 1 & 5,00 & 0,50 \\
\hline Queijo parmesão & $\mathrm{kg}$ & 0.1 & 0,1 & 1 & 16,00 & 1,60 \\
\hline Oleo & litro & 0,03 & 0,03 & 1 & 2,35 & 0,07 \\
\hline Sal & $\mathrm{kg}$ & 0,02 & 0,02 & 1 & 2,00 & 0,04 \\
\hline Pimenta & $\frac{\mathrm{kg}}{\mathrm{kg}}$ & 0,005 & 0,005 & 1 & 4,00 & 0,02 \\
\hline TEMPO MÉDIO DE PREPARO: $15 \mathrm{~min}$ & CUSTC & DOS INGREDIENTE & & & & 40,23 \\
\hline $\begin{array}{l}\text { 4.Refogar a cebola e o alho no azeite, coloc } \\
\text { colocar um pouco do puré de mandioca, o } \\
\text { forno aquecido ate o queijo derreter e servir }\end{array}$ & $\begin{array}{l}\text { ar os frutos do mar (lembra } \\
\text { echeio, e completar com ma }\end{array}$ & $\begin{array}{l}\text { e o polvo já estará } \\
\text { urê (OBS: não dev }\end{array}$ & her demais a & a, pois a mandioca aume & $\begin{array}{l}\text { eite e acrescentar o } \\
\text { de tomate em seguic } \\
\text { de volume!!). Polvill }\end{array}$ & $\begin{array}{l}\text { al e a pimenta; } \\
\text { a; } 5 \text {. MONTAGEM: } \\
\text { ar queijo, levar ao }\end{array}$ \\
\hline Rendimento(kg) & 4,01 & & çōes & & & \\
\hline Porção(R\$/kg) & \#REF! & 0,2 & & & & 31 \\
\hline
\end{tabular}




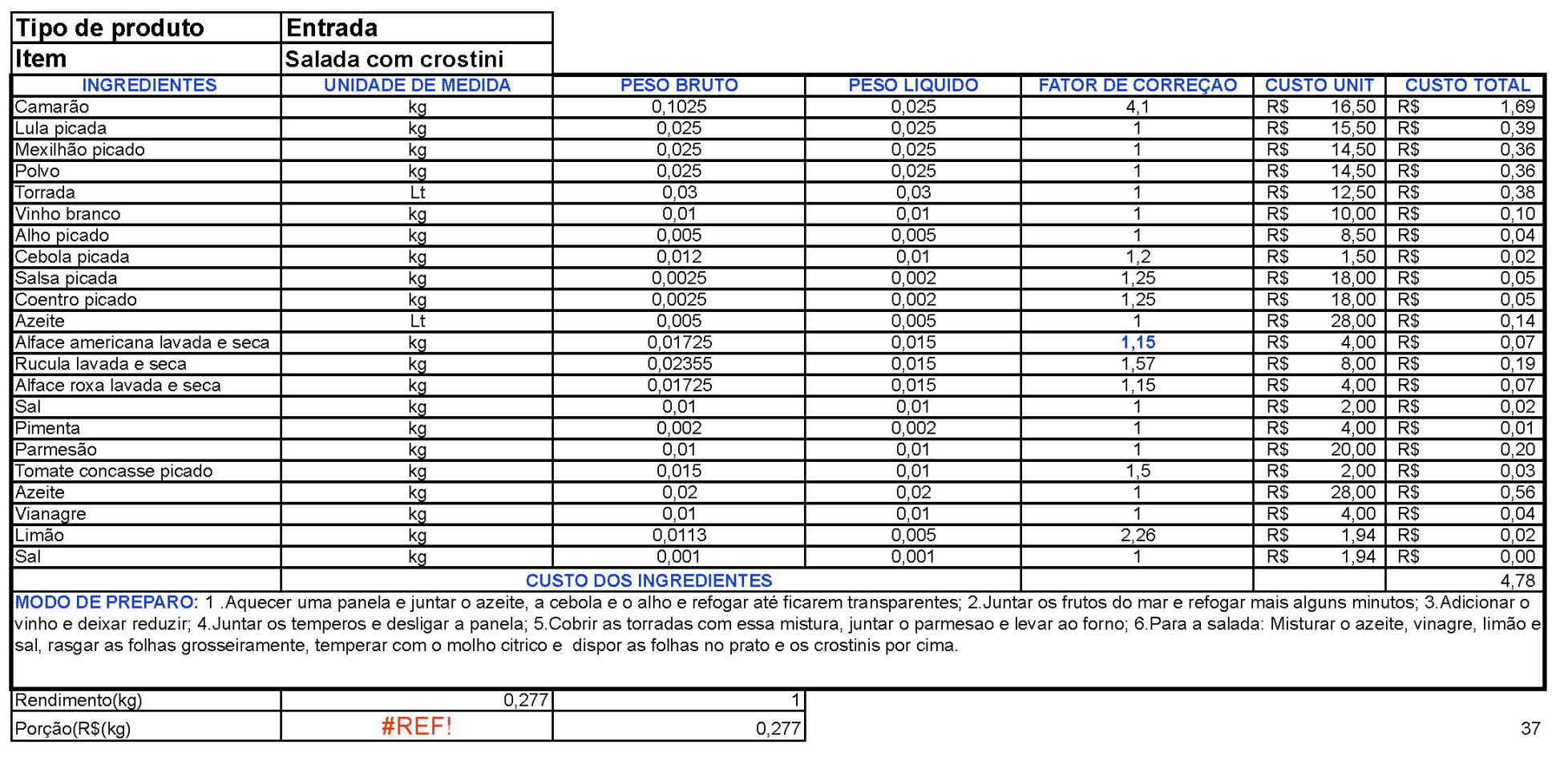




\begin{tabular}{|c|c|c|c|c|c|c|}
\hline \multirow{2}{*}{\begin{tabular}{|l} 
Tipo de produto \\
Item
\end{tabular}} & Entrada & & & & & \\
\hline & \multicolumn{6}{|l|}{ Salada de penne } \\
\hline INGREDIENTES & UNIDADE DE MEDIDA & PESO BRUTO & PESOLIQUIDO & FATOR DE CORREÇAO & CUSTO UNIT & CUSTO TOTAL \\
\hline Penne cozido & $\mathrm{kg}$ & 0,1 & 0,1 & 1 & RS $\quad 10,60$ & $\begin{array}{ll}\mathrm{R} \$ & 1,06 \\
\end{array}$ \\
\hline Lascas de salmão & $\mathrm{kg}$ & 0,217 & 0,1 & 2,17 & 19,50 & 4,23 \\
\hline Tomate picado & $\mathrm{kg}$ & 0,03 & 0,02 & 1,5 & 2,00 & 0,06 \\
\hline Salsa picada & $\mathrm{kg}$ & 0,00625 & 0,005 & 1,25 & 18,00 & 0,11 \\
\hline Cebola picada & $\mathrm{kg}$ & 0,024 & 0,02 & 1,2 & 1,50 & 0,04 \\
\hline Alho amassado & $\mathrm{kg}$ & 0,02 & 0,02 & 1 & 8,50 & 0,17 \\
\hline Pimentão Amarelo picado & $\mathrm{kg}$ & 0,0314 & 0,02 & 1,57 & 9,80 & 0,31 \\
\hline Azeitonas pretas picadas & $\mathrm{kg}$ & 0,0264 & 0,02 & 1,32 & 8,25 & 0,22 \\
\hline Mostarda & $\mathrm{kg}$ & 0,005 & 0,005 & 1 & 1,50 & 0,01 \\
\hline Maionese & $\mathrm{kg}$ & 0,002 & 0,002 & 1 & 5,30 & 0,01 \\
\hline Limão & $\mathrm{kg}$ & 0,0113 & 0,005 & 2,26 & 1,94 & 0,02 \\
\hline Sal & $\mathrm{kg}$ & 0,001 & 0.001 & 1 & 2,00 & 0,00 \\
\hline Pimenta & $\mathrm{kg}$ & 0,001 & 0,001 & 1 & 4,00 & 0,00 \\
\hline Alface americana lavada e seca & $\mathrm{kg}$ & 0,01725 & 0,015 & 1,15 & 4,00 & 0,07 \\
\hline \multirow[t]{3}{*}{ Alface roxa lavada e seca } & $\mathrm{kg}$ & 0,01725 & 0,015 & 1,15 & 4,00 & 0,07 \\
\hline & & & & 6,38 \\
\hline & \multicolumn{2}{|c|}{ PERCENTUAL DE IMPOSTOS SOBRE VENDAS } & & & & \\
\hline \multicolumn{7}{|c|}{$\begin{array}{l}\text { MODO DE PREPARO: } 1 \text {. Escalfar as lascas de salmäo em agua e sal e reservar; } 2 \text {.Misturar os demais ingredientes, exceto as folhas; } 3 \text {. Num prato colocar as follhas rasgadas e } \\
\text { por cima juntar a salada de penne e finalizar com as lascas de salmão. }\end{array}$} \\
\hline Rendimento $(\mathrm{kg})$ & \multirow[t]{2}{*}{0,349} & \\
\hline Porção(R\$/kg) & & \multicolumn{2}{|c|}{0,349} & & & 38 \\
\hline
\end{tabular}




\begin{tabular}{|c|c|c|c|c|c|c|}
\hline Tipo de produto & Guarnição & & & & & \\
\hline Item & Arroz branco & & & & & \\
\hline INGREDIENTES & UNIDADE DE MEDIDA & PESO BRUTO & PESO LIQUIDO & FATOR DE CORREÇAO & CUSTO UNIT & CUSTO TOTAL \\
\hline Arroz & $\mathrm{kg}$ & 0,04 & 0,04 & 1 & RS $\quad 2,00$ & 0,08 \\
\hline Oleo & $t$ & 0,005 & 0,005 & 1 & 2,35 & 0,01 \\
\hline Cebola picada & $\mathrm{kg}$ & 0.0024 & 0,002 & $\overline{1,2}$ & 1,50 & 0,00 \\
\hline \begin{tabular}{|l} 
Alho picado \\
\end{tabular} & $\frac{\mathrm{gg}}{\mathrm{kg}}$ & $0,0,001$ & $0,0,001$ & $\frac{1,2}{1}$ & $\frac{1,00}{5,99}$ & $\frac{0,001}{0,01}$ \\
\hline Agua & $\mathrm{Lt}$ & 0,08 & 0,08 & 1 & $\mathrm{RS}$ & \\
\hline Sal & $\mathrm{kg}$ & 0,002 & 0,002 & 1 & 2,00 & 0,00 \\
\hline & \multicolumn{3}{|c|}{ CUSTO DOS INGREDIENTES } & & & 0,11 \\
\hline \multicolumn{7}{|c|}{$\begin{array}{l}\text { MODO DE PREPARO: 1. Refogar a cebola e o alho no óleo, adicionar o arroz em seguidá; } 2 \text {.Refogar tudo por cerca de } 1 \text { minuto e adicionar o sal e a água; } 3 \text {.Cozinhar até que fique } \\
\text { como o grão cozido. OBS: o arroz deve ser feito com cuidado para que o que está mais proximo ao fundo da panela cozinhe e o que está na superfície permaneça cru. }\end{array}$} \\
\hline Rendimento(kg) & \multicolumn{2}{|c|}{0.13} & \multirow{2}{*}{\multicolumn{4}{|c|}{39}} \\
\hline Porção(R\$(kg) & \#REF! & & & & & \\
\hline
\end{tabular}




\begin{tabular}{|c|c|c|c|c|c|c|}
\hline Tipo de produto & Entrada & & & & & \\
\hline Item & Vinagrete & & & & & \\
\hline INGREDIENTES & UNIDADE DE MEDIDA & PESO BRUTO & PESO LIQUIDO & FATOR DE CORRECAAO & CUSTO UNIT & CUSTO TOTAL \\
\hline & $\mathrm{kg}$ & 0,025 & 0.025 & 1 & $\begin{array}{ll}\mathrm{R} \$ & 15,50 \\
\end{array}$ & 0,3875 \\
\hline Mexilhão & $\mathrm{kg}$ & 0,025 & 0,025 & 1 & 14,50 & 0,3625 \\
\hline Camarão & $\mathrm{kg}$ & 0,1025 & 0.025 & 4,1 & 16,50 & 1,69125 \\
\hline Polvo & $\mathrm{kg}$ & 0,025 & 0.025 & 1 & 14,50 & 0,3625 \\
\hline Tomate & $\mathrm{kg}$ & 0,0375 & 0,025 & 1,5 & 2,00 & 0,075 \\
\hline Cebola picada & $\mathrm{kg}$ & 0,03 & 0.025 & 1,2 & 1,50 & 0,045 \\
\hline Alho amassado & $\mathrm{kg}$ & 0,005 & 0.005 & 1 & 5,99 & 0,02995 \\
\hline Salsa picada & $\mathrm{kg}$ & 0,0025 & 0,002 & 1,25 & 3,00 & 0,0075 \\
\hline Coentro picado & $\frac{\mathrm{gg}}{\mathrm{kg}}$ & 0,0025 & 0,002 & 1,25 & 3,00 & 0,0075 \\
\hline Limão & $\mathrm{kg}$ & 0,0452 & 0,02 & $\frac{1, \angle 5}{2,26}$ & 0,94 & 0,042488 \\
\hline Vinagre & $\mathrm{kg}$ & 0,03 & 0,03 & 1 & 4,00 & 0,12 \\
\hline Azeite de oliva & $\mathrm{Lt}$ & 0,03 & 0,03 & 1 & 28,00 & 0,84 \\
\hline Sal & $\mathrm{kg}$ & 0,005 & 0,005 & 1 & 2,00 & 0,01 \\
\hline Pão baguete (torrada) & $\mathrm{kg}$ & 0,08 & 0,08 & 1 & 10,00 & 0,8 \\
\hline Pimenta & $\mathrm{kg}$ & 0,001 & 0,001 & 1 & 4,00 & 0,004 \\
\hline & CUS & INGREDIENTE & & & & 4,79 \\
\hline $\begin{array}{l}\text { MODO DE PREPARO: 1.Af } \\
\text { deixar por } 8 \text { minutos; } 3 \text {.Pica }\end{array}$ & $\begin{array}{l}\text { camarões a lula e os mexilh } \\
\text { es, mexilhöes, polvo e lula; }\end{array}$ & os tomates & $\begin{array}{l}\text { la de pressão o } \\
\text { alho, salsa, coe }\end{array}$ & $\begin{array}{l}\text { Im pouco de azeite coloca } \\
\text { limão, vinagre, azeite, sal }\end{array}$ & $\begin{array}{l}\text { polvo. Assim que } \\
\text { pimenta; } 5 \text {. Servi }\end{array}$ & $\begin{array}{l}\text { pegar pressão } \\
\text { com torradas. }\end{array}$ \\
\hline Rendimento $(\mathrm{kg})$ & & & & & & \\
\hline Porcão(RS//kg) & \#REF! & 0,0 & & & & 36 \\
\hline
\end{tabular}




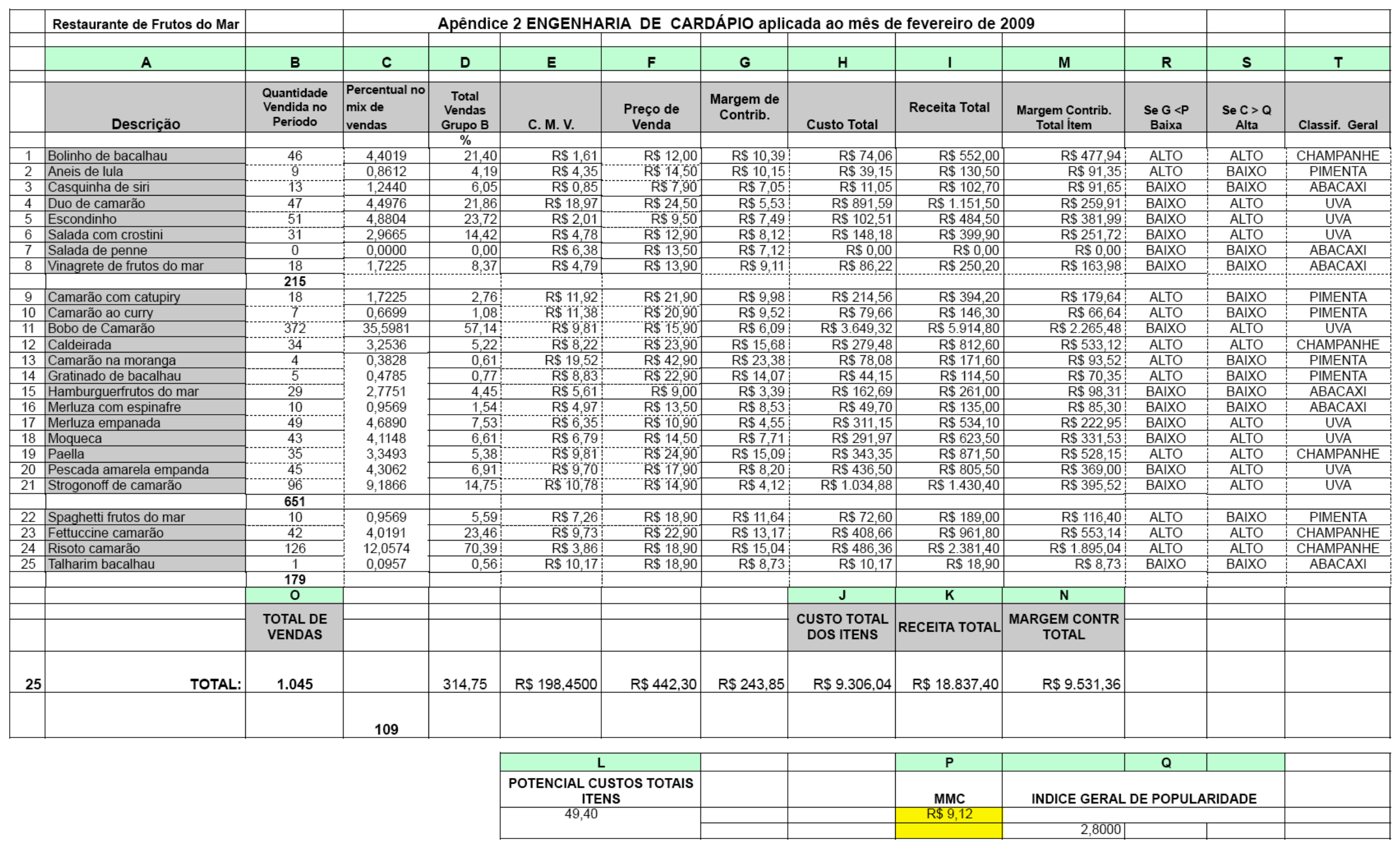




\begin{tabular}{|c|c|c|c|c|c|c|c|c|c|c|c|c|c|}
\hline & Restaurante de Frutos do Mar & & \multicolumn{8}{|c|}{ Apendice 3 ENGENHARIA DE CARDÁPIO aplicada ao mês de março de 2009} & \multirow[b]{2}{*}{$\mathbf{R}$} & \multirow[b]{2}{*}{$\mathbf{s}$} & \multirow[b]{2}{*}{$\mathbf{T}$} \\
\hline & A & B & C & D & $\mathbf{E}$ & $\mathbf{F}$ & G & H & I & M & & & \\
\hline \multirow{2}{*}{\multicolumn{2}{|c|}{ Descrição }} & $\begin{array}{c}\text { Quantidade } \\
\text { Vendida no } \\
\text { Periodo }\end{array}$ & \begin{tabular}{|l|} 
Percentual no \\
mix de \\
vendas \\
\end{tabular} & $\begin{array}{c}\text { Total } \\
\text { Vendas } \\
\text { Grupo B B } \\
\end{array}$ & C. M. V. & $\begin{array}{c}\text { Preço de } \\
\text { Venda }\end{array}$ & $\begin{array}{l}\text { Margem de } \\
\text { Contrib. }\end{array}$ & Custo Total & Receita Total & $\begin{array}{l}\text { Margem Contrib. } \\
\text { Total Ittem }\end{array}$ & $\begin{array}{c}\mathrm{Se} G<P \\
\text { Baixa }\end{array}$ & $\begin{array}{l}\text { Se } C>Q \\
\text { Alta }\end{array}$ & \multirow{2}{*}{ Classif. Geral } \\
\hline & & & & $\%$ & & & & & & & & & \\
\hline 1 & Bolinho de bacalhau & 45 & 4,3353 & 28,66 & $\mathrm{R} \$ 1,61$ & $\mathrm{R} \$ 12,00$ & $\mathrm{R} \$ 10,39$ & $\mathrm{R} \$ 72,45$ & $\mathrm{R} \$ 540,00$ & $\mathrm{R} \$ 467,55$ & ALTO & ALTO & CHAMPANHE \\
\hline 2 & Aneis de lula & 3 & 0,2890 & 1,91 & R\$ 4,35 & $\mathrm{R} \$ 14,50$ & R\$ 10,15 & $R \$ 13,05$ & $\mathrm{R} \$ 43,50$ & $\mathrm{R} \$ 30,45$ & ALTO & BAIXO & PIMENTA \\
\hline$\frac{2}{3}$ & Casquinha de siri & 21 & 2,0231 & $\mid 1,38$ & $\mathrm{R} \$ 0,85$ & R\$7,90 & $\mathrm{R} \$ 7,05$ & $\mathrm{R} \$ 17,85$ & $\mathrm{R} \$ 165,90$ & $\mathrm{R} \$ 148,05$ & BAIXO & BAIXO & ABACAXI \\
\hline 4 & Duo de camarão & 50 & 4,8170 & 31,85 & $\mathrm{R} \$ 18,97$ & $\mathrm{R} \$ 24,50$ & $\mathrm{R} \$ 5,53$ & $\mathrm{R} \$ 948,50$ & $\mathrm{R} \$ 1.225,00$ & $\mathrm{R} \$ 276,50$ & BAIXO & ALTO & UVA \\
\hline 5 & Escondinho & 16 & 1,5414 & 10,19 & $\mathrm{R} \$ 2,01$ & $\mathrm{RS} 9,50$ & $\mathrm{R} \$ 7,49$ & $\mathrm{R} \$ 32,16$ & $\mathrm{R} \$ 152,00$ & $\mathrm{R} \$ 119,84$ & BAIXO & BAIXO & ABACAXI \\
\hline 6 & Salada com crostini & 4 & 0,3854 & 2,55 & R\$ 4,78 & $\mathrm{R} \$ 12,90$ & $\mathrm{R} \$ 8,12$ & $\mathrm{R} \$ 19,12$ & $\mathrm{R} \$ 51,60$ & $\mathrm{R} \$ 32,48$ & ALTO & BAIXO & PIMENTA \\
\hline 7 & Salada de penne & 0 & 0,0000 & 0,00 & $\mathrm{R} \$ 6,38$ & $\mathrm{R} \$ 13,50$ & $\mathrm{R} \$ 7,12$ & $\mathrm{R} \$ 0,00$ & R\$ 0,00 & R $\$ 0,00$ & BAIXO & BAIXO & ABACAXI \\
\hline \multirow[t]{2}{*}{8} & Vinagrete de frutos do mar & 18 & 1,7341 & \multirow{2}{*}{1146} & \multirow{2}{*}{$\mathrm{R} \$ 4,79$} & \multirow{2}{*}{$\mathrm{R} \$ 13,90$} & \multirow[t]{2}{*}{ RS 9,11 } & \multirow{2}{*}{$R \$ 86,22$} & \multirow{2}{*}{$R \$ 250,20$} & \multirow{2}{*}{$\mathrm{R} \$ 163,98$} & \multirow[t]{2}{*}{ ALTO } & \multirow{2}{*}{ BAIXO } & \multirow{2}{*}{ PIMENTA } \\
\hline & & 157 & \multirow{14}{*}{$\begin{array}{c}0,9634 \\
0,2890 \\
38,9210 \\
2,6012 \\
0,2890 \\
0,8671 \\
2,8902 \\
0,9634 \\
0,0000 \\
4,4316 \\
3,1792 \\
4,3353 \\
8,9595\end{array}$} & & & & & & & & & & \\
\hline 9 & Camarão com catupiry & 10 & & 1,40 & $\mathrm{R} \$ 11,92$ & $\mathrm{R} \$ 21,90$ & $\mathrm{R} \$ 9,98$ & $\mathrm{R} \$ 119,20$ & $\mathrm{R} \$ 219,00$ & $\mathrm{R} \$ 99,80$ & ALTO & BAIXO & PIMENTA \\
\hline 10 & Camarão ao curry & 3 & & 0,42 & $\mathrm{R} \$ 11,38$ & $\mathrm{R} \$ 20,90$ & $\mathrm{R} \$ 9,52$ & $\mathrm{R} \$ 34,14$ & $\mathrm{R} \$ 62,70$ & $\mathrm{R} \$ 28,56$ & ALTO & BAIXO & PIMENTA \\
\hline 11 & Bobo de Camarão & 404 & & 56,66 & R\$ 9,81 & $\mathrm{R} \$ 15,90$ & $\mathrm{R} \$ 6,09$ & $\mathrm{R} \$ 3.963,24$ & R\$ $6.423,60$ & $\mathrm{R} \$ 2.460,36$ & BAIXO & ALTO & UVA \\
\hline 12 & Caldeirada & 27 & & 3,79 & $\operatorname{R} \$ 8,22$ & $\mathrm{R} \$ 23,90$ & R\$ 15,68 & $\mathrm{R} \$ 221,94$ & $\mathrm{R} \$ 645,30$ & $\mathrm{R} \$ 423,36$ & ALTO & BAIXO & PIMENTA \\
\hline 13 & Camarão na moranga & 3 & & 0,42 & $\mathrm{R} \$ 19,52$ & $\mathrm{R} \$ 42,90$ & $R \$ 23,38$ & $\mathrm{R} \$ 58,56$ & $\mathrm{R} \$ 128,70$ & $\mathrm{R} \$ 70,14$ & ALTO & BAIXO & PIMENTA \\
\hline 14 & Gratinado de bacalhau & 9 & & 1,26 & R\$ 8,83 & $\mathrm{R} \$ 22,90$ & $\mathrm{R} \$ 14,07$ & $\mathrm{R} \$ 79,47$ & $\mathrm{R} \$ 206,10$ & $\mathrm{R} \$ 126,63$ & ALTO & BAIXO & PIMENTA \\
\hline 15 & Hamburguerfrutos do mar & 30 & & 4,21 & $\mathrm{RS} 5,61$ & RS 9,00 & $\mathrm{R} \$ 3,39$ & RS 168,30 & $\mathrm{R} \$ 270,00$ & $\mathrm{R} \$ 101,70$ & BAIXO & ALTO & UVA \\
\hline 16 & Merluza com espinafre & 10 & & 1,40 & $\mathrm{R} \$ 4,97$ & $\mathrm{R} \$ 13,50$ & $\mathrm{R} \$ 8,53$ & $\mathrm{R} \$ 49,70$ & $\mathrm{R} \$ 135,00$ & $\mathrm{R} \$ 85,30$ & ALTO & BAIXO & PIMENTA \\
\hline 17 & Merluza empanada & 0 & & 0,00 & RS 6,35 & $\mathrm{R} \$ 10,90$ & $\mathrm{R} \$ 4,55$ & $\mathrm{R} \$ 0,00$ & $\mathrm{R} \$ 0,00$ & $\mathrm{R} \$ 0,00$ & BAIXO & BAIXO & ABACAXI \\
\hline 18 & Moqueca & 46 & & 6,45 & $\mathrm{R} \$ 6,79$ & $\mathrm{R} \$ 14,50$ & $\mathrm{R} \$ 7,71$ & $\mathrm{R} \$ 312,34$ & $\mathrm{R} \$ 667,00$ & $\mathrm{R} \$ 354,66$ & BAIXO & ALTO & UVA \\
\hline 19 & Paella & 33 & & 4,63 & $\mathrm{R} \$ 9,81$ & $\mathrm{R} \$ 24,90^{\circ}$ & $\mathrm{R} \$ 15,09$ & $\mathrm{R} \$ 323,73$ & $\mathrm{R} \$ 821,70$ & $\mathrm{R} \$ 497,97$ & ALTO & ALTO & CHAMPANHE \\
\hline 20 & Pescada amarela empanda & 45 & & 6,31 & $R \$ 9,70^{\circ}$ & $\mathrm{R} \$ 17,90$ & $\mathrm{R} \$ 8,20$ & R\$ 436,50 & $\mathrm{R} \$ 805,50$ & $\mathrm{R} \$ 369,00$ & BAIXO & ALTO & UVA \\
\hline 21 & Strogonoff de camarão & 93 & & 13,04 & $\mathrm{R} \$ 10,78$ & $\mathrm{R} \$ 14,90$ & $\mathrm{R} \$ 4,12$ & $\mathrm{R} \$ 1.002,54$ & R\$ $1.385,70$ & $\mathrm{R} \$ 383,16$ & BAIXO & ALTO & UVA \\
\hline & & 713 & & & & & & & & & & & \\
\hline 22 & Spaghetti frutos do mar & 9 & 0,8671 & 5,36 & $\mathrm{R} \$ 7,26$ & $\mathrm{R} \$ 18,90$ & $\mathrm{R} \$ 11,64$ & $\mathrm{R} \$ 65,34$ & $\mathrm{R} \$ 170,10$ & $\mathrm{R} \$ 104,76$ & ALTO & BAIXO & PIMENTA \\
\hline 23 & Fettuccine camarão & 52 & 5,0096 & 30,95 & $\mathrm{R} \$ 9,73$ & $\mathrm{R} \$ 22,90$ & R\$ 13,17 & $\mathrm{R} \$ 505,96$ & R\$ $1.190,80$ & $\mathrm{R} \$ 684,84$ & ALTO & ALTO & CHAMPANHE \\
\hline 24 & Risoto camarão & 107 & 10,3083 & 63,69 & $\mathrm{R} \$ 3,86$ & $\mathrm{R} \$ 18,90$ & $\mathrm{R} \$ 15,04$ & $\mathrm{R} \$ 413,02$ & $\mathrm{R} \$ 2.022,30$ & $\mathrm{R} \$ 1.609,28$ & ALTO & ALTO & CHAMPANHE \\
\hline 25 & Talharim bacalhau & 0 & 0,0000 & 0,00 & $\mathrm{R} \$ 10,17$ & $\mathrm{R} \$ 18,90$ & $\mathrm{R} \$ 8,73$ & $\mathrm{R} \$ 0,00$ & $\mathrm{RS} 0,00$ & $\mathrm{R} \$ 0,00$ & ALTO & BAIXO & PIMENTA \\
\hline & & 168 & & & & & & & & & & & \\
\hline & & 0 & & & & & & $\mathrm{~J}$ & $\mathrm{~K}$ & $\mathrm{~N}$ & & & \\
\hline & & TOTAL DE & & & & & & & & & & & \\
\hline & & VENDAS & & & & & & DOS ITENS & RECEITA TOTAL & TOTAL & & & \\
\hline 25 & TOTAL: & 1.038 & & 300,00 & $\mathrm{R} \$ 198,4500$ & $R \$ 442,30$ & $R \$ 243,85$ & $\mathrm{R} \$ 8.943,33$ & $\mathrm{R} \$ 17.581,70$ & $\mathrm{R} \$ 8.638,37$ & & & \\
\hline & & & 100 & & & & & & & & & & \\
\hline & & & & & $\mathrm{t}$ & & & & $\mathbf{P}$ & & Q & & \\
\hline & & & & & POTENCIAL Cl & TOS TOTAIS & & & MMC & INDICE GERAL & DE POPUI & IDADE & \\
\hline & & & & & $\begin{array}{r}11 \\
50,87\end{array}$ & & & & $\mathrm{R} \$ 8,32$ & & & & \\
\hline & & & & & & & & & & 2,8000 & & & \\
\hline
\end{tabular}




\begin{tabular}{|c|c|c|c|c|c|c|c|c|c|c|c|c|c|}
\hline & Restaurante de Frutos do Mar & & & Apend & lice 4 ENGEN & ARIA DE CA & ARDÁPIO ap & licada ao mês & de abril de 200 & & & & \\
\hline & A & B & c & D & E & $\mathbf{F}$ & G & $\mathrm{H}$ & 1 & M & $\mathbf{R}$ & $\mathbf{s}$ & 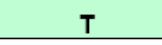 \\
\hline & Descriçäo & $\begin{array}{c}\text { Quantidade } \\
\text { Vendida no } \\
\text { Periodo }\end{array}$ & \begin{tabular}{|l} 
Percentual no \\
mix de \\
vendas \\
\end{tabular} & $\begin{array}{c}\text { Total } \\
\text { Vendas } \\
\text { Grupo B } \\
\end{array}$ & C. M. V. & $\begin{array}{l}\text { Preço de } \\
\text { Venda }\end{array}$ & $\begin{array}{l}\text { Margem de } \\
\text { Contrib. }\end{array}$ & Custo Total & Receita Total & $\begin{array}{c}\text { Margem Contrib. } \\
\text { Total İtem }\end{array}$ & $\begin{array}{c}\text { Se } G<P \\
\text { Baixa }\end{array}$ & $\begin{array}{c}\text { Se } C>Q \\
\text { Alta }\end{array}$ & Classif. Geral \\
\hline & & & & $\%$ & & & & & & & & & \\
\hline 1 & Bolinho de bacalhau & 36 & 3,2997 & 22,36 & $\mathrm{R} \$ 1,61$ & $R \$ 12,00$ & RS 10,39 & $\mathrm{R} \$ 57,96$ & $\mathrm{R} \$ 432,00$ & $\mathrm{R} \$ 374,04$ & ALTO & ALTO & CHAMPAGNE \\
\hline 2 & Aneis de lula & 4 & 0,3666 & 2,48 & $R \$ 4,35$ & $R \$ 14,506$ & $\mathrm{R} \$ 10,15$ & $\mathrm{R} \$ 17,40$ & $R \$ 58,00$ & $\mathrm{R} \$ 40,60$ & ALTO & BAIXO & PIMENTEA \\
\hline 3 & Casquinha de siri & 9 & 0,8249 & 5,59 & $\mathrm{R} \$ 0,85$ & $\mathrm{R} \$ 7,90^{\circ}$ & $\mathrm{R} \$ 7,05$ & $\mathrm{R} \$ 7,65$ & $\mathrm{R} \$ 71,10$ & $\mathrm{R} \$ 63,45$ & BAIXO & BAIXO & $A B A C A X I^{-}$ \\
\hline 4 & Duo de camarão & 35 & 3,2081 & 21,74 & $\mathrm{R} \$ 18,97$ & $R \$ 24,50$ & $\mathrm{R} \$ 5,53$ & $\mathrm{R} \$ 663,95$ & $\mathrm{R} \$ 857,50$ & $\mathrm{R} \$ 193,55$ & BAIXO & ALTO & CHAMPAGNE \\
\hline 5 & Escondinho & 29 & 2,6581 & 18,01 & $\mathrm{R} \$ 2,01$ & $\mathrm{RS} 9,50$ & $\mathrm{R} \$ 7,49$ & $\mathrm{R} \$ 58,29$ & $\mathrm{R} \$ 275,50$ & $\mathrm{R} \$ 217,21$ & BAIXO & BAIXO & CHAMPAGNE \\
\hline 6 & Salada com crostini & 25 & 2,2915 & 15,53 & $\mathrm{R} \$ 4,78$ & $\mathrm{R} \$ 12,90$ & $\mathrm{R} \$ 8,12$ & R\$ 119,50 & $\mathrm{R} \$ 322,50$ & $\mathrm{R} \$ 203,00$ & ALTO & BAIXO & CHAMPAGNE \\
\hline 7 & Salada de penne & 0 & 0,0000 & 0,00 & $\mathrm{R} \$ 6,38$ & $\mathrm{R} \$ 13,50$ & $\mathrm{R} \$ 7,12$ & $\mathrm{R} \$ 0,00$ & $\mathrm{R} \$ 0,00$ & $\mathrm{R} \$ 0,00$ & BAIXO & BAIXO & ABACAXI \\
\hline 8 & Vinagrete de frutos do mar & 23 & 2,1082 & 1429 & $\mathrm{R} \$ 4,79$ & $\mathrm{R} \$ 13,90$ & $\mathrm{RS9}, 11$ & RS 110,17 & $\mathrm{R} \$ 31970$ & $\mathrm{R} \$ 20953$ & ALTO & BAIXO & PIMENTA \\
\hline & & 161 & & & & & & & & & & & \\
\hline 9 & Camarão com catupiry & 22 & 2,0165 & 2,88 & $R \$ 11,92$ & $R \$ 21,90$ & $\mathrm{R} \$ 9,98$ & $\mathrm{R} \$ 262,24$ & $\mathrm{R} \$ 481,80$ & $\mathrm{R} \$ 219,56$ & ALTO & BAIXO & PIMENTA \\
\hline 10 & Camarão ao curry & 3 & 0,2750 & 0,39 & $\mathrm{R} \$ 11,38$ & $R \$ 20,90^{\circ}$ & $R \$ 9,52$ & $\mathrm{R} \$ 34,14$ & $\mathrm{R} \$ 62,70$ & $\mathrm{R} \$ 28,56$ & ALTO & BAIXO & PIMEENTEA \\
\hline 11 & Bobo de Camarão & 341 & 31,2557 & 44,63 & $\mathrm{R} \$ 9,81$ & $R \$ 15,90$ & $\mathrm{R} \$ 6,09$ & $\mathrm{R} \$ 3.345,21$ & R\$ 5.421,90 & $\mathrm{R} \$ 2.076,69$ & BAIXO & ALTO & UVA \\
\hline 12 & Caldeirada & 22 & 2,0165 & 2,88 & $\mathrm{R} 8,22$ & $\mathrm{R} \$ 23,90$ & $\mathrm{R} \$ 15,68$ & R\$ 180,84 & $\mathrm{R} \$ 525,80$ & $\mathrm{R} \$ 344,96$ & ALTO & BAIXO & PIMENTA \\
\hline 13 & Camarão na moranga & 2 & 0,1833 & 0,26 & $\mathrm{R} \$ 19,52$ & $\mathrm{R} \$ 42,90$ & $\mathrm{R} \$ 23,38$ & $\mathrm{R} \$ 39,04$ & $\mathrm{R} \$ 85,80$ & $\mathrm{R} \$ 46,76$ & ALTO & BAIXO & PIMENTA \\
\hline 14 & Gratinado de bacalhau & 5 & 0,4583 & 0,65 & $\mathrm{R} \$ 8,83$ & $\mathrm{R} \$ 22,90$ & $\mathrm{R} \$ 14,07$ & $\mathrm{R} \$ 44,15$ & $\mathrm{R} \$ 114,50$ & $\mathrm{R} \$ 70,35$ & ALTO & BAIXO & PIMENTA \\
\hline 15 & Hamburguerfrutos do mar & 35 & 3,2081 & 4,58 & $\mathrm{RS} 5,61$ & RS 9,00 & $\mathrm{R} \$ 3,39$ & R\$ 196,35 & $\mathrm{R} \$ 315,00$ & RS 118,65 & BAIXO & ALTO & UVA \\
\hline 16 & Merlusa com espinafre & 6 & 0,5500 & 0,79 & $\mathrm{R} \$ 4,97$ & $R \$ 13,50$ & $\mathrm{R} \$ 8,53$ & $\mathrm{R} \$ 29,82$ & $\mathrm{R} \$ 81,00$ & $\mathrm{R} \$ 51,18$ & ALTO & BAIXO & PIMENTA \\
\hline 17 & Merlusa empanada & 114 & 10,4491 & 14,92 & RS 6,35 & $\mathrm{R} \$ 10,90^{\circ}$ & $\mathrm{R} \$ 4,55$ & $\mathrm{RS} 723,90$ & $\mathrm{R} \$ 1.242,60$ & $\mathrm{R} \$ 518,70$ & BAIXO & ALTO & UVA \\
\hline 18 & Moqueca & 40 & 3,6664 & 5,24 & $\mathrm{R} \$ 6,79$ & $R \$ 14,50$ & $\mathrm{R} \$ 7,71$ & $\mathrm{R} \$ 271,60$ & $\mathrm{R} \$ 580,00$ & $\mathrm{R} \$ 308,40$ & BAIXO & ALTO & UVA \\
\hline 19 & Paella & 26 & 2,3831 & 3,40 & $\mathrm{R} \$ 9,81$ & $R \$ 24,90^{\circ}$ & RS 15,09 & $\mathrm{R} \$ 255,06$ & $\mathrm{R} \$ 647,40$ & $\mathrm{R} \$ 392,34$ & ALTO & BAIXO & CHAMPAGNE \\
\hline 20 & Pescada amarela empanada & 57 & 5,2246 & 7,46 & $R \$ 90$ & $R \$ 17,90$ & $\mathrm{R} \$ 8,20$ & $\mathrm{R} \$ 552,90$ & RS $1.020,30$ & $\mathrm{R} \$ 467,40$ & ALTO & ALTO & CHAMPAGNE \\
\hline 21 & Strogonoff de camarão & 91 & 8,3410 & 11,91 & $\mathrm{R} \$ 10,78$ & $\mathrm{R} \$ 14,90^{\circ}$ & $\mathrm{R} \$ 4,12$ & R\$ 980,98 & R\$ $1.355,90$ & $\mathrm{R} \$ 374,92$ & BAIXO & ALTO & UVA \\
\hline & & 764 & & & & & & & & & & & \\
\hline 22 & Spaghetti frutos do mar & 9 & 0,8249 & 5,42 & $\mathrm{R} \$ 7,26$ & $\mathrm{R} \$ 18,90$ & $\mathrm{R} \$ 11,64$ & $\mathrm{R} \$ 65,34$ & $\mathrm{R} \$ 170,10$ & $\mathrm{R} \$ 104,76$ & ALTO & BAIXO & PIMENTA \\
\hline 23 & Fettuccine camarão & 37 & 3,3914 & 22,29 & $\mathrm{R} \$ 9,73$ & $\mathrm{R} \$ 22,90$ & $\mathrm{R} \$ 13,17$ & $\mathrm{R} \$ 360,01$ & $\mathrm{R} \$ 847,30$ & $\mathrm{R} \$ 487,29$ & ALTO & ALTO & CHAMPAGNE \\
\hline 24 & Risoto camarão & 120 & 10,9991 & 72,29 & $\mathrm{R} \$ 3,86$ & $\mathrm{R} \$ 18,90$ & $\mathrm{R} \$ 15,04$ & $\mathrm{R} \$ 463,20$ & $\mathrm{R} \$ 2.268,00$ & $\mathrm{R} \$ 1.804,80$ & ALTO & ALTO & CHAMPAGNE \\
\hline 25 & Talharim bacalhau & 0 & 0,0000 & 0,00 & $\mathrm{R} \$ 10,17$ & $\mathrm{R} \$ 18,90$ & $\mathrm{R} \$ 8,73$ & $\mathrm{R} \$ 0,00$ & $\mathrm{R} \$ 0,00$ & $\mathrm{R} \$ 0,00$ & ALTO & BAIXO & PIMENTA \\
\hline & & 166 & & & & & & & & & & & \\
\hline & & 0 & & & & & & $\mathrm{~J}$ & $\mathrm{~K}$ & $\mathbf{N}$ & & & \\
\hline & & TOTAL DE & & & & & & & & MARGEM CONTR & & & \\
\hline & & VENDAS & & & & & & DOS ITENS & RECEITA TOTAL & TOTAL & & & \\
\hline 25 & TOTAL: & 1.091 & & 300,00 & $\mathrm{R} \$ 198,4500$ & $\mathrm{R} \$ 442,30$ & $R \$ 243,85$ & $\mathrm{R} \$ 8.839,70$ & $\mathrm{R} \$ 17.556,40$ & $\mathrm{R} \$ 8.716,70$ & & & \\
\hline & & & 100 & & & & & & & & & & \\
\hline & & & & & L & & & & $P$ & & $Q$ & & \\
\hline & & & & & $\begin{array}{l}\text { POTENCIAL CL } \\
\text { ITE }\end{array}$ & TOS TOTAIS & & & MMC & INDICE C & E POPL & IDADE & \\
\hline & & & & & $\begin{array}{r}\text { MIL } \\
50,35\end{array}$ & & & & $\mathrm{R} \$ 7,99$ & & & & \\
\hline & & & & & & & & & & 2,8000 & & & \\
\hline
\end{tabular}




\begin{tabular}{|c|c|c|c|c|c|c|c|c|c|c|c|c|c|}
\hline & Restaurante de Frutos do Mar & & & & Apendice 5 & ENGENHAF & RIA DE CAF & RDÁPIO TRIME & ESTRAL & & & & \\
\hline & A & B & c & D & E & $\mathbf{F}$ & G & $\mathrm{H}$ & 1 & M & $\mathbf{R}$ & $\mathbf{s}$ & $\mathbf{T}$ \\
\hline & Descrição & $\begin{array}{c}\text { Quantidade } \\
\text { Vendida no } \\
\text { Periodo }\end{array}$ & \begin{tabular}{|l|} 
Percentual no \\
mix de \\
vendas \\
\end{tabular} & $\begin{array}{c}\text { Total } \\
\text { Vendas } \\
\text { Grupo B }\end{array}$ & C. M. V. & $\begin{array}{l}\text { Preço de } \\
\text { Venda }\end{array}$ & $\begin{array}{l}\text { Margem de } \\
\text { Contrib. }\end{array}$ & Custo Total & Receita Total & $\begin{array}{l}\text { Margem Contrib. } \\
\text { Total item }\end{array}$ & $\begin{array}{c}\text { Se } G<P \\
\text { Baixa }\end{array}$ & $\begin{array}{c}\text { Se } C>Q \\
\text { Alta }\end{array}$ & Classif. Geral \\
\hline & & & & $\%$ & & & & & & & & & \\
\hline 1 & Bolinho de bacalhau & 127 & 4,3139 & 23,83 & $\mathrm{R} \$ 1,61$ & R\$ 12,00 & $\mathrm{R} \$ 10,39$ & $\mathrm{R} \$ 204,47$ & $\mathrm{R} \$ 1.524,00$ & $\mathrm{R} \$ 1.319,53$ & ALTO & ALTO & CHAMPANHE \\
\hline 2 & Aneis de lula & 16 & 0,5435 & 3,00 & $\mathrm{R} \$ 4,35$ & RS 14,50 & $\mathrm{R} \$ 10,15$ & $\mathrm{R} \$ 69,60$ & $\mathrm{R} \$ 232,00$ & $\mathrm{R} \$ 162,40$ & ALTO & BAIXO & PIMENTA \\
\hline 3 & Casquinha de siri & 43 & 1,4606 & 8,07 & $\mathrm{R} \$ 0,85$ & $\mathrm{R} \$ 7,90$ & $\mathrm{R} \$ 7,05$ & $\mathrm{R} \$ 36,55$ & $\mathrm{R} \$ 339,70$ & $\mathrm{R} \$ 303,15$ & BAIXO & BAIXO & ABACAXI \\
\hline 4 & Duo de camarão & 132 & 4,4837 & 24,77 & $\mathrm{R} \$ 18,97$ & $\mathrm{R} \$ 24,50$ & $\mathrm{R} \$ 5,53$ & $\mathrm{R} \$ 2.504,04$ & $\mathrm{R} \$ 3.234,00$ & $\mathrm{R} \$ 729,96$ & BAIXO & ALTO & UVA \\
\hline 5 & Escondinho & 96 & 3,2609 & 18,01 & $\mathrm{R} \$ 2,01$ & $\mathrm{R} \$ 950$ & $\mathrm{R} \$ 7,49$ & $\mathrm{R} \$ 192,96$ & R\$ 912,00 & $\mathrm{R} \$ 719,04$ & BAIXO & ALTO & UVA \\
\hline 6 & Salada com crostini & 60 & 2,0380 & 11,26 & $\mathrm{R} \$ 4,78$ & R\$ 12,90 & $\mathrm{R} \$ 8,12$ & $\mathrm{R} \$ 286,80$ & $\mathrm{R} \$ 774,00$ & $\mathrm{R} \$ 487,20$ & ALTO & BAIXO & PIMENTA \\
\hline 7 & Salada de penne & 0 & 0,0000 & 0,00 & $\mathrm{R} \$ 6,38$ & R\$ 13,50 & $\mathrm{R} \$ 7,12$ & $\mathrm{R} \$ 0,00$ & $\mathrm{R} \$ 0,00$ & $R \$ 0,00$ & BAIXO & BAIXO & ABACAXI \\
\hline 8 & Vinagrete de frutos do mar & 59 & 2,0041 & 11,07 & $\mathrm{R} \$ 4,79$ & R\$ 13,90 & $\mathrm{R} \$ 9,11$ & $\mathrm{R} \$ 282,61$ & RS 820,10 & $R \$ 53749$ & ALTO & BAIXO & PIMENTA \\
\hline & & 533 & & & & & & & & & & & \\
\hline 9 & Camarão com catupiry & 50 & 1,6984 & 2,25 & R\$ 11,92 & $\mathrm{R} \$ 21,90$ & $\mathrm{R} \$ 9,98$ & $\mathrm{R} \$ 596,00$ & $\mathrm{R} \$ 1.095,00$ & $\mathrm{R} \$ 499,00$ & ALTO & BAIXO & PIMENTA \\
\hline 10 & Camarão ao curry & 13 & 0,4416 & 0,58 & RS 11,38 & R\$ 20,90 & $R \$ 9,52$ & $\mathrm{R} \$ 147,94$ & $\mathrm{R} \$ 271,70$ & $\mathrm{R} \$ 123,76$ & ALTO & BAIXO & PIMENTA \\
\hline 11 & Bobo de Camarão & 1117 & 37,9416 & 50,22 & $\mathrm{R} \$ 9,81$ & RS 15,90 & RS 6,09 & R\$ 10.957,77 & $\mathrm{R} \$ 17.760,30$ & $\mathrm{R} \$ 6.802,53$ & BAIXO & ALTO & UVA \\
\hline 12 & Caldeirada & 83 & 2,8193 & 3,73 & $\mathrm{R} \$ 8,22$ & $\mathrm{R} \$ 23,90$ & $\mathrm{R} \$ 15,68$ & $\mathrm{R} \$ 682,26$ & $\mathrm{R} \$ 1.983,70$ & $\mathrm{R} \$ 1.301,44$ & ALTO & ALTO & CHAMPANHE \\
\hline 13 & Camarão na moranga & 9 & 0,3057 & 0,40 & R\$ 19,52 & R\$ 42,90 & $\mathrm{R} \$ 23,38$ & $\mathrm{R} \$ 175,68$ & $\mathrm{R} \$ 386,10$ & $\mathrm{R} \$ 210,42$ & ALTO & BAIXO & PIMENTA \\
\hline 14 & Gratinado de bacalhau & 19 & 0,6454 & 0,85 & $\mathrm{RS} 883$ & $\mathrm{RS} 22,90$ & $\mathrm{R} \$ 14,07$ & $\mathrm{R} \$ 167,77$ & $\mathrm{R} \$ 435,10$ & $\mathrm{R} \$ 267,33$ & ALTO & BAIXO & PIMENTA \\
\hline 15 & Hamburguerfrutos do mar & 94 & 3,1929 & 4,23 & $\mathrm{R} \$ 5,61$ & $\mathrm{R} \$ 9,00$ & $\mathrm{R} \$ 3,39$ & $\mathrm{R} \$ 527,34$ & RS 846,00 & R\$ 318,66 & BAIXO & ALTO & UVA \\
\hline 16 & Merluza com espinafre & 26 & 0,8832 & 1,17 & $R \$ 4,97$ & RS 13,50 & $\mathrm{R} \$ 8,53$ & $\mathrm{R} \$ 129,22$ & $\mathrm{R} \$ 351,00$ & $\mathrm{R} \$ 221,78$ & ALTO & BAIXO & PIMENTA \\
\hline 17 & Merluza empanada & 163 & 5,5367 & 7,33 & $\mathrm{R} \$ 6,35$ & R\$ 10,90 & $R \$ 4,55$ & $\mathrm{R} \$ 1.035,05$ & $\mathrm{R} \$ 1.776,70$ & R\$ 741,65 & BAIXO & ALTO & UVA \\
\hline 18 & Moqueca & 129 & 4,3818 & 5,80 & $\mathrm{R} \$ 6,79$ & R\$ 14,50 & $\mathrm{R} \$ 7,71$ & $\mathrm{R} \$ 875,91$ & $\mathrm{R} \$ 1.870,50$ & $\mathrm{R} \$ 994,59$ & ALTO & ALTO & CHAMPANHE \\
\hline 19 & Paella & 94 & 3,1929 & 4,23 & $R \$ 9,81$ & R $\$ 24,90$ & $\mathrm{R} \$ 15,09$ & $\mathrm{R} \$ 922,14$ & $\mathrm{R} \$ 2.340,60$ & $\mathrm{R} \$ 1.418,46$ & ALTO & ALTO & CHAMPANHE \\
\hline 20 & Pescada amarela empanada & 147 & 4,9932 & 6,61 & $R \$ 9,70$ & $R \$ 17,90$ & $\mathrm{R} \$ 8,20$ & RS $1.425,90$ & $\mathrm{R} \$ 2.631,30$ & $\mathrm{R} \$ 1.205,40$ & ALTO & ALTO & CHAMPANHE \\
\hline 21 & Strogonoff de camarẫo & 280 & 9,5109 & 12,59 & $\mathrm{R} \$ 10,78$ & $\mathrm{R} \$ 14,90$ & $\mathrm{R} \$ 4,12$ & $\mathrm{R} \$ 3.018,40$ & $\mathrm{R} \$ 4.172,00$ & $\mathrm{R} \$ 1.153,60$ & BAIXO & ALTO & UVA \\
\hline & & 2224 & & & & & & & & & & & \\
\hline 22 & Spaghetti frutos do mar & 28 & 0,9511 & 14,97 & $\mathrm{R} \$ 7,26$ & RS 18,90 & $\mathrm{R} \$ 11,64$ & $\mathrm{R} \$ 203,28$ & $\mathrm{R} \$ 529,20$ & $\mathrm{R} \$ 325,92$ & ALTO & BAIXO & PIMENTA \\
\hline 23 & Fettuccine camarão & 52 & 1,7663 & 27,81 & $\mathrm{R} \$ 9,73$ & $\mathrm{R} \$ 22,90$ & $\mathrm{R} \$ 13,17$ & $\mathrm{R} \$ 505,96$ & $\mathrm{R} \$ 1.190,80$ & $\mathrm{R} \$ 684,84$ & ALTO & BAIXO & PIMENTA \\
\hline 24 & Risoto camarão & 107 & 3,6345 & 57,22 & $\mathrm{R} \$ 3,86$ & RS 18,90 & $\mathrm{R} \$ 15,04$ & $\mathrm{R} \$ 413,02$ & $\mathrm{R} \$ 2.022,30$ & $\mathrm{R} \$ 1.609,28$ & ALTO & ALTO & CHAMPANHE \\
\hline 25 & Talharim bacalhau & 0 & 0,0000 & 0,00 & $\mathrm{R} \$ 10,17$ & RS 18,90 & $\mathrm{R} \$ 8,73$ & $\mathrm{R} \$ 0,00$ & $\mathrm{R} \$ 0,00$ & $\mathrm{R} \$ 0,00$ & ALTO & BAIXO & PIMENTA \\
\hline & & 187 & & & & & & & & & & & \\
\hline & & 0 & & & & & & $\mathrm{~J}$ & $\mathrm{~K}$ & $\mathbf{N}$ & & & \\
\hline & & TOTAL DE & & & & & & CUSTO TOTAL & & MARGEM CONTR & & & \\
\hline & & VENDAS & & & & & & DOS ITENS & RECEITA TOTAL & TOTAL & & & \\
\hline 25 & TOTAL: & 2.944 & & 300,00 & $R \$ 198,4500$ & $\mathrm{R} \$ 442,30$ & $\mathrm{R} \$ 243,85$ & $R \$ 25.360,67$ & $\mathrm{R} \$ 47.498,10$ & $R \$ 22.137,43$ & & & \\
\hline & & & 100 & & & & & & & & & & \\
\hline & & & & & L & & & & $P$ & & $Q$ & & \\
\hline & & & & & POTENCIAL CL & STOS TOTAIS & & & & INDICE G & DE POPUL & 2IDADE & \\
\hline & & & & & $\begin{array}{r}\text { ME } \\
53,39\end{array}$ & & & & $\operatorname{RS7,52}$ & & & & \\
\hline & & & & & & & & & & $2,8000 \mid$ & & & \\
\hline
\end{tabular}


Apêndice 6: Classificação de pratos do mês de fevereiro/09 (margem de contribuição e popularidade)

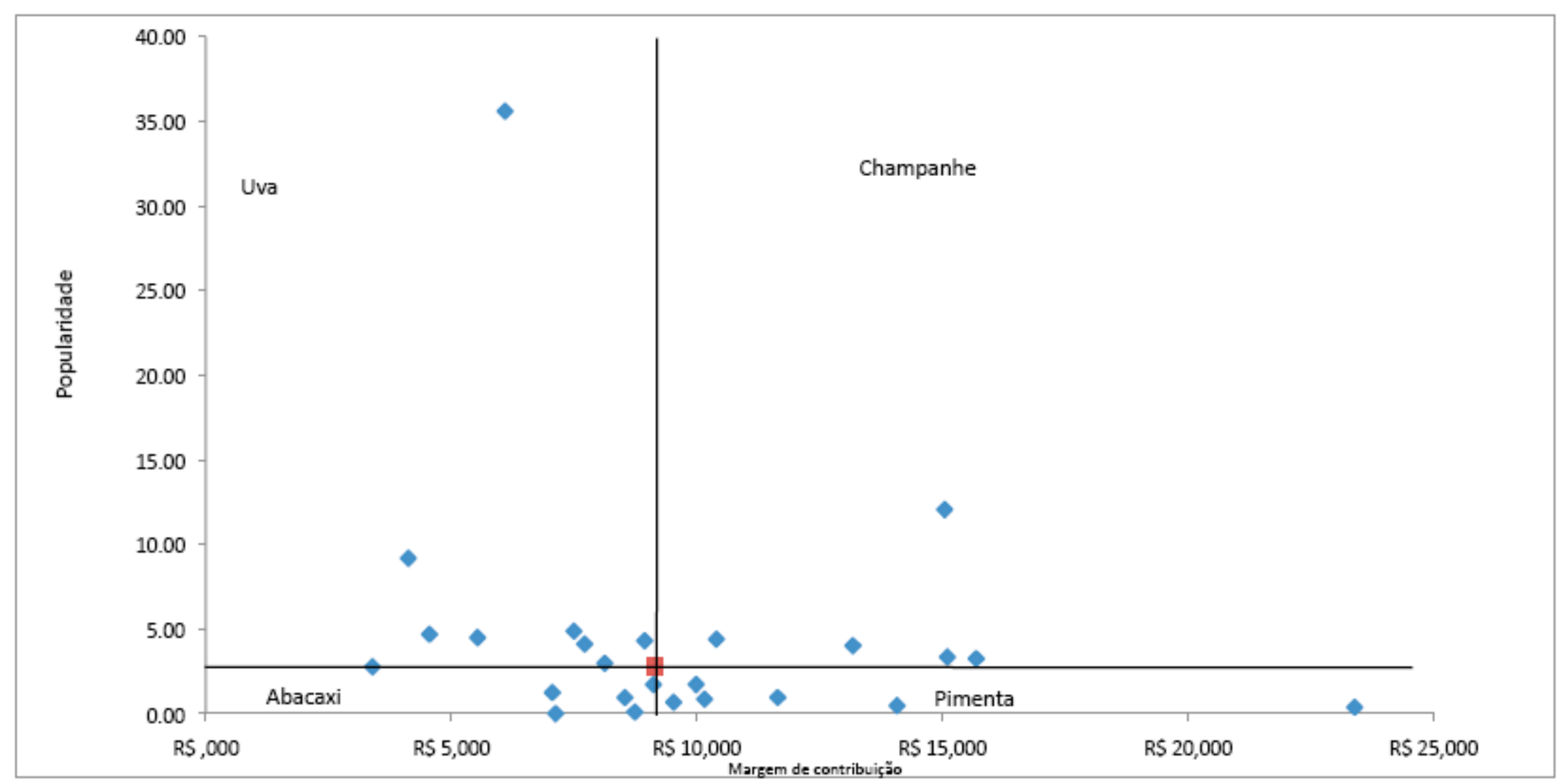


Apêndice 7: Classificação de pratos do mês de março/09 (margem de contribuição e popularidade)

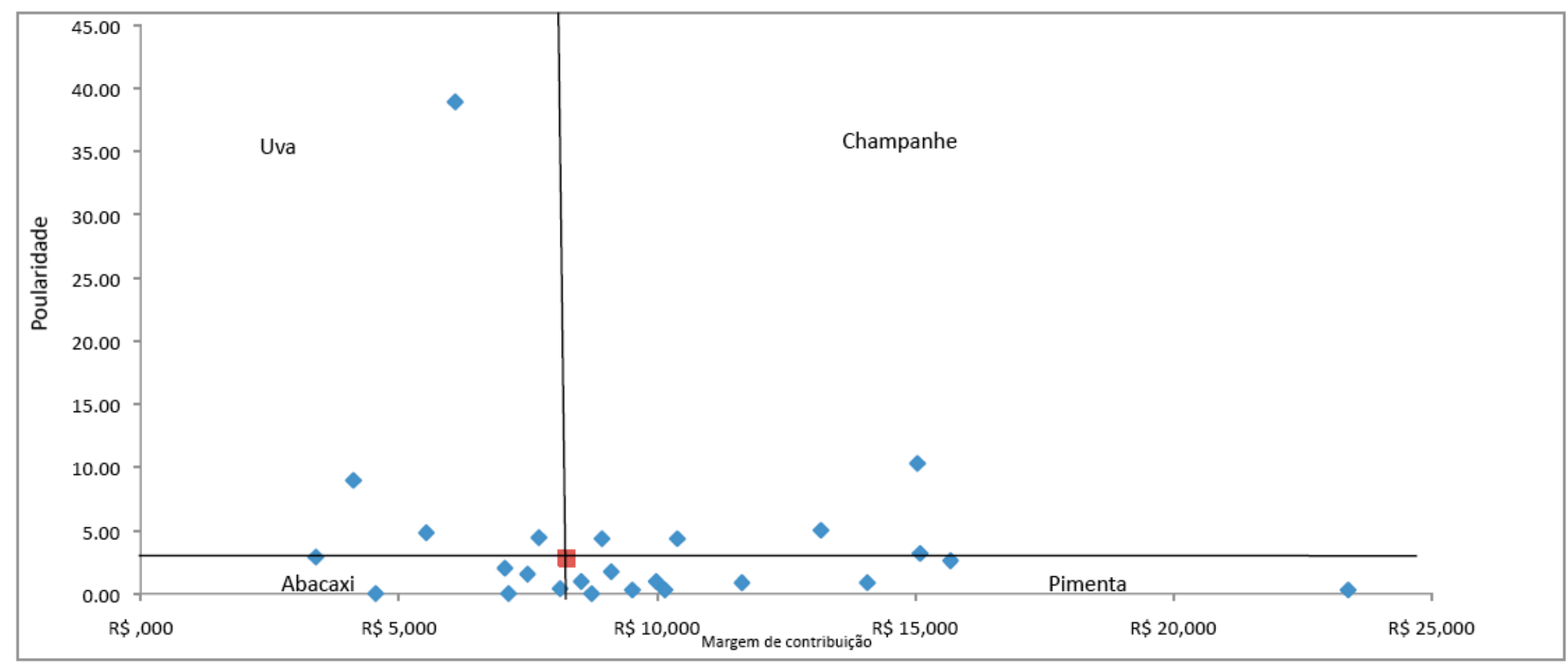


Apêndice 8: Classificação de pratos do mês de abril/09 (margem de contribuição e popularidade)

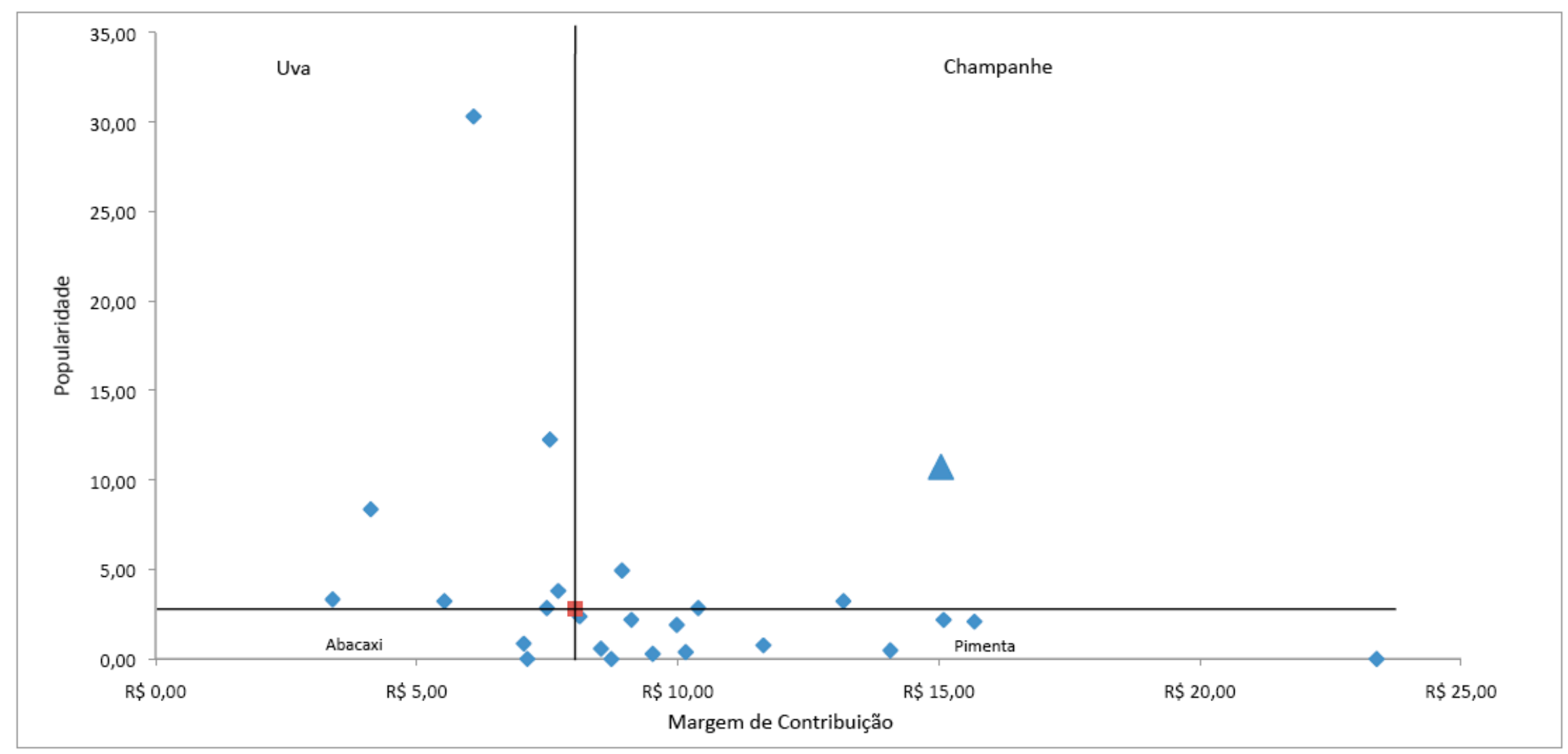


ANEXO 1
Relação diária de vendas do mês
Fevereiro

\begin{tabular}{|c|c|c|c|c|c|c|c|c|c|c|c|c|c|c|c|c|c|c|c|c|c|c|c|c|c|c|c|c|c|c|}
\hline & & 1.2 & 2.2 & 3.2 & 4.2 & 5.2 & 6.2 & 7.2 & 8.2 & 9.2 & 10.2 & 11.2 & 12.2 & 13.2 & 14.2 & 15.2 & 16.2 & 17.2 & 18.2 & 19.2 & 20.2 & 21.2 & 22.2 & 23.2 & 24.2 & 25.2 & 26.2 & 27.2 & 28.2 & Total \\
\hline $\begin{array}{l}\text { PRATOS QUENTES } \\
\text { Camaräa na Moranga }\end{array}$ & $\begin{array}{ll}\text { Valor } \\
2700\end{array}$ & Un & Un & Un & Un & Un 1 & Un & Un & Un & Un 1 & Un 1 & Un & Un & Un 1 & \begin{tabular}{|l|} 
Un \\
\end{tabular} & Un 1 & \begin{tabular}{|l|l|} 
Un \\
\end{tabular} & \begin{tabular}{|l|l|} 
Un \\
\end{tabular} & \begin{tabular}{|l|l|} 
Un \\
$n$
\end{tabular} & Un I & \begin{tabular}{|l|l|} 
Un \\
0
\end{tabular} & \begin{tabular}{|l|} 
Un \\
\end{tabular} & Un & \begin{tabular}{|l|l|} 
Un \\
\end{tabular} & Un & Un I & \begin{tabular}{|l|} 
Un \\
\end{tabular} & \begin{tabular}{|l|} 
Un \\
\end{tabular} & \begin{tabular}{|l} 
Un \\
\end{tabular} & \\
\hline & 格 & & & & & & & & & & & & & & & & & & 0 & & & & & & & & & & & 4 \\
\hline $\begin{array}{l}\text { Caldeirada Don Crustáceo } \\
\text { Duo de Camarão }\end{array}$ & $\begin{array}{l}23,90 \\
2450\end{array}$ & 0 & 0 & $\frac{1}{2}$ & 0 & $\begin{array}{l}1 \\
0\end{array}$ & $\begin{array}{l}0 \\
2\end{array}$ & 2 & $\begin{array}{l}3 \\
3\end{array}$ & 3 & 2 & 0 & 0 & $\begin{array}{l}0 \\
0\end{array}$ & 3 & 3 & $\begin{array}{l}0 \\
0\end{array}$ & ${ }_{0}^{0}$ & $\begin{array}{l}0 \\
0\end{array}$ & 1 & 1 & 2 & 0 & 2 & & 2 & 4 & 2 & 2 & 34 \\
\hline Filé de Pescada empanada & 17,90 & 0 & 1 & 1 & 0 & 3 & 2 & 0 & 3 & 3 & 0 & 5 & 1 & 0 & 3 & 7 & 0 & 0 & 0 & 4 & 1 & 3 & 2 & $\frac{1}{0}$ & 3 & $\begin{array}{l}4 \\
4\end{array}$ & 1 & 0 & 0 & $\begin{array}{l}47 \\
45\end{array}$ \\
\hline Camarão ao Curry & & 1 & 0 & 0 & 0 & 0 & 1 & 0 & 0 & 0 & 0 & 0 & 0 & 2 & 0 & 1 & 0 & 0 & 0 & 0 & 0 & 0 & 0 & 0 & 2 & 0 & 0 & 0 & 0 & 7 \\
\hline Camarão & 21,90 & 0 & 1 & 2 & 1 & 2 & 1 & 3 & 0 & 0 & 0 & 0 & 0 & 2 & 0 & 2 & 0 & 0 & 0 & 0 & 0 & 0 & 0 & 0 & 2 & 0 & 2 & 0 & 0 & 18 \\
\hline Gratinado de Bacalhau & 22,90 & 0 & 0 & 1 & 0 & 0 & 0 & 1 & 1 & 0 & 0 & 0 & 0 & 0 & 0 & 1 & 0 & 0 & 0 & 0 & 0 & 1 & 0 & 0 & 0 & 0 & 0 & 0 & 0 & 5 \\
\hline Paella Marinera & 24,90 & 0 & 0 & 1 & 0 & 4 & 1 & 3 & 1 & 0 & 1 & 0 & 1 & 2 & 2 & 2 & 0 & 0 & 0 & 1 & 3 & 1 & 2 & 1 & 2 & 2 & 3 & 0 & 2 & 35 \\
\hline PRATOS EXECUTIVOS & & & & & & & & & & & & & 0 & 0 & 0 & & & & & & & & & & & & & & & \\
\hline Escondidinho Don Crustácio & 9,50 & 0 & 2 & 5 & 2 & 3 & 1 & 3 & 1 & 1 & 0 & 4 & 1 & 7 & 2 & 2 & 0 & 0 & & 3 & 3 & 2 & 2 & & & 0 & 0 & & 7 & 51 \\
\hline Bobo de Camar & 15,90 & 5 & 7 & 6 & 11 & 13 & 20 & 31 & 11 & 16 & 16 & 12 & 9 & 9 & 19 & 15 & 0 & 0 & 0 & 5 & 13 & 20 & 5 & 14 & 13 & 14 & 24 & 32 & 32 & 372 \\
\hline Moquec & 14,50 & 1 & 1 & 1 & 1 & 1 & 1 & 0 & 2 & 0 & 1 & 1 & 5 & 2 & 4 & 2 & 0 & 0 & 0 & 1 & 3 & 2 & 2 & 2 & 5 & 1 & 0 & & 4 & 43 \\
\hline ao creme de espinafre & 13,50 & 0 & 0 & 0 & 1 & 0 & 1 & 0 & 0 & 1 & 0 & 0 & 0 & 1 & 0 & 1 & 0 & 0 & 0 & 1 & 0 & 2 & 0 & 0 & 0 & 0 & 0 & 0 & 2 & 10 \\
\hline & 14,50 & 0 & 0 & 0 & 0 & 2 & 1 & 0 & 0 & 0 & 1 & 0 & 1 & 0 & 0 & 0 & 0 & 0 & 0 & 0 & 0 & 0 & 0 & 0 & 0 & 1 & 1 & 1 & 1 & 9 \\
\hline nilanesa & 13,90 & 0 & 2 & 2 & 13 & 0 & 0 & 1 & 2 & 1 & 0 & 14 & 2 & 2 & 7 & 2 & 0 & 0 & 0 & 1 & 0 & 0 & 0 & 0 & 0 & 0 & 0 & 0 & 0 & 49 \\
\hline Strogonoff de Camarão & 14,90 & 0 & 4 & 1 & 3 & 5 & 4 & 4 & 4 & 7 & 3 & 5 & 5 & 5 & 7 & 4 & 0 & 0 & 0 & 3 & 2 & 0 & 2 & 5 & 0 & 11 & 0 & 0 & 12 & 96 \\
\hline HAMBURGUES & & & & & & & & & & & & & & & & & & & & & & & & & & & & & & \\
\hline Hamburguer & 13,90 & 2 & 0 & 0 & 2 & 1 & 3 & 1 & 0 & 2 & 3 & 1 & 1 & 0 & 2 & 2 & 0 & 0 & 0 & 2 & 1 & 2 & 2 & 1 & 0 & 0 & 1 & 0 & 0 & 29 \\
\hline MASSAS E RISOTOS & & & & & & & & & & & & & & & & & & & & & & & & & & & & & & \\
\hline Fettuccine ao & 22,90 & 0 & 3 & 0 & 0 & 2 & 1 & 2 & 3 & 0 & 2 & 1 & 1 & 1 & 5 & 4 & 0 & 0 & 0 & 1 & 1 & 2 & 0 & 3 & 2 & 4 & 2 & 0 & 2 & 42 \\
\hline Risoto de Ca & & 4 & 6 & 7 & 4 & 5 & 8 & 7 & 4 & 3 & 4 & 2 & 5 & 6 & 4 & 8 & 0 & 0 & 0 & 3 & 10 & 2 & 7 & 3 & 3 & 8 & 5 & 0 & 8 & 126 \\
\hline Spaguetti com Frutos do Mar & 18,90 & 1 & 1 & 0 & 0 & 0 & 0 & 0 & 0 & 1 & 0 & 1 & 1 & 0 & 0 & 0 & 0 & 0 & 0 & 0 & 0 & 0 & 0 & 1 & 1 & 1 & 0 & 0 & 2 & 10 \\
\hline Talharin ao Bacalha & 19,90 & 0 & 0 & 0 & 0 & 0 & 0 & 0 & 0 & 0 & 0 & 0 & 0 & 0 & 0 & 0 & 0 & 0 & 0 & 0 & 0 & 0 & 0 & 0 & 0 & 1 & 0 & 0 & 0 & 1 \\
\hline & & & & & & & & & & & & & & & & & & & & & & & & & & & & & & \\
\hline Salada & 12,90 & 0 & 1 & 1 & 1 & 1 & 1 & 5 & 1 & 0 & 1 & 0 & 1 & 6 & 2 & 2 & 0 & 0 & 0 & 4 & 2 & 0 & 0 & 2 & 0 & 0 & 0 & 0 & 0 & 31 \\
\hline Vinagrete de & & 1 & 1 & 0 & 2 & 0 & 0 & 2 & 1 & 0 & 1 & 1 & 2 & 0 & 2 & 0 & 0 & c & 0 & 1 & 0 & 1 & 0 & 1 & 1 & 1 & 0 & 0 & 0 & 18 \\
\hline Salada fria de Penn & 13,50 & 0 & 0 & 0 & 0 & 0 & 0 & 0 & 0 & 0 & 0 & 0 & 0 & 0 & 0 & 0 & 0 & 0 & 0 & 0 & 0 & 0 & 0 & 0 & 0 & 0 & 0 & 0 & 0 & 0 \\
\hline & & & & & & & & & & & & & & & & & & & & & & & & & & & & & & \\
\hline Bolinho de Bacalhau & 12,00 & 1 & 1 & 0 & 1 & 2 & 3 & 0 & 5 & 0 & 0 & 0 & 1 & 0 & 1 & 9 & 0 & 0 & 0 & 0 & 6 & 4 & 1 & 5 & 0 & 4 & 0 & 1 & 1 & 46 \\
\hline Casquinha de $S$ & 7,90 & 3 & 1 & 1 & 0 & 0 & 0 & 1 & 0 & 0 & 1 & 0 & 0 & 1 & 1 & 1 & 0 & 0 & 0 & 0 & 0 & 0 & 0 & 1 & 2 & 0 & 0 & 0 & 0 & 13 \\
\hline SOMA & & 21,00 & 4,00 & 32,00 & 43,00 & 45,00 & 52,00 & 67,00 & 45,00 & 38,00 & 42,00 & 48,00 & 39,00 & 47,00 & 67,00 & 75,00 & 0,00 & 0,00 & 0,00 & 31,00 & 49,00 & 46,00 & 26,00 & 42,00 & 38,00 & 58,00 & 45,00 & 36,00 & 75,00 & \\
\hline
\end{tabular}




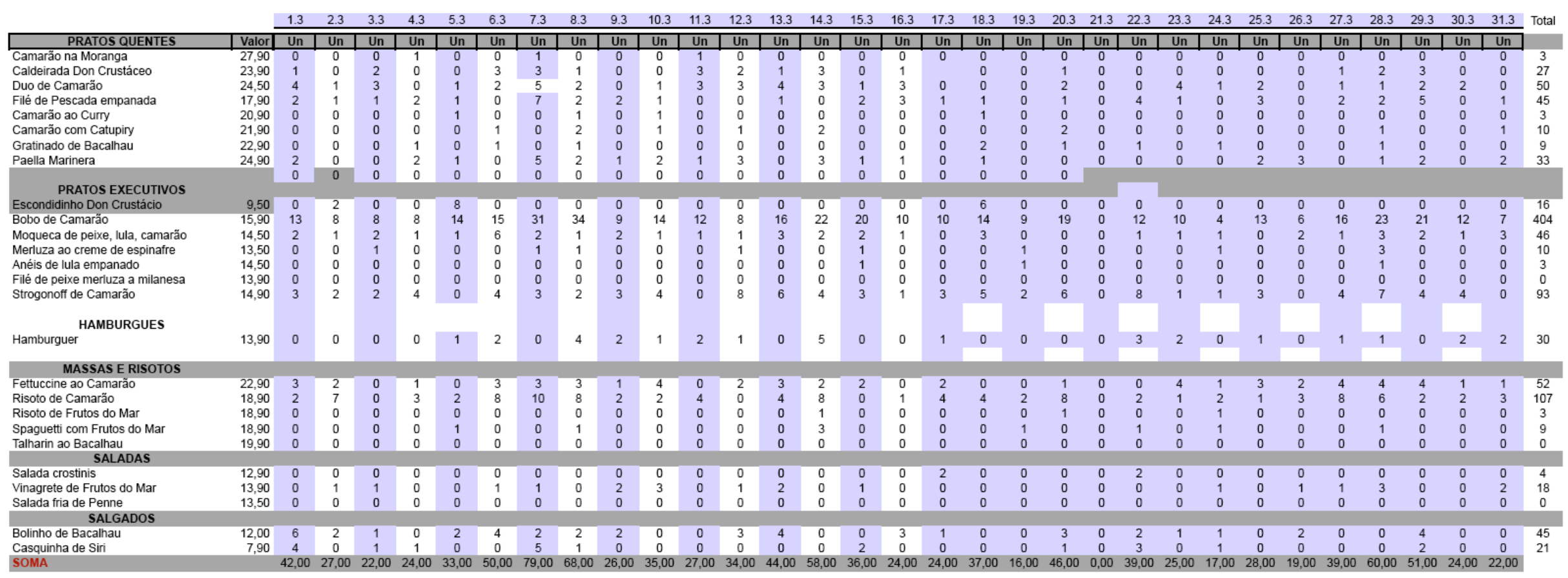


ANEXO 3

Relação diária de vendas do mês

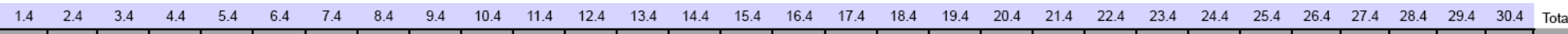

\begin{tabular}{|c|c|c|c|c|c|c|c|c|c|c|c|c|c|c|c|c|c|c|c|c|c|c|c|c|c|c|c|c|c|c|c|c|}
\hline PRATOS QUENTES & r Caixa & Unid | & \begin{tabular}{|l|l|} 
Unid \\
\end{tabular} & \begin{tabular}{|l|l|} 
Unid \\
\end{tabular} & \begin{tabular}{|l|l|} 
Unid \\
\end{tabular} & Unid & \begin{tabular}{|l|} 
Unid \\
\end{tabular} & Unid & \begin{tabular}{|l|l} 
Unid \\
\end{tabular} & \begin{tabular}{|l|} 
Unid \\
\end{tabular} & Unid & \begin{tabular}{|l|l} 
Unid \\
\end{tabular} & Unid & \begin{tabular}{|l|l|} 
Unid \\
\end{tabular} & \begin{tabular}{|l|l} 
Unid \\
\end{tabular} & \begin{tabular}{|l|} 
Unid \\
\end{tabular} & \begin{tabular}{|l|} 
Unid \\
\end{tabular} & \begin{tabular}{|l|l|} 
Unid \\
\end{tabular} & 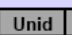 & Unid & Unid & \begin{tabular}{|l|} 
Unid \\
(n)
\end{tabular} & Unid & \begin{tabular}{|l|} 
Unid \\
\end{tabular} & Unid & Unid & \begin{tabular}{|l|l|} 
Unid \\
\end{tabular} & Unid & Unid & Unid & Unid & \\
\hline Camarão na Moranga & 27,90 & 0 & 0 & 1 & 0 & 0 & 0 & 0 & 0 & 0 & 0 & 0 & 0 & 0 & 0 & 0 & 0 & 0 & 0 & 0 & 0 & 0 & 1 & 0 & 0 & 0 & 0 & 0 & 0 & 0 & 0 & 2 \\
\hline Caldeirada Don Crustáceo & 23,90 & 0 & 1 & 2 & 3 & 2 & 0 & 0 & 3 & 3 & 0 & 3 & 0 & 1 & 0 & 0 & 0 & 1 & 2 & 0 & 1 & 0 & 0 & 0 & 0 & 0 & 0 & 0 & 0 & 0 & 0 & \\
\hline Duo de Camarăo & 24,50 & 1 & 2 & 3 & 2 & 0 & 0 & 2 & 0 & 4 & 1 & 3 & 2 & 0 & 0 & 0 & 1 & 0 & 5 & 0 & 0 & 4 & 1 & 2 & 2 & 0 & 0 & 0 & 0 & 0 & 0 & 35 \\
\hline Filé de Pescada empanada & 17,90 & 0 & 5 & 1 & 0 & 3 & 3 & 4 & 1 & 8 & 5 & 0 & 0 & 1 & 2 & 0 & 0 & 2 & 3 & 2 & 2 & 3 & 3 & 1 & 1 & 7 & 0 & 0 & 0 & 0 & 0 & 57 \\
\hline Camarão ao Curry & 20,90 & 0 & 0 & 1 & 0 & 0 & 0 & 1 & 0 & 0 & 0 & 0 & 0 & 0 & 1 & 0 & 0 & 0 & 0 & 0 & 0 & 0 & 0 & 0 & 0 & 0 & 0 & 0 & 0 & 0 & 0 & \\
\hline Camarão com Catupiry & 21,90 & 1 & 0 & 0 & 0 & 0 & 0 & 2 & 0 & 0 & 2 & 2 & 2 & 0 & 1 & 0 & 0 & 0 & 3 & 1 & 4 & 2 & 0 & 0 & 0 & 2 & 0 & 0 & 0 & 0 & 0 & 22 \\
\hline Gratinado de Bacalhau & 22,90 & 0 & 0 & 0 & 0 & 1 & 0 & 0 & 0 & 0 & 0 & 1 & 0 & 0 & 0 & 0 & 0 & 0 & 1 & 0 & 1 & 1 & 0 & 0 & & 0 & 0 & 0 & 0 & 0 & 0 & \\
\hline $\begin{array}{l}\text { Paella Marinera } \\
\text { PRATOS EXECUTIVOS }\end{array}$ & 24,90 & 1 & 0 & 1 & 0 & 4 & 0 & 1 & 0 & 1 & 3 & 0 & 1 & 0 & 0 & 0 & 2 & 2 & 3 & 0 & 0 & 1 & 2 & 0 & 0 & 4 & 0 & 0 & 0 & 0 & 0 & $\begin{array}{c}26 \\
0\end{array}$ \\
\hline Escondidinho Don Crustácio & 9,50 & 0 & 0 & 0 & 0 & 0 & 0 & 0 & 0 & 0 & 0 & 0 & 0 & 0 & 0 & 1 & 1 & 1 & 4 & 2 & 2 & 2 & 3 & 3 & 5 & 6 & 0 & 0 & 0 & 0 & 0 & 30 \\
\hline Bobo de Camarão & 15,90 & 15 & 12 & 18 & 19 & 21 & 11 & 12 & 19 & 25 & 22 & 15 & 7 & 12 & 7 & 5 & 12 & 13 & 19 & 11 & 17 & 6 & 12 & 5 & 14 & 12 & 0 & 0 & 0 & 0 & 0 & 341 \\
\hline queca & & 0 & 2 & 1 & 3 & 0 & 2 & 4 & 0 & 4 & 1 & 0 & 2 & 1 & 1 & 4 & 1 & 1 & 1 & 3 & 1 & 2 & 0 & 2 & 2 & 3 & 0 & 0 & 0 & 0 & 0 & 41 \\
\hline Merluza ao creme de espinafre & 13,50 & 0 & 0 & 0 & 1 & 0 & 0 & 1 & 0 & 0 & 0 & 2 & 0 & 0 & 0 & 2 & 0 & 0 & 0 & 0 & 0 & 0 & 0 & 0 & 0 & 0 & 0 & 0 & 0 & 0 & 0 & \\
\hline Anéis de lula empanado & 14,50 & 0 & 0 & 0 & 0 & 0 & 0 & 0 & 0 & 0 & 0 & 0 & 0 & 0 & 0 & 0 & 0 & 0 & 1 & 0 & 1 & 2 & 0 & 0 & 0 & 0 & 0 & 0 & 0 & 0 & 0 & 4 \\
\hline Filé de peixe merluza empanda & 13,90 & 3 & 8 & 9 & 5 & 4 & 7 & 2 & 6 & 8 & 10 & 12 & 4 & 7 & 2 & 1 & 0 & 1 & 1 & 0 & 2 & 2 & 4 & 0 & 1 & 1 & 0 & 0 & 3 & 7 & 4 & 114 \\
\hline $\begin{array}{l}\text { Strogonoff de Camarão } \\
\text { SANDUícHES }\end{array}$ & 14,90 & 3 & 2 & 3 & 9 & 4 & 0 & 7 & 10 & 9 & 3 & 1 & 4 & 0 & 3 & 2 & 1 & 7 & 6 & 2 & 3 & 3 & 3 & 1 & 1 & 4 & 0 & 0 & 0 & 0 & 0 & $\begin{array}{l}91 \\
0\end{array}$ \\
\hline $\begin{array}{l}\text { Hamburguer } \\
\text { MASSAS E RISOTO }\end{array}$ & 9,50 & 0 & 0 & 0 & 0 & 0 & 0 & 2 & 3 & 3 & 0 & 4 & 3 & 5 & 5 & 0 & 0 & 2 & 1 & 0 & 2 & 3 & 0 & 0 & 2 & 0 & 0 & 0 & 0 & 0 & 0 & $\begin{array}{c}35 \\
0\end{array}$ \\
\hline $\begin{array}{l}\text { MASSA } \\
\text { Fettucine ao } \mathrm{Ca}\end{array}$ & 22,90 & 0 & 0 & 1 & 4 & 4 & 1 & 1 & 1 & 4 & 3 & 0 & 2 & 0 & 2 & 2 & 1 & 0 & 0 & 1 & 0 & 2 & 2 & 1 & 1 & 4 & 0 & 0 & 0 & 0 & 0 & $\begin{array}{c}0 \\
37\end{array}$ \\
\hline Risoto de Cama & 18,90 & 2 & 3 & 6 & 9 & 5 & 2 & 4 & 7 & 7 & 7 & 12 & 5 & 4 & 3 & 3 & 2 & 2 & 10 & & 4 & 2 & 2 & 4 & 7 & 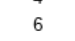 & 0 & 0 & 0 & 0 & 0 & 120 \\
\hline Spaguett & 18,90 & 0 & 0 & 0 & 0 & 0 & 0 & 0 & 1 & 0 & 1 & 0 & 1 & 0 & 0 & 0 & 0 & 0 & 0 & 1 & 0 & 2 & 0 & 0 & 2 & 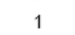 & 0 & 0 & 0 & & & 9 \\
\hline $\begin{array}{l}\text { Talharin ao Bacalhau } \\
\text { SALADAS }\end{array}$ & 19,90 & 0 & 0 & 0 & 0 & 0 & 0 & 0 & 0 & 0 & 0 & 0 & 0 & 0 & 0 & 0 & 0 & 0 & 0 & 0 & 0 & 0 & 0 & 0 & 0 & 0 & 0 & 0 & 0 & 0 & 0 & 0 \\
\hline Crostinis & 12.90 & 0 & 0 & 0 & 0 & 0 & 0 & 0 & 0 & 0 & 0 & 0 & 0 & 1 & 0 & 0 & 2 & & 4 & c & 2 & 2 & & 2 & 4 & & 0 & 0 & 0 & 0 & 0 & 25 \\
\hline & & 1 & 0 & 1 & 1 & 2 & 1 & 0 & 2 & 4 & 0 & 3 & 0 & & 0 & & & & & & & & c & & 2 & & & & & & & \\
\hline Salada fria de Penne & 13,50 & 0 & 0 & 0 & 0 & 0 & 0 & 0 & 0 & 0 & 0 & 0 & 0 & 0 & 0 & 0 & 0 & 0 & 0 & 0 & 0 & 0 & 0 & 0 & 0 & 0 & 0 & 0 & 0 & 0 & 0 & \\
\hline ENTRADAS & & & & & & & & & & & & & & & & & & & & & & & & & & & & & & & & \\
\hline nond & 9,50 & 0 & 0 & 0 & 0 & 0 & 0 & 0 & 0 & 0 & 0 & 0 & 0 & 1 & 1 & 1 & & 2 & 2 & & 0 & & & 0 & 5 & & 0 & 0 & 0 & 0 & 0 & \\
\hline & 12,0 & 0 & & & & & & & & & & & & & & & & & & & & & & & & & & & & & & \\
\hline Inna de s & 7,90 & & & & & & & & & & & & & & & & & & & & & & & & & & & & & & & \\
\hline DMA & & 27 & 35 & 51 & 57 & 52 & 29 & 45 & 55 & 82 & 64 & 60 & 34 & 33 & 30 & & 28 & 39 & & 31 & & & 42 & & & 58 & & & & & & \\
\hline
\end{tabular}

